\title{
Characterization of rat cytomegalovirus genes that play a crucial role in the pathogenesis of virus infection
}

Citation for published version (APA):

Kaptein, S. J. F. (2004). Characterization of rat cytomegalovirus genes that play a crucial role in the pathogenesis of virus infection. [Doctoral Thesis, Maastricht University]. Universiteit Maastricht. https://doi.org/10.26481/dis.20041215sk

Document status and date:

Published: 01/01/2004

DOI:

10.26481/dis.20041215sk

Document Version:

Publisher's PDF, also known as Version of record

\section{Please check the document version of this publication:}

- A submitted manuscript is the version of the article upon submission and before peer-review. There can be important differences between the submitted version and the official published version of record. People interested in the research are advised to contact the author for the final version of the publication, or visit the DOI to the publisher's website.

- The final author version and the galley proof are versions of the publication after peer review.

- The final published version features the final layout of the paper including the volume, issue and page numbers.

Link to publication

\footnotetext{
General rights rights.

- You may freely distribute the URL identifying the publication in the public portal. please follow below link for the End User Agreement:

www.umlib.nl/taverne-license

Take down policy

If you believe that this document breaches copyright please contact us at:

repository@maastrichtuniversity.nl

providing details and we will investigate your claim.
}

Copyright and moral rights for the publications made accessible in the public portal are retained by the authors and/or other copyright owners and it is a condition of accessing publications that users recognise and abide by the legal requirements associated with these

- Users may download and print one copy of any publication from the public portal for the purpose of private study or research.

- You may not further distribute the material or use it for any profit-making activity or commercial gain

If the publication is distributed under the terms of Article 25fa of the Dutch Copyright Act, indicated by the "Taverne" license above, 
Characterization of Rat Cytomegalovirus Genes that Play a Crucial Role in the Pathogenesis of Virus Infection

Suzanne J.F. Kaptein

Maastricht, 2004 
(1) Suzanne Kaptein, Maastricht 2004

ISBN: 90-9018734-0

Cover design: Patrick Beisser

Production: Wöhrmann Print Service, Zutphen, The Netherlands 


\title{
Characterization of Rat Cytomegalovirus Genes that Play a Crucial Role in the Pathogenesis of Virus Infection
}

\author{
Proefschrift \\ ter verkrijging van de graad van doctor aan de Universiteit Maastricht, \\ op gezag van de Rector Magnificus Prof. Mr. G.P.M.F. Mols, \\ volgens het besluit van het College van Decanen, \\ in het openbaar te verdedigen op woensdag 15 december 2004 om 16.00 uur
}

door

Suzanne Johanna Francisca Kaptein

geboren te Waalwijk op 31 december 1971 


\section{Promotor:}

Prof. Dr. C. A. Bruggeman

\section{Co-promotor:}

Dr. C. Vink

\section{Beoordelingscommissie:}

Prof. Dr. I.W. Cohen Tervaert (voorzitter)

Prof. Dr. B. Berkhout (AMC, Amsterdam)

Prof. Dr. W.A. Buurman

Prof. Dr. U.A. Gompels (University of London, UK)

Prof. Dr. M.H. Hofker

Prof. Dr. E.J. Wiertz (LUMC, Leiden) 
Aan mijn ouders, aan Jeroen

en Brigitte 



\section{CONTENTS}

Preface

p. 9

Chapter 1 The Rat Model for CMV Infection and Vascular

p. 15 Disease

Chapter 2 Rat Cytomegalovirus Open Reading Frame R44 is

p. 45 an Early-Late Gene that Encodes a Nuclear Protein

Chapter 3 The Rat Cytomegalovirus R78 G Protein-Coupled

p. 55 Receptor Gene is Required for the Production of Infectious Virus in the Spleen

Chapter 4 The 131 Gene of Rat Cytomegalovirus Encodes a Proinflammatory CC Chemokine Homolog which is Essential for the Production of Infectious Virus in the Salivary Glands

Chapter 5 Summary and General Discussion

p. 105

Samenvatting en Algehele Discussie

p. 112

Dankwoord

p. 121

Curriculum vitae

p. 127

List of Publications

p. 131 

PREFACE 


\section{General introduction}

Within the large family of Herpesviridae, Cytomegaloviruses (CMVs) have been classified as members of the Betaherpesvirinae subfamily [23]. As is common to all herpesviruses, CMVs can induce acute, persistent as well as life-long, latent infections. As a consequence of the life-long relationships with their hosts, CMVs have adopted a diversity of ingenious strategies to either elude or counteract the host immune response, enabling the virus to escape clearance $[3,18]$. In addition to immune evasion, CMV has developed high-standing strategies to exploit the host's inflammatory responses in order to promote inflammation and, consequently, virus dissemination and/or transmission $[17,18]$. Intriguingly, the vast majority of the viral immunoregulatory proteins implicated in subversion of the host's immune system have putatively evolved for the benefit of the virus from cellular immunomodulatory proteins that are encoded by genes which appear to have been hijacked from the host genome by an ancestral virus [3]. Most of the host-derived immunoregulatory genes found within the genome of human CMV (HCMV) constitute mimics of host chemokines and chemokine-binding $G$ protein-coupled receptors (GPCRs). Both chemokines and their receptors form the key components of the chemokine signaling pathway, which is essential for proper functioning of the immune system.

The HCMV genome was shown to harbour at least four GPCR genes, i.e. UL33, UL78, US27 and US28 [7, 8]. Only two of these genes, UL33 and UL78, were found to be conserved amongst the genomes of all known CMVs $[4,5,15,21,24]$ as well as amongst those of other betaherpesviruses [9, 10, 14, 19]. This level of conservation is indicative of their biological relevance. The HCMV genome also comprises a number of genes encoding chemokine homologues. These genes were designated UL146 and UL147, both putatively encoding a CXC chemokine [6], and UL128, which encodes a CC chemokine homologue [2]. Correspondingly, the genomes of various other betaherpesviruses were also predicted to express mimics of cellular chemokines $[2,13,16,25,27]$.

One of the most pending questions today concerns the exact involvement of these viral chemokine (receptor) homologues in CMV disease, not in the least because these mimics very likely represent ideal targets for effective antiviral drug therapy. However, because HCMV exhibits a high degree of species-specificity, investigators are rather restricted in studying the role of the HCMV-encoded chemokines and chemokine receptors in vivo. Consequently, the development and exploitation of animal infection models, such as the rat $C M V(R C M V) /$ rat model that was developed at our department, is of utmost importance.

\section{Outline and aims of the thesis}

In this thesis, different aspects of the RCMV/rat model are described. In the first chapter, an overview is presented of the exploitation of the RCMV/rat model in order to understand the putative role of CMVs in the development of vessel wall pathologies, such as atherosclerosis, arterial sclerosis and transplant vascular sclerosis. The other chapters of the thesis are dedicated to studies on single, crucial RCMV genes, i.e. R44, which encodes the homologue of the HCMV UL44-encoded DNA 
polymerase accessory protein (DPAP), $\mathrm{n131}$, which encodes a chemokine homologue, and R33 and R78, which encode GPCR homologues.

Although a number of antiviral compounds for treatment of CMV infections is available, treatment is usually accompanied by the occurrence of side-effects, of which the generation of (multiple) drug resistant CMV strains constitutes one of the major threats to a successful outcome of the treatment. Therefore, finding novel targets that are suitable for the development of novel antiviral agents is considered to be one of the major challenges. Each of the four CMV genes that are described in this thesis (Chapters 2-4) may be regarded as suitable antiviral targets, since they play either essential (R44) or very important roles (R33, R78 and r131) in the pathogenesis of CMV infection.

\section{The RCMV R44 gene}

As described above, the R44 gene is the RCMV homologue of the HCMV UL44 gene, which encodes the DPAP. This protein is conserved amongst all herpesviruses and was reported to be essential for viral DNA replication $[1,20,22,26]$. In Chapter 2 , we describe the characteristics of the R44 gene and expression pattern, both in vitro and in vivo, of the R44-encoded protein (pR44).

\section{The RCMV GPCR genes, R33 and R78}

Other attractive candidates for the generation of antiviral drugs are the plasma membrane-associated GPCRs encoded by HCMV. Two of these, UL33 and UL78 have homologues in all other betaherpesviruses, including RCMV. We previously reported that the RCMV homologues of both UL33 and UL78, which were named $R 33$ and $R 78$, respectively $[4,5]$, have crucial functions in the pathogenesis of RCMV infection. In addition, we found that the R33 gene encodes a constitutively active GPCR $[11,12]$. However, since not much was known about the expression of the R33- and R78-encoded proteins ( $P R 33$ and pR78, respectively), we set out to generate and study recombinant RCMV strains expressing enhanced green fluorescent protein (EGFP.)fused versions of $p R 33$ or $p R 78$ instead of native $p R 33$ or pR78. The results from the study on these recombinant strains are presented in Chapter 3.

\section{The RCMV chemokine genes, $\mathrm{r} 129$ and $\mathrm{r} 131$}

In addition to the viral GPCRs, the ligands of chemokine receptors, i.e. viral chemokines, also constitute eligible candidates for the development of antiviral drugs. The RCMV genome was found to encompass two adjacent genes, $r 129$ and $r 131$, which encode homologues of CC chemokines $[2,25]$. In Chapter 4 , we present data on the structure as well as transcription of these genes. Additionally, in order to address the role of the 131 gene in the pathogenesis of RCMV infection, RCMV knockout strains were generated in which the 131 open reading frame was disrupted. The growth characteristics and dissemination of these knockout viruses were compared to those of wild-type RCMV in vitro and in vivo.

Finally, the results and conclusions obtained from the studies described in this thesis are summarized and discussed in Chapter 5. 


\section{References}

1. Agulnick, A.D., Thompson, J.R., lyengar, S., Pearson, G., Ablashi, D., Ricciardi, R.P. (1993). Identification of a DNA-binding protein of human herpesvirus 6 , a putative DNA polymerase stimulatory factor. J. Gen. Virol. 74, 1003-1009.

2. Akter, P., Cunningham, C., McSharry, B.P., Dolan, A., Addison, C., Dargan, D.J., Hassan-Walker, A.F., Emery, V.C., Griffiths, P.D., Wilkinson, G.W.G., Davison, A.J. (2003). Two novel spliced genes in human cytomegalovirus. J. Gen. Virol. 84, 1117-1122.

3. Alcami, A., Koszinowski, U.H. (2000). Viral mechanisms of immune evasion. Trends Microbiol. 8. 410-418.

4. Beisser, P.S., Grauls, G., Bruggeman, C.A., Vink, C. (1999). Deletion of the R78 $G$ protein-coupled receptor gene from rat cytomegalovirus results in an attenuated, syncytium-inducing mutant strain. J. Virol. 73, 7218-7230.

5. Beisser, P.S., Vink, C., van Dam, J.G., Grauls, G., Vanherle, S.J., Bruggeman, C.A. (1998). The R33 G protein-coupled receptor gene of rat cytomegalovirus plays an essential role in the pathogenesis of viral infection. J. Virol. 72, 23522363.

6. Cha, T.A., Tom, E., Kemble, G.W., Duke, G.M., Mocarski, E.S., Spaete, R.R. (1996). Human cytomegalovirus clinical isolates carry at least 19 genes not found in laboratory strains. J. Virol. 70, 78-83.

7. Chee, M.S., Bankier, A.T., Beck, S., Bohni, R., Brown, C.M., Cerny, R., Horsnell, T., Hutchison III, C.A., Kouzarides, T., Martignetti, J.A., Preddie, E., Satchwell, S.C., Tomlinson, P., Weston, K.M., Barrell, B.G. (1990a). Analysis of the proteincoding content of the sequence of human cytomegalovirus strain AD169. Curr. Top. Microbiol. Immunol. 154, 125-169.

8. Chee, M.S., Satchwell, S.C., Preddie, E., Weston, K.M., Barrell, B.G. (1990b). Human cytomegalovirus encodes three $G$ protein-coupled receptor homologues. Nature 344, 774-777.

9. Dominguez, G., Dambaugh, T.R., Stamey, F.R., Dewhurst, S., Inoue, N., Pellett, P.E. (1999). Human herpesvirus $6 \mathrm{~B}$ genome sequence: coding content and comparison with human herpesvirus 6A. J. Virol. 73, 8040-8052.

10. Gompels, U.A., Nicholas, J., Lawrence, G., Jones, M., Thomson, B.J., Martin, M.E., Efstathiou, S., Craxton, M., Macaulay, H.A. (1995). The DNA sequence of human herpesvirus-6: structure, coding content, and genome evolution. Virology 209, 29-51.

11. Gruijthuijsen, Y.K., Beuken, E.V.H., Smit, M.J., Leurs, R., Bruggeman, Vink, C. (2004). Mutational analysis of the R33-encoded G protein-coupled receptor of rat cytomegalovirus: identification of amino acid residues critical for cellular localization and ligand-independent signaling. J. Gen. Virol. 85, 897-909.

12. Gruijthuijsen, Y.K., Casarosa, P., Kaptein, S.J.F., Broers, J.L.V., Leurs, R., Bruggeman, C.A., Smit, M.J., Vink, C. (2002). The rat cytomegalovirus R33encoded $G$ protein-coupled receptor signals in a constitutive fashion. J. Virol. 76, 1328-1338.

13. Haggerty, S.M., Schleiss, M.R. (2002). A novel CC-chemokine homolog encoded by guinea pig cytomegalovirus. Virus Genes 25, 271-279. 
14. Isegawa, Y., Mukai, T., Nakano, K., Kagawa, M., Chen, J., Mori, Y., Sunagawa, T., Kawanishi, K., Sashihara, J., Hata, A., Zou, P., Kosuge, H., Yamanishi, K. (1999). Comparison of the complete DNA sequences of human herpesvirus 6 variants $A$ and $B$. J. Virol. 73, 8053-8063.

15. Liu, Y., Biegalke, B.J. (2001). Characterization of a cluster of late genes of guinea pig cytomegalovirus. Virus Genes 23, 247-256.

16. MacDonald, M.R., Li, X.Y., Virgin IV, H.W. (1997). Late expression of a b chemokine homolog by murine cytomegalovirus. J. Virol. 71, 1671-1678.

17. Mocarski, E.S. (2002). Immunomodulation by cytomegaloviruses: manipulative strategies beyond evasion. Trends immunol. 10, 332-339.

18. Murphy, P.M. (2001). Viral exploitation and subversion of the immune system through chemokine mimicry. Nat. immunol. 2,116-122.

19. Nicholas, J. (1996). Determination and analysis of the complete nucleotide sequence of human herpesvirus 7. J. Virol. 70, 5975-5989.

20. Pari, G.S., Kacica, M.A., Anders, D.G. (1993). Open reading frames UL44, IRS1/ TRS1, and UL36-38 are required for transient complementation of human cytomegalovirus oriLyt-dependent DNA synthesis. J. Virol. 67, 2575-2582.

21. Rawlinson, W.D., Farrell, H.E., Barrell, B.G. (1996). Analysis of the complete DNA sequence of murine cytomegalovirus. J. Virol. 70, 8833-8849.

22. Ripalti, A., Boccuni, M.C., Campanini, F., Landini, M.P. (1995). Cytomegalovirusmediated induction of antisense mRNA expression to UL44 inhibits virus replication in astrocytoma cell line: identification of an essential gene. J. Virol. $69,2047-2057$.

23. Roizman, B. (1996). Herpesviridae. In Fields, B.N., Knipe, D.M., Howley, P.M., (Eds-in-chief). Fields Virology, 3th ed, vol.2 Lippincott-Raven Publishers, Philadelphia, New York, USA, p. 2221-2230.

24. Schleiss, M.R. (2002). Animal models of congenital cytomegalovirus infection: an overview of progress in the characterization of guinea pig cytomegalovirus (GPCMV). J. Clin. Virol. 25, S37-S49.

25. Vink, C., Beuken, E., Bruggeman, C.A. (2000). Complete DNA sequence of the rat cytomegalovirus genome. J. Virol. 74, 7656-7665.

26. Wu, C.A., Nelson, N.J., McGeoch, D.J., Challberg, M.D. (1988). Identification of herpes simplex virus type 1 genes required for origin-dependent synthesis. J. Virol. 62, 435-443.

27. Zou, P., Isegawa, Y., Nakano, K., Haque, M., Horiguchi, Y., Yamanishi, K. (1999). Human herpesvirus 6 open reading frame $U 83$ encodes a functional chemokine. J. Virol. 73, 5926-5933. 


\section{CHAPTER 1}

\section{The Rat Model for CMV Infection and Vascular Disease}

Suzanne J.F. Kaptein, Cornelis Vink, Cathrien A. Bruggeman, Frank R.M. Stassen

In Cytomegaloviruses: Pathogenesis, Molecular Biology, and Infection Control (2005) M.J. Reddehase (Ed.), Horizon Scientific Press, Wymondham, UK, in press 


\begin{abstract}
The rat cytomegalovirus $(R C M V) /$ rat model has been exploited to address various aspects of the biology of cytomegaloviruses (CMVs). One of these aspects is the putative role of CMVs in the development and/or aggravation of vessel wall pathology. In this chapter, the findings regarding this issue will be reviewed and discussed.
\end{abstract}

\title{
Introduction - Rat Cytomegalovirus (Maastricht strain)
}

The Maastricht strain of rat cytomegalovirus (RCMV) was first isolated in 1982 from the salivary glands of wild brown rats (Rattus norvegicus) and passed in rat embryo fibroblasts (REF) in vitro as well as in laboratory rats [19]. Sequencing of the entire $230-\mathrm{kbp}$ genome of RCMV was completed nearly 20 years later [159]. The RCMV genome is arranged as a single unique sequence flanked by terminal direct repeats and its sequence was found to be largely colinear with that of $\operatorname{HCMV}$ and MCMV $[25,111$, $158,159]$. Moreover, the RCMV genome was predicted to encompass at least 170 open reading frames (ORF), approximately half of which are conserved amongst the HCMV, MCMV and RCMV genomes and about two-thirds are conserved amongst both rodent CMV genomes [159]. Interestingly, although the vast majority of the genes encode viral (structural) proteins, the genome was also found to encode proteins that show homology to host proteins which, thus, appear to be hijacked from the host genome by an ancestral virus. These include $R 33$ and $R 78$, both putatively encoding $G$ protein-coupled receptors [5, 7], $r 144$, encoding a major histocompatibility class I heavy chain homolog [6], and $\mathrm{r} 131$ and $\mathrm{r} 129$, both encoding homologs of CC chemokines $[61,159]$. Intriguingly, the RCMV genome also contains a unique ORF, r127, with similarity to the rep gene of parvoviruses as well as ORF U94 of human herpesvirus type 6A (HHV-6A) and 6B (HHV-6B) $[153,159]$. Hitherto, counterparts of these ORFs have not been found in any of the other sequenced herpesvirus genomes.

\section{RCMV Infection as a Model for Human CMV Infection and Disease}

\section{The Course of RCMV Infection}

In general, RCMV infection in vivo can be divided in several phases. In the first, acute phase, infection of rats with RCMV results in a widespread systemic infection. However, the viral load present in the organs of infected rats depends largely on the immune status of the host, the inoculation route, the amount of virus injected, and genetic factors of the host $[12,18]$. Infection of immunocompetent rats via the intraperitoneal route results in dissemination of virus to spleen, kidney, heart, thymus, bone marrow, blood and urine during the first week post infection (p.i.). However, the viral DNA titers found in these organs, tissues and fluids are relatively low [12]. RCMV infection develops in a variety of cells, mainly in cells originating from the mesothelium as well as in brown fat cells $[16,134]$. In case of subcutaneous inoculation, dissemination of virus is somewhat delayed, resulting in virus-positive organs during the second week. 
The acute phase of infection is followed by the chronic phase, starting at approximately 2 weeks p.i., in which infectious virus can be recovered exclusively from the salivary glands and saliva. In contrast to the rather low virus titers in the internal organs in the acute phase, the virus levels in the salivary glands are significantly higher following either intraperitoneal or subcutaneous inoculation, indicating that this organ is the primary site of infection $[17,18]$. Infectious virus can be detected within the salivary glands as soon as 10 days p.i., reaching peak levels at day 28 p.i., after which virus levels gradually decline for several months $[17,18]$. As to the localization within the salivary glands, RCMV is confined exclusively to the striated duct cells $[18,64]$. At 6 months p.i., RCMV DNA is present predominantly in the salivary glands and occasionally in the spleen, liver, lungs, pancreas, heart, brain, aorta and carotid artery [12]. However, infectious virus can only be extracted from the salivary glands at this time point $[12,17]$. From this time onward, $C M V$ persists in the body in a latent state $[17,18]$. To date, the exact localization of latent RCMV is still enigmatic. Cells suspected of harboring latent RCMV are blood monocytes and bone marrow cells. However, since RCMV DNA is found only rarely in blood and is undetectable in bone marrow at 6 months p.i., they probably do not represent the major sites of latent RCMV infection [12]. The latent infection can reactivate under conditions of immunological stress, such as immunosuppression and organ transplantation, resulting in replication of the virus $[15,174,175]$. Reactivation of latent virus can further be accomplished through stimulation with allogeneic cells [22].

\section{Pathology of RCMV Infection}

Although infection with RCMV usually does not elicit overt disease in immunocompetent rats, RCMV is considered a lethal agent when rats are immunocompromised prior to RCMV infection, causing considerable morbidity and even mortality [134]. At the very most, RCMV generates minor pathological changes in immunocompetent rats. In these hosts, RCMV is capable of inducing vascular injury, as demonstrated by minimal endothelial cell damage and an increased adherence of leukocytes to the aortic endothelium [129]. A study using electron microscopy revealed that RCMV infection causes the formation of swollen endothelial cells accompanied by the formation of blebs and microvilli on their cell surface as well as the accumulation of lipids within endothelial cells and the subendothelial space of the large vessels [128]. Further, infections with RCMV lead to the influx of leukocytes (lymphocytes and macrophages) in the subendothelium and, finally, to loosening of endothelial cells from the basement membrane [128]. In immunocompromised rats, on the other hand, the induced pathologies are more severe, depending on the virus dose administered. Profound histopathological changes are mostly found in the liver, spleen, lungs, kidneys and bone marrow [134]. Briefly, rats inoculated with a lethal dose of RCMV showed extensive organ damage which was characterized by cell necrosis and massive congestion of organs with immunoreactive cells, predominantly macrophages, containing viral antigens and/or viral DNA [138]. Also, intraperitoneal (generalized) RCMV administration resulted in multiple haemorrhages in lung, liver, spleen, and kidney as well as in inflammation, ulcerative lesions, and haemorrhages throughout the gastrointestinal tract [106]. In addition, during both a generalized and a local infection, in which virus is subcutaneously injected in the hind paw of rats, RCMV induced damage 
of the microvascular endothelium, vasculitis, and thrombotic occlusions [106]. Moreover, endothelial cells of the post-capillary as well as capillary venules were found positive for RCMV when stained with monoclonal antibodies directed against RCMV [106]. Intriguingly, the RCMV-induced histopathological findings closely resemble those observed in immunocompromised patients suffering from a symptomatic HCMV infection $[34,40,45,53,71,95,134,148,156]$. Thus, the RCMV/rat model seems to constitute a suitable model for acute CMV infection in immunocompromised humans. Moreover, the RCMV/rat model using immunocompromised rats is a very attractive tool for therapeutic intervention studies $[134,137]$ as well as for studying the effectiveness of (novel) antiviral compounds in rat organ transplantation models in vivo $[21,89,135,136,138]$. Finally, because the changes to the endothelium induced by an RCMV infection in rats are similar to those induced by hypercholesterolemia in rats [128] and because endothelial cell injury constitutes the first step in the development of vascular disease [114], it has been speculated that CMV might be implicated in the genesis or exacerbation of vascular disease $[32,77,80,91,93]$.

\section{The RCMV/rat Model and Vascular Disease}

\section{Atherosclerosis}

Atherosclerosis is a chronic inflammatory disorder of the large and medium-sized arteries [115]. To date, it is commonly accepted that atherosclerosis develops as a response to injury [114]. The primary event in the atherosclerotic process seems to be the injury or dysfunction of endothelial cells due to physical, biochemical or biological factors. Subsequently, the affected endothelium expresses and releases a variety of adhesion molecules, growth factors and chemotactic factors, and the permeability of the vascular wall increases, leading to adhesion of platelets and monocytes/macrophages to the endothelium lining the vessel and extravasation of leukocytes (monocytes, macrophages and lymphocytes) into the subendothelium. Concomitantly, smooth muscle cells (SMCS) migrate from the media to the subendothelial layer, where they proliferate and secrete extracellular matrix proteins upon activation by growth factors, causing intimal thickening. In case of a hypercholesterolemic environment, macrophages and SMCs imbibe oxidized lipid (primarily cholesteryl ester droplets), generating the socalled 'foam cells', which successively progress into fatty streaks. Fatty streaks are flat intimal cell aggregations of predominantly lipid-laden macrophages, $T$ lymphocytes and SMCs. Subsequently, proliferating SMCs, macrophages and Tlymphocytes generate connective tissue, leading to the formation of fibro-fatty lesions that are characterized by the presence of a covering fibrous cap. Finally, fibro-fatty lesions gradually progress into atherosclerotic plaques as a result of ongoing cell replication, lipid accumulation, connective tissue formation and necrosis. Since the outer thinner parts of the fibrous cap of the plaque contain only relatively small amounts of connective tissue, cracks in these parts make the plaque unstable. Instability ultimately may cause rupture of the plaque and the emergence of acute vascular accidents. 


\section{CMV and Atherosclerosis}

Over the years, herpesviruses have increasingly attracted attention with regard to their potential role in the process of atherosclerosis. In particular, the putative relation between CMV and atherosclerosis has been a favourite subject of investigation in both human and animal studies. In this respect, the RCMV/rat model system has proven to be a useful tool, shedding some light on the mechanisms by which CMV may contribute to atherosclerosis.

The existence of a possible association between $C M V$ infection and atherosclerosis was originally based on a case-control study of cardiovascular patients undergoing surgery [1]. This study showed a higher incidence of positive CMV antibodies in patients requiring vascular surgery for atherosclerosis than in control patients. Likewise, results from a cohort study performed by Nieto and coworkers [98] suggested that CMV infection constitutes a risk factor for atherosclerosis. In this study, the level of carotid intimal-medial thickening (IMT) was compared with titers of antibodies directed against $C M V$, which were measured in sera obtained approximately 15 years earlier. Interestingly, subjects with higher levels of IMT also had higher mean CMV antibody titers than control subjects, suggesting that CMV might play a causal role in atherosclerosis. A potential association between $C M V$ and atherosclerosis was further supported by seroepidemiological studies, which reported a higher prevalence of CMV and higher levels of anti-CMV antibodies in patients suffering from atherosclerotic disease $[43,97,127$, 160]. In contrast, in other studies, a correlation between CMV antibody levels and cardiovascular disease was not found $[2,112]$. It should be mentioned, however, that the study of Ridker et al. did not give consideration to the height of anti-CMV antibody titers, since only high but not low titers seem to be correlated with atherosclerotic disease $[43,98]$.

In addition to data from sero-epidemiological studies, data from histopathological as well as in vitro studies render further support to the hypothesis that CMV appears to be implicated in the pathogenesis of atherosclerosis. Arterial SMCs derived from plaque samples of patients suffering from severe atherosclerotic disease were not only found to harbor CMV DNA, but, when cultured, were also demonstrated to express CMV antigens $[27,51,52,92,93,107]$. More specifically, Hendrix et al. [52] reported that CMV DNA was present in $90 \%$ of the arterial walls of patients with severe atherosclerotic changes (grade III) compared to $50 \%$ of those in control subjects with no or only small atherosclerotic changes (grade 1 at the most), as detected by PCR. Similar percentages of CMV DNA were observed by other investigators [92, 110]. However, Melnick et al. [92] were not able to demonstrate a significant difference between the presence of CMV DNA in atherosclerotic plaque tissue and that in non-atherosclerotic regions within the same patient. On the other hand, atherosclerotic plaques with thrombosis from patients with carotid artery stenosis who required surgical endarterectomy were found to contain more CMV than plaques without thrombosis in carotid endarterectomy samples within the same patient [28]. As described earlier, experiments in infected rats revealed that $C M V$ induced early vascular lesions, as exemplified by endothelial cell damage, increased adhesion of leukocytes to the endothelium followed by diapedesis through the endothelium into the subendothelial space, and presence of leukocytes (lymphocytes and macrophages) in the subendothelium [128, 129]. Moreover, the CMVinduced early vascular lesions were characterized by the presence of lipophages as well 
as lipid accumulation in the endothelium and subendothelial space that consisted of extracellular lipid deposition and the location of subendothelial foam cells $[128,129]$. Additionally, CMV infection was shown to cause morphological alterations of the endothelium and subendothelial space of the large vessels in rats [128]. These changes included swollen endothelial cells with the formation of blebs, microvilli and craters on their surfaces. Moreover, CMV infection in rats led to the partial detachment of endothelial cells from the basement membrane, followed by an expansion of the space between the endothelium and the basement membrane and filling it with increasing amounts of basal lamina-like material mixed with collagen [128]

The increased adherence of leukocytes (polymorphonuclear and monocytes) following a CMV infection was also supported by data from in vitro experiments [131]. CMV infection of endothelial cells was accompanied by the expression of glycoproteins on their cell surface, promoting the adhesion of granulocytes to endothelial cells [131]. In vitro as well as in vivo studies further revealed that apart from endothelial cells, a wide variety of cell types are permissive for $C M V$, including monocytes/macrophages, fibroblasts and SMCs $[18,56,123,126,149,164]$. Although the exact mechanism underlying the role of $C M V$ in atherogenesis has not been elucidated yet, several studies did raise some ideas on how CMV might be involved. CMV was reported to induce $S M C$ migration and proliferation, increase modified low density lipoprotein (LDL) uptake in vascular SMCs, promote leukocyte influx, and induce an increased expression of adhesion molecules (e.g. ICAM-1), inflammatory cytokines (e.g. IL-6) and chemokines (e.g. MCP-1), ultimately contributing to the aggravation of the atherosclerotic process $[3,20,49,116,120,130,179,183]$.

Apart from the RCMV/rat model, the MCMV/mouse model has also been employed to study atherosclerosis-related issues. Currently, several transgenic mouse strains are available, e.g. apolipoprotein $\mathrm{E}(\mathrm{apoE} \%$ ) knockout mice and LDL receptor (LDLrec $\%$ ) knockout mice, with the propensity to develop severe atherosclerosis $[59,108,178]$. Analogous to studies using the RCMV/rat model, data from studies utilizing the MCMV/ apoE $\%$ knockout mouse model indicated that $M C M V$ might be capable of aggravating atherosclerosis $[55,161,162]$, corroborating the hypothesis that $C M V$ is involved in the atherosclerotic disease process.

\section{Arterial Restenosis}

Patients suffering from severe symptomatic occlusive artery disease are commonly treated with balloon angioplasty (Percutaneous Coronary intervention, $\mathrm{PCl}$ ) or atherectomy. However, in $30-50 \%$ of the cases treatment with $\mathrm{PCl}$ leads to renewed narrowing (coronary or arterial restenosis) of the initially successfully dilated vessel [44]. The processes that are responsible for restenosis and atherosclerosis are similar but not identical. Atherosclerosis is an ongoing chronic inflammatory process developing over a period of several years, whereas restenosis is triggered by an acute mechanical injury ultimately leading to luminal narrowing within a period of several weeks to months. On the other hand, restenosis, like atherosclerosis, is thought to be a multifactorial phenomenon and some of the mechanisms involved in restenosis are similar to those involved in atherogenesis. As in atherosclerosis, the angioplasty-induced injury induces the expression of growth factors, cytokines and adhesion molecules as well as the production of free radicals and the activation of genes that are implicated in inflammatory 
and immune responses [36]. Moreover, $\mathrm{PCl}$-induced injury appears to be associated with SMC proliferation and accumulation, vascular remodeling, platelet aggregation and thrombus formation [36]. Like in atherosclerosis, SMCs and endothelial cells constitute factors of crucial importance in the development of restenosis [146]. Briefly, upon activation due to injury SMCs proliferate and migrate to the subintima, where proliferation continues. Also, upon arrival in the subintimal layer SMCs start to secrete extracellular matrix proteins. Subsequently, the resulting neointima expands more and more, obstructing the vessel lumen and diminishing blood flow and ultimately leading to vascular remodeling, in which the overall cross-sectional luminal diameter of the vessel narrows [36]. Finally, it seems plausible that factors (e.g. viruses) further contributing to changes in the vascular wall that augment plaque formation in atherosclerosis might also be responsible for enhancing neointimal formation and vascular remodeling in restenosis.

\section{CMV and Arterial Restenosis}

Several studies have reported a link between CMV infection and restenosis. Patients seropositive for HCMV were shown to be at greater risk for restenosis after angioplasty than seronegative patients [180]. Interestingly, the risk for restenosis was found to correlate with IgG rather than IgM antibody levels. Moreover, IgG antibody levels between the primary intervention and the follow-up angiogram were quite consistent, indicating that a prior CMV infection rather than an acute $C M V$ infection should be considered an (independent) risk factor for restenosis [180]. Additionally, patients with high anti-CMV antibody titers developed restenosis more frequently than patients with low anti-CMV antibody titers, implying that high anti-CMV antibody levels may predict the emergence of restenosis following coronary angioplasty [13]. Studies using a carotid injury model in rats further support CMV involvement in restenosis [181, 182]. In this model, endothelial denudation using a balloon catheter causes intimal damage, ultimately resulting in increased intimal hyperplasia and thickening. Using this model, CMV infection, either acute or chronic persistent, was found to augment the neointimal response to injury $[181,182]$. Since the CMV-induced increased neointimal response to injury occurs even in the absence of virus in the vascular wall, inflammatory and immune responses to CMV infection of non-vascular tissues are likely to contribute to this response $[181,182]$. Corresponding results were reported using the so-called rose Bengal model, which is based on a photochemical reaction between transluminal green light $(540 \mathrm{~nm})$ and intravenously administered rose Bengal to induce endothelial injury and intimal thickening in rats $[63,119]$. In the rose Bengal model, RCMV infection was found to stimulate arterial SMC proliferation, leading to neointima formation. Additionally, only limited numbers of RCMV DNA copies were present within the vascular wall, rendering further support to the hypothesis that CMV-mediated inflammatory and immune responses are more important in enhancing vascular injury than local virus replication (G. Kloppenburg, S. Herngreen, G. Grauls, C. Bruggeman, and F. Stassen, unpublished data).

Another mechanism by which CMV might, at least partially, contribute to restenosis is through promoting SMC proliferation by blocking the anti-proliferative effect of the tumor suppressor gene p53 [133]. In particular, p53 function might be abolished by the viral immediate early protein IE84, which was shown to be expressed by infected, 
cultured SMCs (grown from restenotic lesions) and which is capable of binding to $p 53$, thereby sequestering the p53 protein and, hence, eliminating its capacity to impede cell cycle progression causing excessive proliferation of SMCs and inhibition of apoptosis $[132,133,185]$. In addition, IE84-binding to p53 was demonstrated to inhibit the transcriptional activity of $\mathrm{p} 53$, thereby further impairing the suppressor function of p53 [133]. Interestingly, $80 \%$ of the samples that were positive for HCMV DNA were also positive for p53 that has lost its inhibitory function [133]. These findings are compatible with the assumption that injury to the coronary artery wall at the time of angioplasty might mediate the reactivation of latent HCMV in cells of the arterial wall [133]. CMV reactivation leads to expression of IE84 which, in turn, may inactivate the cell cycle regulatory protein $\mathrm{p} 53$ and allow uncontrolled smooth muscle cell proliferation [133]. The idea that reactivation of latent CMV might be involved, was also raised by other investigators. Persoons and coworkers hypothesized that a local injury (e.g. due to balloon angioplasty) might reactivate latent $C M V$ residing in arterial SMCs, thereby initiating an acute infection [104], which in turn might trigger SMC proliferation. However, although the above-mentioned hypotheses might seem attractive, they are difficult to reconcile with the observation that CMV DNA is not readily detected in the vessel wall.

\section{Transplant Vascular Sclerosis}

Transplant vascular sclerosis (TVS), also designated transplant-associated arteriosclerosis (TAA) or chronic rejection, has emerged as the major factor affecting long-term survival of transplanted organs $[4,9]$. TVS has been identified as the most important cause of graft failure following the first posttransplant year [103]. In cardiac allograft recipients the incidence of TVS is nearly $50 \%$ at 5 years after transplantation $[41,99]$. However, TVS is not restricted to cardiac allografts; it can develop after transplantation of a broad range of solid organs, including kidney, lung, liver and small bowel transplantation. In all transplanted solid organs the proliferative vascular changes have a similar appearance in TVS, being most prominent in the kidney and heart, whereas changes in the functional unit of the organ are dependent on organ specificity [33]. In TVS the manifestations are generalized, affecting the entire length of the vessel (arteries and arterioles), and allograft intimal thickening is concentric and develops rapidly, whereas the slowly progressing atherosclerotic process is characterized by focal, eccentric lesions containing cholesterol deposits $[9,11,41,50,99,113,118]$. Moreover, TVS is associated with a persistent perivascular and interstitial inflammation and a usually intact internal elastic lamina, whereas in atherosclerosis, perivascular inflammation is absent and the internal elastic lamina is disrupted $[9,113]$. Cardiac allografts undergoing chronic rejection showed vascular intimal thickening, due to proliferation of SMCs and infiltration of inflammatory cells (macrophages and activated T lymphocytes), together with interstitial fibrosis $[10,33,152]$. The pathophysiological mechanism of TVS is complicated and immunological as well as non-immunological factors, such as hyperlipidemia, pretransplant ischemia and CMV infection, are thought to be involved $[8,35,41,42,46,90,99,122,142,171]$. 


\section{CMV and Transplant Vascular Sclerosis}

Infection with CMV was hypothesized to be associated with an increased incidence of graft failure as well as increased recipient mortality rates following transplantation, indicating that CMV either induces or expedites TVS $[62,85,87]$. Indeed, various clinical studies suggested the existence of a relationship between TVS and CMV. Grattan and coworkers showed that allograft vasculopathy occurred more frequently as well as earlier in CMV-infected cardiac transplant recipients than in non-infected recipients [46]. Also, the rate of graft loss was significantly higher in CMV-infected patients than in non-infected patients [46]. Other investigators reported similar observations in cardiac transplant recipients infected with $C M V[86,90]$. Additionally, prolonged CMV infection accompanied by viremia was found to correlate with the development of allograft vasculopathy in cardiac recipients [39]. When allografts were examined for the presence of CMV nucleic acids using in situ hybridization with a CMV DNA probe, coronary arteries of allografted hearts with severe accelerated arteriosclerosis were found to harbor CMV nucleic acids (DNA and/or RNA), whereas these were absent in cardiac transplant patients showing no signs of allograft vasculopathy $[54,173]$. Correspondingly, Koskinen et al. [67, 70] found comparable results when using endomyocardial biopsies and angiography. These investigators also observed a link between CMV antigenemia and the induction of vascular cell adhesion molecules in the graft of cardiac transplant patients [66]. Finally, CMV infection putatively induces immune activation and subendothelial inflammation, subsequently contributing to graft arteriosclerosis and rejection $[68,69]$. Besides cardiac allografts, CMV was reported to be implicated in TVS pathogenesis in a variety of allografts, including renal, kidney, liver and lung allografts $[14,72,74,109,139]$.

The most compelling evidence that CMV might be involved in the development of TVS comes from various transplantation models in rats. Lemström and coworkers extensively studied the role of RCMV in transplant arteriosclerosis using the rat aortic transplant model. In this model, the thoracic aorta is transplanted between inbred rats in syngeneic and allogeneic combinations in the absence of immunosuppressive compounds [94]. Using this model, RCMV infection was shown to boost cell-mediated and humoral immune responses resulting in increased leukocyte influx, SMC and EC proliferation, and intimal thickening in the rat aortic as well as cardiac allografts [77, 80]. Additionally, RCMV infection caused the induction of inflammation in the adventitia and subendothelium of the allografted vascular wall, as was evident by an increased infiltration of monocytes/macrophages and T lymphocytes [69, 77, 82, 83]. Similar findings were reported using the rat renal transplant model, in which RCMV infection was found to both accelerate and enhance the early immune response and the development of chronic rejection in renal allografts [73]. Moreover, RCMV infection stimulated the induction of growth factors, the synthesis of collagen and the generation of fibrosis in rat renal allografts $[58,73]$. In different kinds of allograft recipients, RCMV infection caused an increased expression of adhesion molecules VCAM-1 and ICAM-1 as well as increased numbers of inflammatory cells expressing activation markers LFA1 and VLA-4 in the vascular endothelium, all contributing to the CMV-mediated acceleration of allograft arteriosclerosis $[65,88,140,176]$. In addition, other antigens of which the expression was reported to be increased were MHC class I, MHC class II, IL-2 receptor, and several growth factors (e.g. PDGF-AA, PDGF-BB, TGF- $\beta 1, B-F D F$ ), 
cytokines (e.g. TNF, IFN- $\gamma$ ) and chemokines (e.g. RANTES, MIP-1 $\alpha$, Fractalkine, IP-10, Lymphotactin) $[57,75,141,143,150,155,163,177]$. On the other hand, other studies failed to show a CMV-mediated upregulation of MHC class II molecules $[120,121$, $151,155]$. However, in all these cases only in vitro experiments were carried out, abrogating a possible indirect effect of CMV on MHC class II expression. Indeed, when endothelial cells were co-cultured with allogeneic $C D 4^{+} T$ cells from subjects positive for CMV antibodies, CMV infection of cultured endothelial cells resulted in a substantial increase in MHC class II expression [168]. Moreover, this CMV-mediated increase in MHC class II expression could be abolished entirely by adding anti-IFN- $\gamma$ antibodies to the culture medium, implicating that CMV indirectly, through IFN- $\gamma$, enhances MHC class II expression [168].

CMV-mediated activation of the immune system, which mounts an additional inflammatory response to the alloresponse, is crucial in accelerated TVS pathogenesis, since treatment of animals with immunosuppressive compounds significantly diminished the CMV-induced exacerbation of transplant arteriosclerosis $[23,76,78,79,81]$. In addition, differences in MHC antigens between donor and recipient are also required, as enhanced graft-associated arteriosclerosis by $C M V$ was rarely observed in syngeneic graft recipients $[30,77,78]$. Interestingly, although more vascular lesions were observed in the class II-mismatched allografts, substantial CMV-mediated neointima formation was only observed in allografts of rats with MHC class I disparity, probably due to CMV-linked increase in perivascular influx of monocytes/macrophages [84]. The importance of the alloreactive immune response in CMV acceleration of TVS was further supported by a study using bone marrow chimerism in a rat small bowel transplant model and a rat heart transplant model [101]. In this model, recipients lack an alloreactive response because of donor-specific tolerance induced by bone marrow chimerism, which was demonstrated to prevent transplant arteriosclerosis and chronic rejection [101]. Clearly, the alloreactive environment plays a crucial role in CMV-accelerated TVS, since allograft recipients given autologous bone marrow failed to develop TVS even when infected with RCMV [101]. In summary, CMV infection has the potential to modulate the allorecognition and alloreaction process, resulting in an intensified immune response.

\section{The Role of Endothelial Cells in CMV-mediated Vascular Disease: Endotheliotropism}

The endothelium performs a pivotal role in the pathogenesis of vascular disease [114]. Under normal conditions, the endothelium lining the vessel wall provides a protective barrier between the circulating blood and the vessel wall, maintaining an anticoagulant status. Moreover, the endothelial layer regulates vascular functions that offer resistance to a CMV invasion. Endothelial dysfunction constitutes a main event in the atherosclerotic disease process that may result from immunological destruction and clearance of CMV-infected ECs (Figure 1). Also, CMV infection is capable of modulating the status of ECs from an anticoagulant to a procoagulant one [154]. Originally, permissiveness of endothelial cells for CMV was thought to be rather restricted, depending on the activation state of the cells, the virus strain used, and the origin of the endothelial cells $[125,126,164,165,170]$. Notably, in vitro, CMV has traditionally been propagated in fibroblasts. However, extensive virus propagation in 
fibroblasts was demonstrated to be associated with alterations in phenotypic characteristics presumably due to the occurrence of mutations in the viral genome during long-term propagation in fibroblasts, resulting in loss of tropism for various, otherwise natural host cells, including ECs $[24,124,169,170]$. Endothelial-based propagation, on the other hand, was demonstrated to preserve the natural endothelial cytopathogenicity of the original clinical isolate $[169,170]$. Intriguingly, results from unpublished studies indicate that the UL131-UL128 locus is required for endotheliotropism, although this locus most likely does not represent the sole determinant for EC tropism (Baldanti et al., International Cytomegalovirus Workshop 2003, Maastricht, The Netherlands; Hahn et al., International Cytomegalovirus Workshop 2003, Maastricht, The Netherlands).

In addition to a direct detrimental effect to the endothelium, CMV may indirectly promote atherosclerosis via the release of inflammatory mediators (Figure 1). As stated earlier, CMV infection was found to upregulate the expression of a variety of cytokines (e.g. IL-1, IL-2, IL-6, and IL-8) either directly by ECs or indirectly by other cells, e.g. leukocytes, which interact with the infected cells through the cytokine-mediated pathway $[3,29,96,166,167,172]$. Directly, CMV infection of ECS may increase the expression of adhesion molecules on the endothelial cell surface, such as VCAM-1, ICAM-1 and LFA-3, raising the endothelium to an activated, highly immunogenic state that can

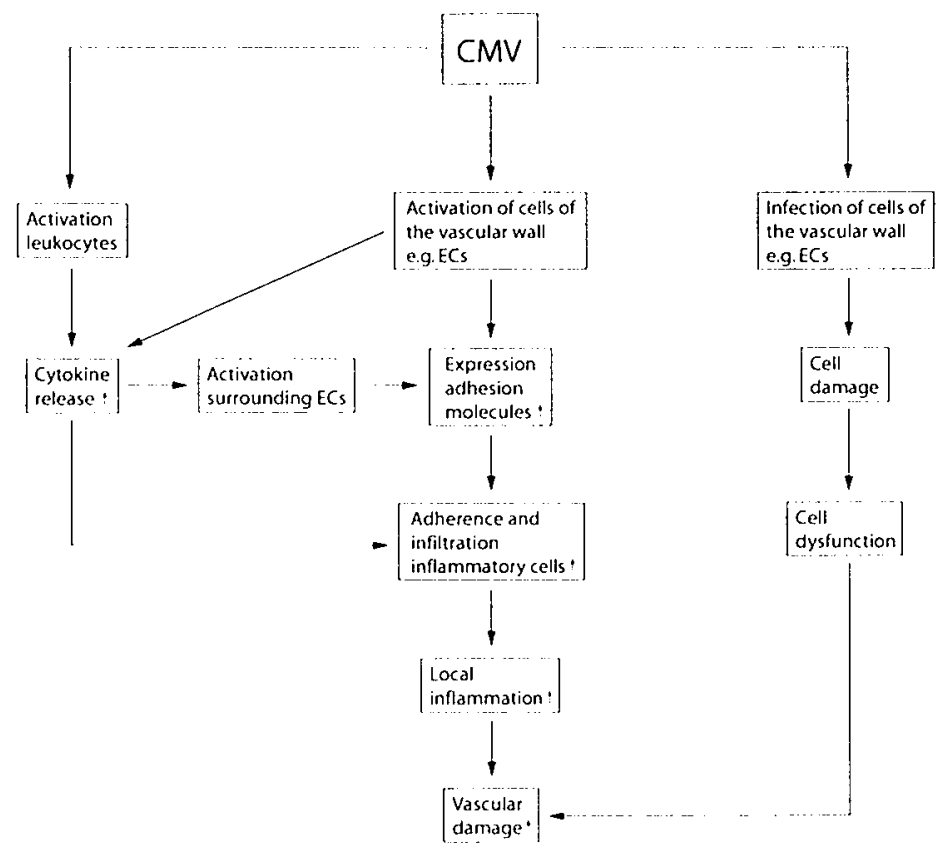

Indirect

Direct

Figure 1. Scheme of the major direct and indirect routes by which the endothelium might be implicated in aggravating CMV-mediated vascular diseases. CMV may enhance vascular damage through endothelial dysfunction as well as through (endothelial-mediated) modulation of the immune responses. 
promote adherence and transendothelial migration of inflammatory cells, but also vascular damage $[29,120,140]$. Indirectly, CMV-infected, allogeneic ECs can activate $T$ lymphocytes $\left(C D 4^{+}\right)$, resulting in proliferation and production of $\mathrm{IL}-2$, which in turn stimulates the release of other T cell-derived cytokines, such as IFN- $\gamma$ [166]. Also, CMVinfected ECs may activate and stimulate allogeneic $\mathrm{CD4} 4^{+}$and $\mathrm{CD} 8^{+} \mathrm{T}$ lymphocytes to release cytokines (IFN- $\gamma$ and TNF- $\alpha$, respectively) that subsequently activate surrounding ECs and induce expression of adhesion molecules on their cell surface $[130,167,168]$. Finally, CMV infection of ECs may induce the upregulation of chemokines (e.g. MCP1 ), creating a chemokine gradient near the vessel wall and promoting leukocyte adherence and infiltration and, eventually, vascular disease [147]. Interestingly, since CMV is capable of promoting vascular disease even in the absence of viral DNA in the vessel wall, the indirect pathway most likely represents the primary mechanism by which CMV augments atherogenesis.

Recently, a novel interesting mechanism in atherogenesis was reported that involves the interplay between leukocytes and endothelial cells and in which the proinflammatory cytokine IL-6, an important regulator of inflammation and immunity (e.g. activation of T lymphocytes), plays a key role [117]. It was postulated that $T$ lymphocytes that are clonally expanded in response to antigens presented by CMV infection, home and reside to sites of vascular damage via binding to adhesion molecules. Due to the presence of pathogen antigens in the plaque or cross-reaction with host protein homologs of pathogen antigens, $T$ lymphocytes release IL- 6 , which in turn triggers ECS in situ to release $M C P-1$. Thereupon, $M C P-1$, which is chemoattractant to monocytes and $\mathrm{CD}^{+}$ as well as $\mathrm{CD} 8^{+} \mathrm{T}$ lymphocytes, recruits even more monocytes and $\mathrm{T}$ cells into the vascular wall, resulting in an aggravation of local inflammation and, hence, atherosclerosis $[117,147]$. Although numerous pathways are involved in CMV-mediated exacerbation of vascular disease, this hypothesis sets a good example of the refined interplay between leukocytes and endothelial cells.

\section{The Role of CMV-encoded GPCRs in Vascular Wall Pathology and CMV Disease}

As is evident, chemokines and chemokine receptors play a prominent role in the development of vasculopathies. Chemokine receptors belong to the superfamily of the $G$ protein-coupled receptors (GPCRs). Interestingly, the HCMV genome was found to encompass four genes encoding proteins with homology to host GPCRs, namely those encoded by UL33, UL78, US27 and US28 $[25,26]$. Intriguingly, the HCMV US28encoded protein ( $p U S 28$ ), comprises the first CMV-encoded protein reported to be putatively involved in SMC migration to sites of atherogenesis or stenosis and, hence, in the development of vascular disease. Streblow and coworkers [145] found that HCMV infection of SMCs that were isolated from the aorta induced their migration. This migration was cell-type specific, not occurring in case of venous SMCs, ECs or fibroblasts. Since infection with a mutant HCMV strain lacking a functional US28 gene (HCMV$\triangle U S 28$ ) failed to induce SMC migration, US28 was considered a prerequisite for HCMVinduced cellular migration. This notion was further supported by the observation that co-infection with adenoviruses expressing pUS28 was capable of rescuing the migration of SMCs that were infected with HCMV- $\Delta U S 28$. Moreover, expression of pUS28 lent 
SMCs the capability to migrate by chemokinesis as well as chemotaxis in the presence of CC chemokines, including RANTES or MCP-1 [145]. Altogether, these data may indicate that by virtue of pUS28 HCMV might induce SMC migration to sites of vascular inflammation, thereby contributing to the process of chronic vascular diseases [144, 145].

Although the US28 gene appears to be dispensable for virus replication in vitro [157], this finding does not preclude the assumption that US28 plays an essential role in CMV disease in vivo. However, due to the species-specificity as well as ethical considerations, it is practically impossible to study the role of pUS28 in HCMV pathogenesis in vivo. Likewise, the function of the HCMV-encoded US27 protein (pUS27) also remains speculative. Both the HCMV UL33 and UL78 gene, however, are well conserved in all currently known betaherpesvirus genomes, including the RCMV genome $[5,7]$, enabling investigators to elucidate the in vivo function of homologues of the UL33- and UL78-encoded proteins (pUL33 and pUL78, respectively). Interestingly, the first pUL33-like GPCR that was demonstrated to be capable of signaling in a ligandindependent (i.e. constitutive) way was the receptor encoded by the RCMV R33 gene $[47,48]$. In order to study the in vivo function of the R33 gene, recombinant viruses were generated in which the R33 gene is disrupted [7]. Subsequently, the replication characteristics of these null mutant strains were compared to those of wild-type (WT) $R C M V$ both in vitro and in vivo. This study showed that the $R 33$ gene was not required for the replication of RCMV in vitro. However, pronounced differences were found between animals infected with the R33-knockout viruses and those infected with WT RCMV. First, whereas WT RCMV was capable of establishing a high-titer infection in the salivary glands, the R33-knockout viruses were unable to replicate efficiently in this organ. This implied that R33 plays an important role in virus dissemination to or replication in the salivary glands. Second, a significantly lower mortality rate was observed amongst rats infected with the R33-knockout strains than amongst those infected with WT RCMV, demonstrating a more general role of R33 during in vivo infection. Similar findings were reported for the UL33-like gene present within the genome of murine CMV (MCMV), denoted M33 [31], underlining the biological importance of the UL33-like genes in CMV pathogenesis.

An identical strategy was implemented to clarify the in vivo function of the GPCR encoded by the UL78-like gene within the RCMV genome (denoted R78), i.e. comparison of the replication characteristics of recombinant RCMV strains from which part of the R78 sequence was deleted to those of WT RCMV. In contrast to the R33 null mutants, the R78-knockout viruses displayed a diminished production of progeny virus in vitro $[5,60]$. Similar results were found for the UL78-like gene present in the MCMV genome, M78 [100]. Moreover, during infection of fibroblasts with the R78-knockout strains a conspicuous morphological phenomenon was observed in vitro. Unlike WT RCMV-infected fibroblasts, fibroblasts infected with the R78 null mutants developed a syncytium-like appearance [5]. The ability of these R78 knockout strains to induce syncytium formation in infected fibroblasts led to the suggestion that R78 might be implicated in stabilizing glycoprotein complexes in order to establish cell-to-cell contacts [5]. Similarly to the replication in vitro, replication of a recombinant R78 strain expressing an enhanced green fluorescent protein (EGFP)-tagged version of pR78 instead of native pR78 was also shown to be attenuated in vivo [60]. While infectious virus was readily detected in the spleen of WT RCMV-infected rats, virus could not be detected in the 
spleen of rats infected with the recombinant $R 78$ strain. Correspondingly, recombinant M78 strains replicated less efficiently in the spleen as well as in the liver and salivary glands of infected mice than WT MCMV [100]. Summarizing, these data indicate that the UL78-like genes of RCMV and MCMV constitute non-essential genes that are, nevertheless, required for efficient CMV replication, at least in the spleen. Moreover, deletion of the R78 and $M 78$ gene from the RCMV and MCMV genome, respectively, resulted in mutant strains with reduced virulence in vivo, implying that the UL78-like genes play an important role in the pathogenesis of CMV infection $[5,100]$.

\section{Concluding Remarks}

The RCMV/rat model has proven to be suitable for studying the CMV-mediated development of vascular disease, particularly in atherosclerosis, arterial restenosis and transplant vascular sclerosis. The use of this model resulted in substantial data showing a stimulatory role of CMV in the pathogenesis of various types of vascular disease. RCMV was found to exert its detrimental effects both directly, through dysfunction of cells of the vascular wall, and indirectly, through modulation of the inflammatory and immune responses, which putatively represents the main mechanism of action. Also, CMV seems to affect all stages of the vascular disease process. However, this activity may not be unique for CMV. Several studies are indicative of the existence of a positive correlation between the number of infectious pathogens to which a subject has been exposed (e.g. CMV, Chlamydia pneumoniae, Helicobacter pylori, Epstein-Barr virus) and the degree of atherogenesis, giving rise to the so-called 'pathogen burden hypothesis' [37, 38, 184]. Nonetheless, more animal studies are required to elucidate the mechanisms of CMV-enhanced progression of vascular disease, which may ultimately provide us with new targets for prophylaxis and/or treatment.

\section{Acknowledgements}

C.V. is supported by a fellowship of the Royal Netherlands Academy of Arts and Sciences (KNAW).

\section{References}

1. Adam, E., Melnick, J.L., Probtsfield, J.L., Petrie, B.L., Burek, J., Bailey, K.R., McCollum, C.H., and DeBakey, M.E. (1987). High levels of cytomegalovirus antibody in patients requiring vascular surgery for atherosclerosis. Lancet 2, 291-293.

2. Adler, S.P., Hur, J.K., Wang, J.B., and Vetrovec, G.W. (1998). Prior infection with cytomegalovirus is not a major risk factor for angiographically demonstrated coronary artery atherosclerosis. J. Infect. Dis. 177, 209-212.

3. Almeida, G.D., Porada, C.D., St Jeor, S., and Ascensao, J.L. (1994). Human cytomegalovirus alters interleukin- 6 production by endothelial cells. Blood $83,370-$ 376. 
4. Barnart, G.R., Pascoe, E.A., Mills, A.C., Szentpetery, S., Eich, D.M., Mohanacumar, T., Hastillo, A., Thompson, J.A., Hess, M.L., and Lower, R.R. (1987). Accelerated coronary arteriosclerosis in cardiac transplant recipients. Transplant. Rev. 1, 31-46.

5. Beisser, P.S., Grauls, G.E.L.M., Bruggeman. C.A., and Vink, C. (1999). Deletion of the $R 78 \mathrm{G}$ protein-coupled receptor gene from rat cytomegalovirus results in an attenuated, syncytium-inducing mutant strain. J. Virol. 73, 7218-7230.

6. Beisser, P.S., Kloover, J.S., Grauls, G.E.L.M., Blok, M.J., Bruggeman. C.A., and Vink, C. (2000). The 144 major histocompatibility complex class I-like gene of rat cytomegalovirus is dispensable for both acute and long-term infection in the immunocompromised host. J. Virol. 74, 1045-1050.

7. Beisser, P.S., Vink, C., van Dam, J.G., Grauls, G.E.L.M., Vanherle, S.J.V., and Bruggeman, C.A. (1998). The R33 G protein-coupled receptor gene of rat cytomegalovirus plays an essential role in the pathogenesis of viral infection. J. Virol. 72, 2352-2363.

8. Bieber, C.P., Hunt, S.A., Schwimm, D.A., Jamieson, S.A., Reaitz, B.A., Oyer, P.E., Shumway, N.E., and Stinson, E.B. (1981). Complications in long-term survivors of cardiac transplantation. Transplant. Proc. 13, 207-211.

9. Billingham, M.E. (1987). Cardiac transplant atherosclerosis. Transplant. Proc. 19 (Suppl.5), 19-25.

10. Billingham, M.E. (1989). Graft coronary disease: The lesions and the patients. Transplant. Proc. 21, 3665-3666.

11. Billingham, M.E. (1992). Histopathology of graft coronary disease. J. Heart Lung Transpl. 11, S38-S44.

12. Blok, M.J., Savelkouls, K.G.M., Grauls, G.E.L.M., Bruggeman, C.A., and Vink, C. (2001). Immediate early-1 mRNA expression and virus production are restricted during the acute phase of rat cytomegalovirus infection in immunocompetent rats. In Monitoring the course of CMV infection by detection of specific viral transcripts, M.J. Blok, ed. (Geleen, The Netherlands: ANDI Press), pp. 91-124.

13. Blum, A., Giladi, M., Weinberg, M., Kaplan, G., Pasternack, H., Laniado, S., and Miller, H. (1998). High anti-cytomegalovirus (CMV) IgG antibody titer is associated with coronary artery disease and may predict post-coronary balloon angioplasty restenosis. Am. J. Cardiol. 81, 866-868.

14. Boyce, N.W., Hayes, K., Gee, D., Holdsworth, S.R., Thomson, N.M., Scott, D., and Atkins, R.C. (1988). Cytomegalovirus infection complicating renal transplantation and its relationship to acute transplant glomerulopathy. Transplantation 45, 706709.

15. Bruggeman, C.A. (1993). Cytomegalovirus and latency: an overview. Virchows Arch. B cell Pathol. 64, 325-333.

16. Bruggeman, C.A., Bruning, J.H., Grauls, G., van den Bogaard, A.E., and Bosman, F. (1987). Presence of cytomegalovirus in brown fat. Study in a rat model. Intervirology 27, 32-37.

17. Bruggeman, C.A., Debie, W.H.M., Grauls, G.E.L.M., Majoor, G., and van Boven, C.P.A. (1983). Infection of laboratory rats with a new cytomegalo-like virus. Arch. Virol. 76, 189-199.

18. Bruggeman, C.A., Meijer, H., Bosman, F., and van Boven, C.P.A. (1985). Biology of rat cytomegalovirus infection. Intervirology 24, 1-9. 
19. Bruggeman, C.A., Meijer, H., Dormans, P.H.J., Debie, W.H.M., Grauls, G.E.L.M., and van Boven, C.P.A. (1982). Isolation of a cytomegalovirus-like agent from wild rats. Arch. Virol. 73, 231-241.

20. Bruggeman, C.A., and van Dam-Mieras, M.C. (1991). The possible role of cytomegalovirus in atherogenesis. Prog. Med. Virol. 38,1-26.

21. Bruning, J.H., Bruggeman, C.A., van Boven, C.P., and van Breda Vriesman, P.J. (1986). Passive transfer of latent rat cytomegalovirus by cardiac and renal organ transplants in a rat model. Transplantation 41, 695-698.

22. Bruning, J.H., Bruggeman, C.A., van Boven, C.P., and van Breda Vriesman, P.J. (1989). Reactivation of latent rat cytomegalovirus by a combination of immunosuppression and administration of allogeneic immunocompetent cells. Transplantation 47, 917-918.

23. Bruning, J.H., Persoons, M.C.J., Lemström, K.B., Stals, F.S., De Clercq, E., and Bruggeman, C.A. (1994). Enhancement of transplantation-associated atherosclerosis by $C M V$, which can be prevented by antiviral therapy in the form of HPMPC. Transplant. Int. 7(Suppl. 1), S365-\$370.

24. Cha, T.A., Tom, E., Kemble, G.W., Duke, G.M., Mocarski, E.S., and Spaete, R.R. (1996). Human cytomegalovirus clinical isolates carry at least 19 genes not found in laboratory strains. J. Virol. 70, 78-83

25. Chee, M.S., Bankier, A.T., Beck, S., Bohni, R., Brown, C.M., Cerny, R., Horsnell, T., Hutchinson III, C.A., Kouzarides, T., Martignetti, J.A., Preddie, E., Satchwell, S.C., Tomlinson, P., Weston, K.M., and Barrell, B.G. (1990). Analysis of the protein-coding content of the sequence of human cytomegalovirus strain AD169. Curr. Top. Microbiol. Immunol. 154, 125-169.

26. Chee, M.S., Satchwell, S.C., Preddie, E., Weston, K.M., and Barrell, B.G. (1990) Human cytomegalovirus encodes three $G$ protein-coupled receptor homologues. Nature 344, 774-777.

27. Chen, R., Xiong, S., Yang, Y., Fu, W., Wang, Y., and Ge, J. (2003). The relationship between human cytomegalovirus infection and atherosclerosis development. Mol. Cell. Biochem. 249, 91-96.

28. Chiu, B., Viira, E., Tucker, W., and Fong, I.W. (1997). Chlamydia pneumoniae, cytomegalovirus and herpes simplex virus in atherosclerosis of the carotid artery. Circulation 96, 2144-2148.

29. Craigen, J.L., and Grundy, J.E. (1996). Cytomegalovirus induced up-regulation of LFA-3 (CD58) and ICAM-1 (CD54) is a direct viral effect that is not prevented by ganciclovir or foscarnet treatment. Transplantation 62,1102-1108.

30. Cramer, D.V., Qian, S.Q., Harnaha, J., Chapman, F.A., Estes, L.W., Starzl, T.E., and Makowka, L.(1989). Cardiac transplantation in the rat. The effect of histoincompatibility differences on graft arteriosclerosis. Transplantation 47, 414419.

31. Davis-Poynter, N.J., Lynch, D.M., Vally, H., Shellam, G.R., Rawlinson, W.D., Barrell, B.G., and Farrell, H.E. (1997). Identification and characterization of a G proteincoupled receptor homolog encoded by murine cytomegalovirus. J. Virol. 71, 1521 1529.

32. Danesh, J., Collins, R., and Peto, R. (1997). Chronic infections and coronary heart disease: is there a link? Lancet 350, 430-436. 
33. Demetris, A.J., Zerbe, T., and Banner, B. (1989). Morphology of solid organ allograft arteriopathy: Identification of proliferating intimal cell populations. Transplant. Proc. 21, 3667-3669.

34. DeRodriguez, C.V., Fuhrer, J., and Lake-Bakaar, G. (1994). Cytomegalovirus colitis in patients with acquired immunodeficiency syndrome. J. R. Soc. Med. 87, 203205.

35. Eich, D., Thompson, J.A., Ko, D., Hastillo, A., Lower, R., Katz, S., Katz, M., and Hess, M.L. (1991). Hypercholesterolemia in long-term survivors of heart transplantation; an early marker of accelerated coronary artery disease. J. Heart Lung Transplant. 10, 45-49.

36. Epstein, S.E., Speir, E., Zhou, Y.F, Guetta, E., Leon, M., and Finkel, T. (1996). The role of infection in restenosis and atherosclerosis: focus on cytomegalovirus. Lancet 348, S13-S17.

37. Epstein, S.E., Zhu, J., Burnett, M.S., Zhou, Y.F, Vercellotti, G., and Hajjar, D. (2000). Infection and atherosclerosis: potential roles of pathogen burden and molecular mimicry. Arterioscler. Thromb. Vasc. Biol. 20,1417-1420.

38. Espinola-Klein, C., Rupprecht, H.J., Blankenberg, S., Bickel, C., Kopp, H., Rippin, G., Victor, A., Hafner, G., Schlumberger, W., and Meyer, J. (2002). Impact of infectious burden on extent and long-term prognosis of atherosclerosis. Circulation $105,15-21$.

39. Everett, J.P., Hershberger, R.E., Norman, D.J., Chou, S., Ratkovec, R.M., Cobanoglu, A., On, G.Y., and Hosenpud, J.D. (1992). Prolonged cytomegalovirus infection with viremia is associated with development of cardiac allograft vasculopathy. J. Heart Lung Transplant. 11, S133-S137.

40. Francis, N.D., Boylston, A.W., Roberts, A.H., Parkin, J.M., and Pinching, A.J. (1989). Cytomegalovirus infection in gastrointestinal tracts of patients with HIV-1 or AIDS. J. Clin. Pathol. 42, 1055-1064.

41. Gao, S.Z., Alderman, E.L., Schroeder, J.S., Silverman, J.F., and Hunt, S.A. (1988). Accelerated coronary vascular disease in the heart transplant patient: coronary arteriographic findings. J. Am. Coll. Cardiol. 12, 334-340.

42. Gao, S.Z., Schroeder, J.S., Alderman, E.L., Hunt, S.A., Silverman, J.F., Wiederholt, V., and Stinson, E.B. (1987). Clinical and laboratory correlates of accelerated coronary artery disease in the cardiac transplant patient. Circulation 76 (Suppl.4), 56-61.

43. Gattone, M., lacoviello, L., Colombo, M., Castelnuovo, A.D., Soffiantino, F., Gramoni, A., Picco, D., Benedetta, M., and Giannuzzi, P. (2001). Chlamydia pneumoniae and cytomegalovirus seropositivity, inflammation markers, and the risk of myocardial infarction at a young age. Am. Heart J. 142, 633-640.

44. Glagov, S. (1994). Intimal hyperplasia, vascular modeling, and the restenosis problem. Circulation 89, 2888-2891.

45. Golden, M.P., Hammer, S.M., Wanke, C.A., and Albrecht, M.A. (1994). Cytomegalovirus vasculitis. Case reports and reviews of the literature. Medicine 73, 246-255.

46. Grattan, M.T., Moreno-Cabral, C.E., Starnes, V.A., Oyer, P.E., Stinson, E.B., and Shumway, N.E. (1989). Cytomegalovirus is associated with cardiac allograft rejection and atherosclerosis. JAMA 261, 3561-3566.

47. Gruijthuijsen, Y.K., Beuken, E.V.H., Smit, M.J., Leurs, R., Bruggeman, Vink, C. (2004). Mutational analysis of the $R 33$-encoded $G$ protein-coupled receptor of rat 
cytomegalovirus: identification of amino acid residues critical for cellular localization and ligand-independent signaling. J. Gen. Virol. 85, 897-909.

48. Gruijthuijsen, Y.K., Casarosa, P., Kaptein, S.J.F., Broers, J.L.V., Leurs, R., Bruggeman, C.A., Smit, M.J., and Vink, C. (2002). The rat cytomegalovirus R33-encoded G protein-coupled receptor signals in a constitutive fashion. J. Virol. 76, 1328-1338.

49. Grundy, J.E., and Downes, K.L. (1993). Up-regulation of LFA-3 and ICAM-I on the surface of fibroblasts infected with cytomegalovirus. Immunology 78, 405-412.

50. Häyry, P., Mennander, A., Räisänen, A., Ustinov, J., Lemström, K., Aho, P., Yilmaz, S., Lautenschlager, I., and Paavonen, T. (1993). Pathophysiology of vascular wall changes in chronic allograft rejection. Transplant. Rev. 7, 1-20.

51. Hendrix, M.G., Dormans, P.H., Kitselaar, P., Bosman, F., and Bruggeman, C.A. (1989). The presence of CMV nucleic acids in arterial walls of atherosclerotic and nonatherosclerotic patients. Am. J. Pathol. 134, 1151-1157.

52. Hendrix, M.G., Salimans, M.M., van Boven, C.P., and Bruggeman, C.A. (1990). High prevalence of latently present cytomegalovirus in arterial walls of patients suffering from grade III atherosclerosis. Am. J. Pathol. 136, 23-28.

53. Ho, M. (1991). Cytomegalovirus. Biology and infection (New York: Plenum Medical Book Company).

54. Hruban, R.H., Wu, T.C., Beschorner, Cameron, D.E., Ambinder, R.F., W.E., Baumgartner, W.A., Reitz, B.A., and Hutchins, G.M. (1990). Cytomegalovirus nucleic acids in allografted hearts. Hum. Pathol. 21, 981-983.

55. Hsich, E., Zhou, Y.F., Paigen, B., Johnson, T.M., Burnett, M.S., and Epstein, S.E. (2001). Cytomegalovirus infection increases development of atherosclerosis in Apolipoprotein-E knockout mice. Atherosclerosis 156, 23-28.

56. Ibanez, C.E., Schrier, R., Ghazal, P., Wiley, C., and Nelson, J.A. (1991). Human cytomegalovirus productively infects primary differentiated macrophages. J. Virol. 65, 6581-6588.

57. Inkinen, K., Holma, K., Soots, A., Krogerus, L., Loginov, R., Bruggeman, C., Ahonen, J., and Lautenschlager, I. (2003). Expression of TGF-beta and PDGF-AA antigens and corresponding mRNAs in cytomegalovirus-infected rat kidney allografts. Transplant. Proc. 35, 804-805.

58. Inkinen, K., Soots, A., Krogerus, L., Bruggeman, C., Ahonen, J., and Lautenschlager, I. (1999). CMV increases collagen synthesis in chronic rejection in rat renal allograft. Transplant. Proc. 31, 1361.

59. Ishibashi, S., Brown, M.S., Goldstein, J.L., Gerard, R.D., Hammer, R.E., and Herz, J. (1993). Hypercholesterolemia in low density lipoprotein receptor knockout mice and its reversal by adenovirus-mediated gene delivery. J. Clin. Invest. 92, 883893.

60. Kaptein, S.J.F., Beisser, P.S., Gruijthuijsen, Y.K., Savelkouls, K.G.M., van Cleef, K.W.R., Beuken, E., Grauls, G.E.L.M., Bruggeman, C.A., and Vink, C. (2003). The rat cytomegalovirus $\mathrm{R} 78 \mathrm{G}$ protein-coupled receptor gene is required for the production of infectious virus in the spleen. J. Gen. Virol. 84, 2517-2530.

61. Kaptein, S.J.F., van Cleef, K.W.R, Gruijthuijsen, Y.K., Beuken E.V.H., Van Buggenhout, L., Beisser, P.S., Stassen, F.R.M., Bruggeman, C.A., and Vink, C. (2004). The r131 gene of rat cytomegalovirus encodes a proinflammatory $\mathrm{CC}$ chemokine homolog which is essential for the production of infectious virus in the salivary glands. Virus Genes 29, 43-61. 
62. Kendall, T.J., Wilson, J.E., Radio, S.J., Kandolf, R., Gulizia, J.M., Winters, G.L., Costanzo-Nordin, M.R., Malcom, G.T., Thieszen, S.L., Miller, L.W., and McManus, B.M. (1992). Cytomegalovirus and other herpes viruses: do they have a role in the development of accelerated coronary arterial disease in human heart allografts? J. Heart Lung Transplant. 11, 14-20.

63. Kikuchi, S., Umemura, K., Kondo, K., and Nakashima, M. (1996). Tranilast suppresses intimal hyperplasia after photochemically induced endothelial injury in the rat. Eur. J. Pharmac. 295, $221-227$.

64. Kloover, J.S., Hillebrands, J.L., de Wit, G., Grauls, G., Rozing, J., Bruggeman, C.A., and Nieuwenhuis, P. (2000). Rat cytomegalovirus replication in the salivary glands is extensively confined to striated duct cells. Virchows Arch. 437, 413-421.

65. Kloover, J.S., Soots, A.P., Krogerus, L.A., Kauppinen, H.O., Loginov, R.J., Holma, K.L., Bruggeman, C.A., Ahonen, P.J., and Lautenschlager, I.T. (2000). Rat cytomegalovirus infection in kidney allograft recipients is associated with increased expression of intracellular adhesion molecule-1 vascular adhesion molecule-1, and their ligands leukocyte function antigen-1 and very late antigen-4 in the graft. Transplantation 69, 2641-2647.

66. Koskinen, P.K. (1993). The association of the induction of vascular cell adhesion molecule-I with cytomegalovirus antigenemia in human allografts. Transplantation 53, 1103-1108.

67. Koskinen, P., Krogerus, L.A., Nieminen, M.S., Mattila, S.P., Häyry, P., and Lautenschlager, I.T. (1993). Quantitation of cytomegalovirus infection-associated histologic findings in endomyocardial biopsies of heart allografts. J. Heart Lung Transplant. 12, 343-354.

68. Koskinen, P., Krogerus, L.A., Nieminen, M.S., Mattila, S.P., Häyry, P., and Lautenschlager, I.T. (1994). Cytomegalovirus infection-associated generalized immune activation in heart allograft recipients: a study of cellular events in peripheral blood and endomyocardial biopsy specimens. Transplant. Int. 7, 163-171.

69. Koskinen, P., Lemström, K., Bruggeman, C., Lautenschlager, I., and Häyry, P. (1994). Acute cytomegalovirus infection induces a subendothelial inflammation (endothelialitis) in the allograft vascular wall. A possible linkage with enhanced allograft arteriosclerosis. Am. J. Pathol. 144, 41-50.

70. Koskinen, P., Nieminen, M.S., Krogerus, L.A., Mattila, S.P., Häyry, P., and Lautenschlager, I.T. (1993). Cytomegalovirus infection accelerates cardiac allograft vasculopathy: correlation between angiographic and endomyocardial biopsy findings in heart transplant patients. Transplant. Int. 6, 341-347.

71. Lai, I.R., Chen, K.M., Shun, C.T., and Chen, M.Y. (1996). Cytomegalovirus enteritis causing massive bleeding in a patient with AIDS. Hepatogastroenterology 43, 987991.

72. Lautenschlager, I., Höckerstedt, K., Jalanko, H., Loginov, R., Salmela, K., Taskinen, E., and Ahonen, J. (1997). Persistent CMV in liver allografts ending up with chronic rejection. Hepatology 25, 190-194.

73. Lautenschlager, I., Soots, A., Krogerus, L., Inkinen, K., Kloover, J., Loginov, R., Holma, K., Kauppinen, H., Bruggeman, C., and Ahonen, J. (1999). Time-related effects of cytomegalovirus infection on the development of chronic renal allograft rejection in a rat model. Intervirology $42,279-284$. 
74. Lautenschlager, I., Soots, A., Krogerus, L., Kauppinen, H., Saarinen, O., Bruggeman, C., and Ahonen, J. (1997). Effect of cytomegalovirus on an experimental model of chronic renal allograft rejection under triple-drug treatment in the rat. Transplantation 64, 391-398.

75. Lemström, K.B., Aho, P.T., Bruggeman, C.A., and Häyry, P.J. (1994). Cytomegalovirus enhances $m R N A$ expression of platelet-derived growth factor $B B$ and transforming growth factor-beta 1 in rat aortic allografts. Possible mechanism for cytomegalovirusenhanced graft arteriosclerosis. Arterioscler. Thromb. 14, 2043-2052.

76. Lemström, K.B., Bruning, J.H., Bruggeman, C.A., Koskinen, P.K., Aho, P.T., Yilmaz, S., Lautenschlager, I.T., and Häyry, P.J. (1994). Cytomegalovirus infection-enhanced allograft arteriosclerosis is prevented by DHPC prophylaxis in the rat. Circulation 90, 1969-1978.

77. Lemström, K.B., Bruning, J.H., Bruggeman, C.A., Lautenschlager, I.T., and Häyry, P.J. (1993). Cytomegalovirus infection enhances smooth muscle cell proliferation and intimal thickening of rat aortic allografts. J. Clin. Invest. 92, 549-558.

78. Lemström, K.B., Bruning, J.H., Bruggeman, C.A., Lautenschlager, I.T., and Häyry, P.J. (1994). Triple drug immunosuppression significantly reduces immune activation and allograft arteriosclerosis in cytomegalovirus-infected rat aortic allografts and induces early latency of viral infection. Am. J. Pathol. 144, 1334-1347.

79. Lemström, K.B., Bruning, J., Koskinen, P., Bruggeman, C., Lautenschlager, I., and Häyry, P.J. (1994). Triple-drug immunosuppression significantly reduces chronic rejection in noninfected and RCMV-infected rats. Transplant. Proc. 26, 1727-1728.

80. Lemström, K., Koskinen, P., Krogerus, L., Daemen, M., Bruggeman, C., and Häyry, P. (1995). Cytomegalovirus antigen expression, endothelial cell proliferation, and intimal thickening in rat cardiac allografts after cytomegalovirus infection. Circulation 92, 2594-2604

81. Lemström, K., Sihvola, R., Bruggeman, C., Häyry, P., and Koskinen, P. (1997). Cytomegalovirus infection-enhanced cardiac allograft vasculopathy is abolished by DHPG prophylaxis in the rat. Circulation 95, 2614-2616.

82. Li, F., Grauls, G., Yin, M., and Bruggeman, C. (1996). Correlation between the intensity of cytomegalovirus infection and the amount of perivasculitis in aortic allografts. Transpl. Int. 9, S340-S344.

83. Li, F., Grauls, G., Yin, M., and Bruggeman, C. (1996). Initial endothelial injury and cytomegalovirus infection accelerate the development of allograft arteriosclerosis. Transplant. Proc. 27, 3552-3554.

84. Li, F., Yin, M., van Dam, J.G., Grauls, G., Rozing, J., and Bruggeman, C.A. (1998). Cytomegalovirus infection enhances the neointima formation in rat aortic allografts: effect of major histocompatibility complex class I and class II antigen differences. Transplantation 65, 1298-1304.

85. Light, J.A., and Burke, D.S. (1979). Association of cytomegalovirus (CMV) infections with increased recipient mortality following transplantation. Transplant. Proc. 11, 79-82.

86. Loebe, M., Schüler, S., Zais, O., Warnecke, H., Fleck, E., and Hetzer, R. (1990). Role of cytomegalovirus infection in the development of coronary artery disease in the transplanted heart. J. Heart Lung Transplant. 9, 707-711. 
87. Lopez, C., Simmons, R.L., Mauer, S.M., Park, B., Najarian, J.S., and Good, R.A. (1972). Virus infections may trigger rejection in immunosuppressed renal transplant recipients. Proc. Clin. Dial. Transplant. Forum 2, 107-111.

88. Martelius, T., Krogerus, L., Höckerstedt, K., Bruggeman, C., and Lautenschlager, I. (1998). Cytomegalovirus infection is associated with increased inflammation and severe bile duct damage in rat liver allografts. Hepatology 27, 996-1002.

89. Martelius, T., Scholz, M., Krogerus, L., Höckerstedt, K., Loginov, R., Bruggeman, C., Cinatl Jr, J., Doerr, H.W., and Lautenschlager, I. (1999). Antiviral and immunomodulatory effects of desferrioxamine in cytomegalovirus-infected rat liver allografts with rejection. Transplantation 68, 1753-1761.

90. McDonald, K., Rector, T.S., Braulin, E.A., Kubo, S.H., and Olivari, M.T. (1989). Association of coronary artery disease in cardiac transplant recipients with cytomegalovirus infection. Am. J. Cardiol. 64, 359- 362.

91. Melnick, J.L., Adam, E., and DeBakey, M.E. (1990). Possible role of cytomegalovirus in atherogenesis. J. Am. Med. Assoc. 263, 2204-2207.

92. Melnick, J.L., Hu, C., Burek, J., Adam, E., and DeBakey, M.E. (1994). Cytomegalovirus DNA in arterial wall of patients with atherosclerosis. J. Med. Virol. 42, 170-174.

93. Melnick, J.L., Petrie, B.L., Dreesman, G.R., Burek, J., McCollum, C.H., and DeBakey, M.E. (1983). Cytomegalovirus antigen within human arterial smooth muscle cells. Lancet 2, 644-647.

94. Mennader, A., Tiisala, S., Harttunen, J., Yilmaz, S., Paavonen, T., and Häyry, P. (1991). Chronic rejection in rat aortic allografts: an experimental model for transplant arteriosclerosis. Arterioscler. Thromb. 11, 671-680.

95. Muldoon, J., O'Riordan, K., Rao, S., and Abecassis, M. (1996). Ischaemic colitis secondary to venous thrombosis. A rare presentation of cytomegalovirus vasculitis following renal transplantation. Transplantation 61, 1651-1653.

96. Murayama, T., Mukaida, N., Khabar, K.S.A., and Matsushima, K. (1998). Potential involvement of IL-8 in the pathogenesis of human cytomegalovirus infection. J. Leuk. Biol. 64, 62-67.

97. Musiani, M., Zurbini, M.L., Muscari, A., Puddu, G.M., Gentilomi, G., Gibellini, D., Gallinella, G., Puddu, P., and La Placa, M. (1990). Antibody patterns against cytomegalovirus and Epstein-Barr virus in human atherosclerosis. Microbiologica 13, 35-41.

98. Nieto, F.., Adam, E., Sorlie, P., Farzadegan, H., Melnick, J.L., Comstock, G.W., and Szklo, M. (1996). Cohort study of cytomegalovirus infection as a risk factor for carotid intimal-medial thickening, a measure of subclinical atherosclerosis [see comments]. Circulation 94, 922-927.

99. Olivari, M.T., Homans, D.C., Wilson, R.F., Kubo, S.H., and Ring, W.S. (1989). Coronary artery disease in cardiac transplant patients receiving triple-drug immunosuppressive therapy. Circulation 80 (Suppl.III), 111-115.

100. Oliveira, S.A., and Shenk, T.E. (2001). Murine cytomegalovirus M78 protein, a G protein-coupled receptor homologue, is a constituent of the virion and facilitates accumulation of immediate-early viral mRNA. Proc. Natl. Acad. Sci. USA 98, $3237-$ 3242.

101. Orloff, S.L., Streblow, D.N., Söderberg-Nauclér, C., Yin, Q., Kreklywich, C., Corless, C.L., Smith, P.A., Loomis, C.B., Mills, L.K., Cook, J.W., Bruggeman, C.A., Nelson, 
J.A., and Wagner, C.R. (2002). Elimination of donor-specific alloreactivity prevents cytomegalovirus-accelerated chronic rejection in rat small bowel and heart transplants. Transplantation 73, 679-688.

102. Orloff, S.L., Yin, Q., Corless, C.L., Orloff, M.S., Rabkin, J.M., and Wagner, C.R. (2000). Tolerance induced by bone marrow chimerism prevents transplant vascular sclerosis in a rat model of small bowel transplant chronic rejection. Transplantation 69, 1295-1303.

103. Paul, L.C. (1993). Chronic rejection of organ allografts: Magnitude of the problem. Transplant. Proc. 25, 2024-2025.

104. Persoons, M.C., Daemen, M.J., Bruning, J.H., and Bruggeman, C.A. (1994). Active cytomegalovirus infection of arterial smooth muscle cells in immunocompromised rats. A clue to herpesvirus-associated atherogenesis? Circ. Res. 75, 214-220.

105. Persoons, M.C., Daemen, M.J., van Kleef, E.M., Grauls, G.E., Wijers, E., and Bruggeman, C.A. (1997). Neointimal smooth muscle cell phenotype is important in its susceptibility to cytomegalovirus (CMV) infection: a study in rat. Cardiovasc. Res. 36, 282-288.

106. Persoons, M.C., Stals, F.S., van Dam-Mieras, M.C., and Bruggeman, C.A. (1998). Multiple organ involvement during experimental cytomegalovirus infection is associated with disseminated vascular pathology. J. Pathol. 184, 103-109.

107. Petrie, B.L., Melnick, J.L., Adam, E., Burek, J., McCollum, C.H., and DeBakey, M.E. (1987). Nucleic acid sequences of cytomegalovirus in cells cultured from human arterial tissue. J. Infect. Dis. 155, 158-159.

108. Plump, A.S., Smith, J.D., Hayek, T., Aalto Setala, K., Walsh, A., Verstuyft, J.G., Rubin, E.M., and Breslow, J.L. (1992). Severe hypercholesterolemia and atherosclerosis in apolipoprotein E-deficient mice created by homologous recombination in ES cells. Cell 71, 343-353.

109. Pouteil-Noble, C., Ecochard, R., Landrivon, G., Donia-Mged, A., Tardy, J.C., Bossshard, S., Colon, S., Betuel, H., Aymard, M., and Touraine, J.L. (1993). Cytomegalovirus infection - an etiological factor for rejection. A prospective study in 242 renal transplant patients. Transplantation 55, 851-857.

110. Qavi, H.B., Melnick, J.L., Adam, E., and DeBakey, M.E. (2000). Frequency of coexistence of cytomegalovirus and Chlamydia pneumoniae in atherosclerotic plaques. Cent. Eur. J. Public Health 8, 71-73.

111. Rawlinson, W.D., Farrell, H.E., and Barrell, B.G. (1996). Analysis of the complete DNA sequence of murine cytomegalovirus. J. Virol. 70, 8833-8849.

112. Ridker, P.M., Hennekens, C.H., Stampfer, M.J., and Wang, F. (1998). Prospective study of herpes simplex virus, cytomegalovirus, and the risk of future myocardial infarction and stroke. Circulation 98, 2796-2799.

113. Ross, R. (1986). The pathogenesis of atherosclerosis - An update. N. Eng. J. Med. 314, 488-499

114. Ross, R. (1993). The pathogenesis of atherosclerosis: a perspective for the 1990s. Nature 362, 801-809.

115. Ross, R. (1999). Atherosclerosis - an inflammatory disease. N. Engl. J. Med. 340, $115-126$.

116. Rott, D., Zhu, J., Burnett, M.S., Zhou, Y.F., Wasserman, A., Walker, J., and Epstein, S.E. (2001). Serum of cytomegalovirus-infected mice induces monocyte 
chemoattractant protein-1 expression by endothelial cells. J. Infect. Dis. 184, 11091113.

117. Rott, D., Zhu, J., Zhou, Y.F., Burnett, M.S., Zalles-Ganley, A., and Epstein, S.E. (2003). IL-6 is produced by splenocytes derived from CMV-infected mice in response to $C M V$ antigens, and induces MCP-1 production by endothelial cells: a new mechanistic paradigm for infection-induced atherogenesis. Atherosclerosis 170 , 223-228.

118. Russell, M.E., Fujita, M., Masek, M.A., Rowan, R.A., and Billingham, M.E. (1993). Cardiac graft vascular disease. Non-selective involvement of large and small vessels. Transplantation 56, 762-764.

119. Saniabadi, A.R., Umemura, K., Matsumoto, N., Sakuma, S., and Nakashima, M. (1995). Vessel wall injury and arterial thrombosis induced by a photochemical reaction. Thromb. Haemost. 73, 868-872.

120. Sedmak, D.D., Knight, D.A., Vook, N.C., and Waldman, J.W. (1994). Divergent patterns of ELAM-1, ICAM-1, and VCAM-1 expression on cytomegalovirus-infected endothelial cells. Transplantation 58, 1379-1385.

121. Sedmak, D.D., Roberts, W.H., Stephens, R.E., Buesching, W.J., Morgan, L.A., Davis, D.H., and Waldman, W.J. (1990). Inability of cytomegalovirus infection of cultured endothelial cells to induce HLA class II antigen expression. Transplantation 49, 458-462.

122. Sharples, L.D., Caine, N., Mullins, P., Scott, J.P., Solis, E., English, T.A., Large, S.R., Schofield, P.M., and Wallwork, J. (1991). Risk factor analysis for the major hazards following heart transplantation - rejection, infection, and coronary occlusive disease. Transplantation 52, 244-252.

123. Sinzger, C., Grefte, A., Plachter, B., Gouw, A.S.H., The, T.H., and Jahn, G. (1995). Fibroblasts, epithelial cells, endothelial cells and smooth muscle cells are major targets of human cytomegalovirus infection in lung and gastrointestinal tissues. J. Gen. Virol. 76, 741-750.

124. Sinzger, C., Schmidt, J., Knapp, J., Kahl, M., Beck, R., Waldman, J., Hebart, H., Einsele, H., and Jahn, G. (1999). Modification of human cytomegalovirus tropism through propagation in vitro is associated with changes in the viral genome. J. Gen. Virol. 80, 2867-2877.

125. Slobbe-van Drunen, M.E., Vossen, R.C., Couwenberg, F.M., Hulsbosch, M.M., Heemskerk, J.W., van Dam-Mieras, M.C., and Bruggeman, C.A. (1997). Activation of protein kinase $C$ enhances the infection of endothelial cells by human cytomegalovirus. Virus Res. 48, 207-213.

126. Smiley, M.L., Mar, E.C., and Huang, E.S. (1988). Cytomegalovirus infection and viral induced transformation of human endothelial cells. J. Med. Virol. 25, $213-$ 226.

127. Sorlie, P.D., Adam, E., Melnick, S.L., Folsom, A., Skelton, T., Chambless, L.E., Barnes, R., and Melnick, J.L. (1994). Cytomegalovirus/herpesvirus and carotid atherosclerosis: the ARIC study. J. Med. Virol. 42, 33-37.

128. Span, A.H.M., Frederik, P.M., Grauls, G, van Boven, C.P.A., and Bruggeman, C.A. (1993). CMV induced vascular injury: an electron-microscopic study in the rat. In vivo $7,567-574$. 
129. Span, A.H.M., Grauls, G., Bosman, F., van Boven, C.P.A., and Bruggeman, C.A. (1992). Cytomegalovirus infection induces vascular injury in the rat. Atherosclerosis 93, 41-52.

130. Span, A.H.M., Mullers, W., Miltenburg, A.H.M., and Bruggeman, C.A. (1991). Cytomegalovirus-induced PMN adherence in relation to an ELAM-I antigen present on infected endothelial cell monolayers. Immunology 72, 355-360.

131. Span, A.H.M., van Dam-Mieras, M.C.E., Mullers, W., Endert, J., Muller, A.D., and Bruggeman, C.A. (1991). The effect of virus infection on the adherence of leukocytes or platelets to endothelial cells. Eur. J. Clin. Invest. 21, 331-338.

132. Speir, E., Huang, E.S., Modali, R., Leon, M.B., Shawl, F., Finkel, T., and Epstein, E.S. (1995). Interaction of human cytomegalovirus with p53: possible role in coronary restenosis. Scand. J. Infect. Dis. Suppl. 99, 78-81.

133. Speir, E., Modali, R., Huang, E.S., Leon, M.B., Shawl, F., Finkel, T., and Epstein, E.S. (1994). Potential role of human cytomegalovirus and p53 interaction in coronary restenosis. Science 265, 391-394.

134. Stals, F.S., Bosman, F., van Boven, C.P.A., and Bruggeman, C.A. (1990). An animal model for therapeutic intervention studies of $C M V$ infection in the immunocompromised host. Arch. Virol. 114, 91-107.

135. Stals, F.S., de Clercq, E., and Bruggeman, C.A. (1991). Comparative activity of (S)-1-(3-hydroxy-2-phosphonylmethoxypropyl)cytosine and 9-(1,3-dihydroxy-2propoxymethyl)-guanine against rat cytomegalovirus infection in vitro and in vivo. Antimicrob. Agents Chemother. 35, 2262-2266.

136. Stals, F.S., Wagenaar, S.S., and Bruggeman, C.A. (1994). Generalized cytomegalovirus (CMV) infection and $C M V$-induced pneumonitis in the rat: combined effect of 9-(1,3-dihydroxy-2-propoxymethyl)-guanine and specific antibody treatment. Antiviral Res. 25, 147-160.

137. Stals, F.S., Wagenaar, S.S., Kloover, J.S., Vanagt, W.Y., and Bruggeman, C.A. (1996). Combinations of ganciclovir and antibody for experimental CMV infections. Antiviral Res. 29, 61-64.

138. Stals, F.S., Zeytinoglu, A., Havenith, M., de Clercq, E., and Bruggeman, C.A. (1993). Rat cytomegalovirus-induced pneumonitis after allogeneic bone marrow transplantation: effective treatment with (S)-1-(3-hydroxy-2phosphonylmethoxypropyl)cytosine. Antimicrob. Agents Chemother. 37, 218-223.

139. Steinhoff, G., You, X.M., Steinmüller, C., Bauer, D., Lohmann-Matthes, M.L., Bruggeman, C.A., and Haverich, A. (1996). Enhancement of cytomegalovirus infection and acute rejection after allogeneic lung transplantation in the rat. Transplantation 61, 1250-1260.

140. Steinhoff, G., You, X.M., Steinmüller, C., Boeke, K., Stals, F.S., Bruggeman, C.A., and Haverich, A. (1995). Induction of endothelial adhesion molecules by rat cytomegalovirus in allogeneic lung transplantation in the rat. Scand. J. Infect. Dis. Suppl. 99, 58-60.

141. Steinmüller, C., Steinhoff, G., Bauer, D., You, X.M., Denzin, H., Franke-Ullmann, G., Hausen, B., Bruggeman, C.A., Wagner, T.O., Lohmann-Matthes, M.L., and Emmendorffer, A. (1997). Analysis of leukocyte activation during acute rejection of pulmonary allografts in noninfected and cytomegalovirus-infected rats. J. Leukoc. Biol. 61, 40-49. 
142. Stovin, P.G.I., Sharples, L., Hutter, J.A., Wallwork, J., and English, T.A.H. (1991). Some prognostic factors for the development of transplant-related coronary artery disease in human cardiac allografts. J. Heart Lung Transplant. 10, 38-44.

143. Streblow, D.N.., Kreklywich, C., Yin, Q., De La Melena, V.T., Corless, C.L., Smith, P.A., Brakebill, C., Cook, J.W., Vink, C., Bruggeman, C.A., Nelson, J.A., and Orloff, S.L. (2003). Cytomegalovirus-mediated upregulation of chemokine expression correlates with the acceleration of chronic rejection in rat heart transplants. I. Virol. 77, 2182-2194.

144. Streblow, D.N., Orloff, S.L., and Nelson, J.A. (2001). The HCMV chemokine receptor US28 is a potential target in vascular disease. Curr. Drug Targets Infect. Disord. 1, 151-158.

145. Streblow, D.N., Söderberg-Nauclér, C., Vieira, J., Smith, P., Wakabayashi, E., Ruchti, F., Mattison, K., Altschuler, Y., and Nelson, J.A. (1999). The human cytomegalovirus chemokine receptor US28 mediates vascular smooth muscle cell migration. Cell 99, 511-520.

146. Tanaka, H., Suzuki, A., Schwartz, D., Sukhova, G., and Libby, P. (1995). Activation of smooth muscle and endothelial cells following balloon injury. Ann. N. Y. Acad. Sci. 748, 526-529.

147. Taub, D.D., Proost, P., Murphy, W.J., Anver, M., Anver, M., Longo, D.L., van Damma, J., and Oppenheim, J.J. (1995). Monocyte chemotactic protein-1 (MCP1), protein-2 and protein-3 are chemotactic fot human $T$ lymphocytes. J. Clin. Invest. 95, 1370-1376.

148. Ten-Napel, H.H., Houthoff, H.J., and The, T.H. (1984). Cytomegalovirus hepatitis in normal and immune compromised hosts. Liver 4, 184-194.

149. Tumilowicz, J.J., Gawlik, M.E., Powell, B.B., and Trentin, J.J. (1985). Replication of cytomegalovirus in human arterial smooth muscle cells. J. Virol. 56, 839-845.

150. Ustinov, J.A., Bruggeman, C.A., Häyry, P.J., and Lautenschlager, I.T. (1994). Cytomegalovirus-induced class II expression in rat kidney. Transplant. Proc. 26, 1729.

151. Ustinov, J.A., Loginov, R.J., Mattila, P.M., Nieminen, V.K., Suni, J.I., Häyry, P.J., and Lautenschlager, I.T. (1991). Cytomegalovirus infection of human kidney cells in vitro. Kidney int. 40, 954-960.

152. Uys, C., and Rose, A. (1984). Pathologic findings in long-term cardiac transplants. Arch. Pathol. Lab. Med. 108, 112-116.

153. van Cleef, K.W.R., Scaf, W.M.A., Maes, K., Kaptein, S.J.F., Beuken E., Beisser, P.S., Stassen, F.R.M., Grauls, G.E.L.M., Bruggeman, C.A., and Vink, C. (2004). The rat cytomegalovirus homologue of parvoviral rep genes, $\mathrm{r} 27$, encodes a nuclear protein with single- and double-stranded DNA-binding activity that is dispensable for virus replication. J. Gen. Virol. 85, 2001-2013.

154. van Dam-Mieras, M.C., Muller, A.D., van Hinsbergh, V.W., Mullers, W.J., Bomans, P.H., and Bruggeman, C.A. (1992). The procoagulant response of cytomegalovirus infected endothelial cells. Thromb. Haemost. 68, 364-370.

155. van Dorp, W.T., Jonges, E., Bruggeman, C.A., Daha, M.R., van Es, L.A., and van der Woude, F.J. (1989). Direct induction of MHC class I, but not class II, expression on endothelial cells by cytomegalovirus infection. Transplantation 48, 469-472.

156. Vanstapel, M.J., and Desmet, V.J. (1983). Cytomegalovirus hepatitis: a histological and immunohistochemical study. Appl. Pathol. 1, 41-49. 
157. Vieira, J., Schall, T.J., Corey, L., and Geballe, A.P. (1998). Functional analysis of the human cytomegalovirus US28 gene by insertion mutagenesis with the green fluorescent protein gene. J. Virol. 72, 8158-8165.

158. Vink C., Beuken, E., and Bruggeman, C.A. (1996). Structure of the rat cytomegalovirus genome termini. J. Virol. 70, 5221-5229.

159. Vink C., Beuken, E., and Bruggeman, C.A. (2000). Complete DNA sequence of the rat cytomegalovirus genome. J. Virol. 74, 7656-7665.

160. Visseren, F.L., Bouter, K.P., Pon, M.J., Hoekstra, J.B., Erkelens, D.W., and Diepersloot, R.J. (1997). Patients with diabetes mellitus and atherosclerosis; a role for cytomegalovirus? Diabetes Res. Clin. Pract. 36, 49-55.

161. Vliegen, I., Duijvestijn, A., Grauls, G., Herngreen, S., Bruggeman, C., and Stassen, F. (2004). Cytomegalovirus infection aggravates atherogenesis in apoE knockout mice by both local and systemic immune activation. Microbes. Infect. 6, 17-24.

162. Vliegen, I., Stassen, F., Grauls, G., Blok, R., and Bruggeman, C. (2002). MCMV infection increases early $\mathrm{T}$-lymphocyte influx in atherosclerotic lesions in apoE knockout mice. J. Clin. Invest. 25, S159-S171.

163. von Willebrand, E., Pettersson, E., Ahonen, J., and Häyry, P. (1986). CMV infection, class $I I$ antigen expression, and human kidney allograft rejection. Transplantation 42, 364-367.

164. Vossen, R.C., Derhaag, J.G., Slobbe-van Drunen, M.E., Duijvestijn, A.M., van Dam-Mieras, M.C., and Bruggeman, C.A. (1996). A dual role for endothelial cells in cytomegalovirus infection? A study of cytomegalovirus infection in a series of rat endothelial cell lines. Virus Res. 46, 65-74.

165. Vossen, R.C., Persoons, M.C., Slobbe-van Drunen, M.E., Bruggeman, C.A., and van Dam-Mieras, M.C. (1997). Intracellular thiol redox status affects rat cytomegalovirus infection of vascular cells. Virus Res. 48, 173-183.

166. Waldman, W.J., Adams, P.W., Orosz, C.G., and Sedmak, D.D. (1992). T lymphocyte activation by cytomegalovirus-infected, allogeneic cultured human endothelial cells. Transplantation 54, 887-896.

167. Waldman, W.J., and Knight, D.A. (1996). Cytokine-mediated induction of endothelial adhesion molecule and histocompatibility leukocyte antigen expression by cytomegalovirus-activated $T$ cells. Am. J. Pathol. 148, 105-119.

168. Waldman, W.J., Knight, D.A., Adams, P.W., Orosz, C.G., and Sedmak, D.D. (1993). In vitro induction of endothelial HLA class II antigen expression by cytomegalovirusactivated $\mathrm{CD}^{+} \mathrm{T}$ cells. Transplantation 56, 1504-1512.

169. Waldman, W.J., Roberts, W.H., Davis, D.H., Williams, M.V., Sedmak, D.D., and Stephens, R.E. (1991). Preservation of natural endothelial cytopathogenicity of cytomegalovirus bt propagation in endothelial cells. Arch. Virol. 117, 143-164.

170. Waldman, W.J., Sneddon, J.M., Stephens, R.E., and Roberts, W.H. (1989). Enhanced endothelial cytopathogenicity induced by a cytomegalovirus strain propagated in endothelial cells. J. Med. Virol. 28, 223-230.

171. Winters, G.L., Kendall, T.J., Radio, S.J., Wilson, J.E., Constanzo-Nordin, M.R., Switzer, B.L., Remmenga, J.A., and McManus, B.M. (1990). Posttransplant obesity and hyperlipidemia predictors of severity of coronary arteriopathy in failed human heart allografts. J. Heart Lung Transplant. 9, 364-371. 
172. Woodroffe, S.B., Garnett, H.M., and Danis, V.A. (1993). Interleukin-1 production and cell-activation response to cytomegalovirus infection of vascular endothelial cells. Arch. Virol. 133, 295-308.

173. Wu, T.C., Hruban, R.H., Ambinder, R.F., Pizzorno, M., Cameron, D.E., Baumgartner, W.A., Reitz, B.A., Hayward, G.S., and Hutchins, G.M. (1992). Demonstration of cytomegalovirus nucleic acids in the coronary arteries of transplanted hearts. Am.

J. Pathol. 140, 739-747.

174. Yagyu, K., Steinhoff, G., Duijvestijn, A.M., Bruggeman, C.A., Matsumoto, H., and van BredaVriesman. P.J. (1992). Reactivation of rat cytomegalovirus in lung allografts: an experimental and immunohistochemical study in rats. J. Heart Lung Transplant. 11, $1031-1040$.

175. Yagyu, K., van BredaVriesman, P.J., Duijvestijn, A.M., Bruggeman, C.A., and Steinhoff, G. (1993). Reactivation of cytomegalovirus with acute rejection and cytomegalovirus infection with obliterative bronchiolitis in rat lung allografts. Transplant. Proc. 25, 1152-1154.

176. Yilmaz, S., Koskinen, P.K., Kallio, E., Bruggeman, C.A., Häyry, P.J., and Lemström, K.B. (1996). Cytomegalovirus infection-enhanced chronic kidney allograft rejection is linked with intercellular adhesion molecule-1 expression. Kidney Int. 50, 526537.

177. You, X.M., Steinmüller, C., Wagner, T.O., Bruggeman, C.A., Haverich, A., Steinhoff, G. (1996). Enhancement of cytomegalovirus infection and acute rejection after allogeneic lung transplantation in the rat: virus-induces expression of major histocompatibility complex class II antigens. J. Heart Lung Transplant. 15, 11081119.

178. Zhang, S.H., Reddick, R.L., Piedrahita, J.A., and Maeda, N. (1992). Spontaneous hypercholesterolemia and arterial lesions in mice lacking apolipoprotein $\mathrm{E}$. Science 258, 468-471.

179. Zhou, Y.F., Guetta, E., Yu, Z.X., Finkel, T., and Epstein, S.E. (1996). Human cytomegalovirus increases modified low density lipoprotein uptake and scavenger receptor mRNA expression in vascular smooth muscle cells. J. Clin. Invest. 98, 2129-2138.

180. Zhou, Y.F., Leon, M.B., Waclawiw, M.A., Popma, J.J., Yu, Z.X., Finkel, T., and Epstein, S.E. (1996). Association between prior cytomegalovirus infection and the risk of restenosis after coronary atherectomy. N. Eng. J. Med. 335, 624-630.

181. Zhou, Y.F., Shou, M., Guetta, E., Guzman, R., Unger, E.F., Yu, Z.X., Zhang, J., Finkel, T., and Epstein, S.E. (1999). Cytomegalovirus infection of rats increases the neointimal response to vascular injury without consistent evidence of direct infection of the vascular wall. Circulation 100, 1569-1575.

182. Zhou, Y.F., Shou, M., Harrell, R.F., Yu, Z.X., Unger, E.F, and Epstein, S.E. (2000). Chronic non-vascular cytomegalovirus infection: effects on the neointimal response to experimental vascular injury. Cardiovasc. Res. 45, 1019-1025.

183. Zhou, Y.F., Yu, Z.X., Wanishsawad, C., Shou, M., and Epstein, S.E. (1999). The immediate early gene products of human cytomegalovirus increase vascular smooth muscle cell migration, proliferation, and expression of PDGF beta-receptor. Biochem. Biophys. Res. Commun. 256, 608-613. 
184. Zhu, J.H., Quyyumi, A.A., Norman, J.E., Csako, G., Waclawiw, M.A., Shearer, G.M., and Epstein, S.E. (2000). Effects of total pathogen burden on coronary artery disease risk and C-reactive protein levels. Am. J. Cardiol. 85, 140-146.

185. Zhu, H., Shen, Y., and Shenk, T. (1995). Human cytomegalovirus IE1 and IE2 proteins block apoptosis. J. Virol. 69, 7960-7970. 


\title{
CHAPTER 2
}

Rat Cytomegalovirus Open Reading Frame R44 is an Early-Late Gene that Encodes a Nuclear Protein

\author{
Brief Report \\ Suzanne J.F. Kaptein, Erik Beuken, Gert E.L.M. Grauls, Cathrien A. \\ Bruggeman, Cornelis Vink
}

Archives of Virology 2001, 146, 2211-2218 


\section{Abstract}

Rat cytomegalovirus (RCMV) open reading frame $\mathrm{R} 44$ is the homolog of human cytomegalovirus gene UL44, which encodes the DNA polymerase accessory protein. Here, we show that R44 is transcribed as a $3.6-\mathrm{kb}$ mRNA within the early and late phases of infection in vitro. In order to find potential monoclonal antibodies (MoAbs) directed against the R44-encoded protein ( $p R 44$ ), a panel of anti-RCMV MoAbs was screened for binding to $\mathrm{PR} 44$ recombinant proteins. Thus, an anti-pR44 MoAb, termed RCMV8, was identified. By using this MoAb, pR44 could be detected as early as $8 \mathrm{~h}$ after RCMV infection in vitro. The pR44 protein was determined to have a molecular mass of approximately $55 \mathrm{kDa}$ and was found to be localized to the nucleus of RCMV-infected cells

Infections with human cytomegalovirus (HCMV), a member of the betaherpesvirus subfamily, usually do not present with clinical symptoms in the immunocompetent host. However, in the immunocompromised host, HCMV can cause severe and sometimes fatal infections. In order to enable in vivo studies of $C M V$ infections, a rat cytomegalovirus (RCMV)/rat model has been developed in our laboratory. Previous studies with this model demonstrated many similarities between the pathogenesis of RCMV infection and that of HCMV infection [32].

Recently, we have determined the complete nucleotide sequence of the RCMV (strain Maastricht) genome, which was found to accommodate 166 open reading frames (ORFs) [34]. Most of these ORFs have homologs in the genomes of both murine CMV (MCMV) and HCMV. These ORFs include R54 and R57, putatively encoding the viral DNA polymerase and the major DNA binding protein, respectively [4]. Like their homologs from other herpesviruses, these two genes may encode proteins that play a role in viral DNA replication. Another RCMV ORF that is likely to encode a protein with an important function in viral DNA replication is R44. This ORF is the counterpart of the HCMV UL44 gene, which encodes the DNA polymerase accessory protein (DPAP) or infected cell protein 36 (ICP36) [10,27]. This gene is conserved among herpesviruses of which the genome sequence has been (partially) determined $[8,9,11,18,21,26,28,33]$. The significance of DPAP in the herpesvirus replication cycle was demonstrated for the gene products encoded by HCMV UL44, human herpesvirus type 6 (HHV-6) U27, and herpes simplex virus type 1 (HSV-1) UL42. These genes were found to be essential for origindependent viral DNA replication [1, 17, 25, 29, 35]. As a consequence, herpesvirus DPAPs may be regarded as highly suitable targets for antiviral therapy. Since the RCMV/ rat model allows in vivo studies on the effectiveness of antiviral drugs, we initiated a study to characterize the RCMV R44 gene and its products in vitro as well as in vivo.

The R44 ORF is localized between nucleotides 41,045 and 42,301 of the RCMV genome [34]. It has the capacity to encode a 419-amino acid polypeptide with a predicted molecular mass of $45.6 \mathrm{kDa}$ and a theoretical isoelectric point of $\mathrm{pH} 8.75$. Search of the Prosite database (http://psort.nibb.ac.jp) revealed the presence of two potential $\mathrm{N}$-linked glycosylation sites, $16 \mathrm{~N}$-myristoylation sites, and three amidation sites in the R44-encoded amino acid sequence. Additionally, this sequence contains a CAMP- and CGMP-dependent protein kinase phosphorylation site, thirteen protein kinase C (PKC) phosphorylation sites, and nine casein kinase II (CK2) phosphorylation sites, indicating that the R44-encoded protein (pR44) may be highly phosphorylated. In analogy, the MCMV homolog of pR44, 
ppM44 (or pp50), was found to be the most highly phosphorylated viral protein in MCMVinfected mouse fibroblasts [22]. Furthermore, counterparts of pR44 in HCMV, HHV-6, HSV-1, Epstein-Barr virus (EBV), and Kaposi's sarcoma-associated herpesvirus (KSHV) are also highly phosphorylated $[7,8,13,18,26,30]$.

The pR44 amino acid sequence was compared to the sequences of pR44 homologs from other herpesviruses. As expected, the highest level of similarity was found between pR44 and sequences derived from MCMV M44 and HCMV UL44 (69\% and 55\% overall identity, respectively). A significantly lower similarity was seen between pR44 and its counterparts from HHV-6 and HHV-7 (34\% and 35\% overall identity, respectively), which also belong to the betaherpesvirus subfamily.

Interestingly, a consensus nuclear localization signal (NLS) "PSAKKQK" is located near the C terminus of pR44 (amino acids 412-418). The NLS sequence may mediate nuclear import of proteins via the importin-dependent pathway $[14,15]$. Consensus NLS sequences have previously also been identified at similar positions within the amino acid sequences encoded by M44, UL44, HHV-6 U27 and HHV-7 U27 [23].

In contrast to the amino acid sequences derived from both MCMV M44 and HCMV UL44, the RCMV R44 sequence lacks an Arg-Gly-Asp (RGD) motif. RGD motifs can be recognized by integrins, which are cell surface adhesion molecules that play a role in cellcell adhesion and interactions between cells and extracellular matrix proteins [16, 31]. Indeed, both the M44- and UL44-encoded proteins (ppM44 and ppUL44, respectively) were demonstrated to mediate RGD sequence-dependent cell adhesion in vitro [24].

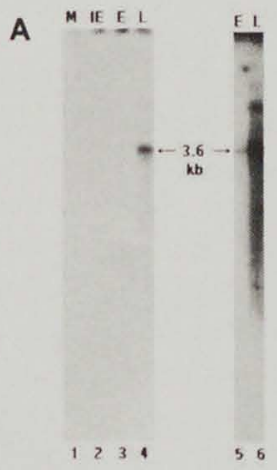

B

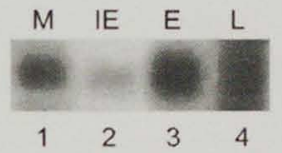

Figure 1. Transcription of the R44 gene. (A) Autoradiographs of a Northern blot that was hybridized with a strand-specific (antisense) R44 probe. Poly(A)+RNA was isolated from mock-infected ( $M$; lane 1 ) and RCMV-infected REF, either at immediate early (IE; lane 2), early ( $E$; lane 3 and 5), or late (L; lane 4 and 6) post infection (p.i.), as described previously [3]. The R44 probe was generated as follows. A 1.0-kb NarlNcol fragment from the R44 ORF (position 41,297-42,298 of the RCMV genome [34]) was treated with DNA polymerase I Klenow fragment (Klenow: Amersham Pharmacia Biotech) and cloned into EcoRIdigested and Klenow-treated plasmid PGEM-3Z. A plasmid clone with the insert in the correct orientation, i.e. with the R44 coding strand downstream of the T7 RNA polymerase promoter, was selected. This plasmid was linearized with Bsp1407I and used in a 'run off' linear amplification reaction by incubation with Taq DNA polymerase, the universal reverse sequencing primer, dNTPs and $\left[\alpha-{ }^{32}\right.$ P]dATP (ICN) for 30 cycles ( 1 min at $95^{\circ} \mathrm{C}, 30 \mathrm{sec}$ at $55^{\circ} \mathrm{C}$, and $30 \mathrm{sec}$ at $72{ }^{\circ} \mathrm{C}$ ). Hybridization and autoradiography were performed as described earlier [5]. The estimated size of the R44 transcript is depicted in between the autoradiographs. Lane 5 and 6 represent a 10-fold longer exposure of lane 3 and 4. (B) Autoradiograph of the same Northern blot as shown in (A), after stripping of the R44 probe, and hybridization with a digoxygenin-labeled rat glyceraldehyde-3-phosphate-dehydrogenase (GAPDH) probe. Labeling, hybridization and detection were performed using a digoxygenin DNA-labeling and chemoluminescence detection kit (Boehringer Mannheim) and Dig Easy Hyb hybridization solution (Boehringer Mannheim). 
To investigate transcription of the R44 gene at immediate early (IE), early (E), and late (L) times of RCMV infection in rat embryo fibroblasts (REF), Northern blot analysis was performed. As shown in Fig. 1, an abundant R44-specific transcript could be detected exclusively in the $L$ phase of infection (lane 4). However, after longer exposure times, a transcript of similar length can also be observed in the $E$ phase of infection (lane 5), although the signal intensity of this transcript was significantly lower than that of the Lphase transcript (lane 6). These results indicate that RCMV R44 is primarily a late gene, but is also expressed, albeit at relatively low levels, in the $E$ phase of infection.

The R44-specific transcript has an estimated length of $3.6 \mathrm{~kb}$. Interestingly, the R44 ORF is only $1.3 \mathrm{~kb}$ in length, which indicates that the R44 transcript contains either a long untranslated sequence or one or more additional ORFs. The HCMV UL44 and MCMV M44 transcripts were also reported to be relatively long ( $4.5 \mathrm{~kb}$ and $>6.0 \mathrm{~kb}$, respectively), whereas their respective ORFs measure only 1.3 and $1.2 \mathrm{~kb}$, respectively $[12,20,22$, 27].

Previously, a panel of mouse monoclonal antibodies (MoAbs) directed against RCMVinduced antigens was generated in our laboratory [6]. To identify MoAbs that are directed against pR44, we set out to screen the anti-RCMV MoAbs for binding to recombinant pR44 by Western blot analysis. For this purpose, we generated two different recombinant R44 expression constructs. These constructs can mediate bacterial expression of glutathione $S$-transferase (GST; $27.5 \mathrm{kDa}$ ) fused at its $C$ terminus to either full-length pR44 (CST-pR44) or the C-terminal 100 amino acids of pR44 (GST- $\Delta p R 44$ ). Both fusion proteins were

A

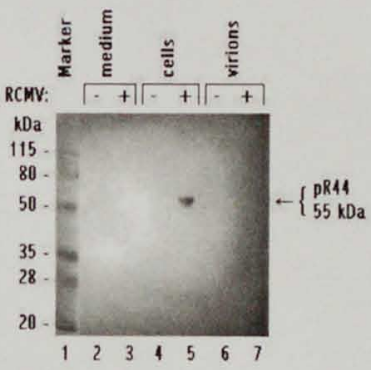

B

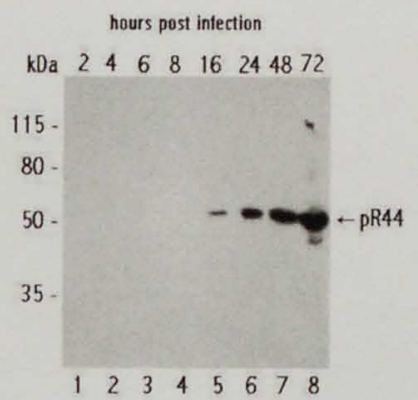

Figure 2. Analysis of pR44 expression in RCMV-infected cells at various times after infection. (A) Detection of pR44 from RCMV-infected cells on a Western blot. REF were either mock-infected (-) or infected with RCMV at a multiplicity of infection of $0.01(+)$. At $48 \mathrm{~h}$ p.i., the presence of pR44 was investigated in the culture medium (lane 2 and 3), cells (lane 4 and 5), and virions (lane 6 and 7 ). Proteins were separated by sodium dodecyl sulphate-10\% polyacrylamide gel electrophoresis (SDS-PAGE), essentially according to the Laemmli method [19]. The gel was transferred to nitrocellulose (PROTRAN, $0.2 \mu \mathrm{m}$; Schleicher \& Schuell) and incubated successively with mouse anti-RCMV monoclonal antibody 8 (RCMV8; 1:5000 diluted) and peroxidase-conjugated, rabbit anti-mouse immunoglobulins (1:1000 diluted; Dako). The generation of RCMV8 has previously been described [6]. The blot was developed using diaminobenzidine as substrate. The location (indicated by an arrow) and size of pR44 is depicted to the right of the blot. Sizes of prestained protein markers (broad molecular weight marker, BioRad; lane 1) are indicated to the left of the blot.(B) The expression kinetics of pR44. REF were infected with RCMV and harvested at 2, 4, $6,8,16,24,48$, and $72 \mathrm{~h}$ p.i., as indicated above the lanes. The R44 protein was detected by Western blot analysis using RCMV8. The blot was developed using a luminescent detection system (ECL; Amersham Pharmacia Biotech). The location of pR44 is depicted to the right of the blot. Sizes of prestained protein markers (broad molecular weight marker, BioRad; lane 1) are shown to the left of the blot. 
separately expressed in E. coliand purified by affinity chromatography. To investigate whether any of our anti-RCMV MoAbs could recognize either GST-pR44 or GST- $\triangle \mathrm{pR} 44$, both recombinant proteins were separated on an SDS-polyacrylamide gel, transferred to a nitrocellulose filter, and incubated with either MoAb RCMV8, RCMV10, RCMV14, RCMV15, and RCMV16 [6]. One of these MoAbs, RCMV8, was found to react strongly with both GST-pR44 and GST- $\triangle$ pR44, but not with GST alone (data not shown). This indicated that RCMV8 is directed against an epitope of pR44 that is situated in the Cterminal 100 amino acids of the protein.

To detect the expression of RCMV pR44 in vitro, REF were either RCMV- or mockinfected. At $48 \mathrm{~h}$ after infection, proteins from the infected cells as well as proteins from extracellular virus particles were analyzed by Western blotting. As shown in Fig. 2A, RCMV8 did not react with proteins from either the culture medium (lanes 2 and 3 ), mock-infected cells (lane 4), or virions (lanes 6 and 7). By contrast, RCMV8 was found to react strongly with a protein from RCMV-infected cells (lane 5). The molecular mass of this protein was estimated to be approximately $55 \mathrm{kDa}$, which is higher than the calculated molecular mass of pR44 (45.6 kDa). However, since the predicted amino acid sequence of pR44 contains numerous consensus posttranslational modification sites, as described above, it is likely that the difference between the calculated and estimated molecular mass is due to posttranslational modification of $\mathrm{pR} 44$.
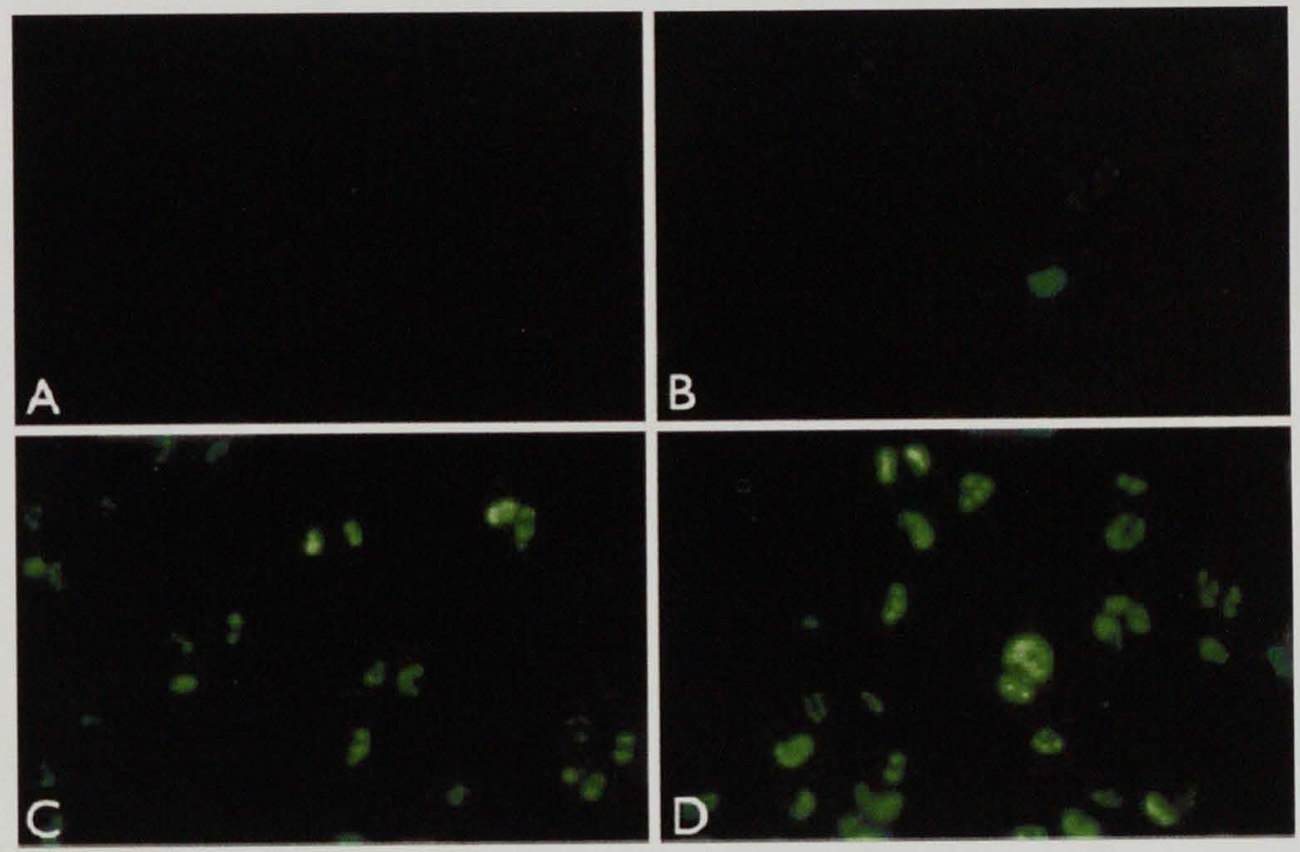

Figure 3. Nuclear localization of pR44 in RCMV-infected cells. REF were grown in 96-well tissue culture plates (Costar) and infected with RCMV at an MOI of 0.01 . At various times after infection, cells were fixed with $3.7 \%$ paraformaldehyde in PBS, permeabilized with $0.05 \%$ Nonidet-P40, and washed. RCMV8, diluted in PBS, was added and incubated for $30 \mathrm{~min}$ at $37^{\circ} \mathrm{C}$. After washing, the cells were incubated with FITC-conjugated, rabbit anti-mouse immunoglobulins (Dako), 1:100 diluted in PBS, and examined at various times after infection with an Axiovert 100 fluorescence microscope (Zeiss). The time points investigated are 0 (A), 8 (B), 24 (C), and 48 (D) h p.i. Magnification $\times 400$. 
To investigate the kinetics of expression of $p R 44$, REF were infected with RCMV, harvested at various times after infection and subjected to Western blotting. As shown in Fig. 2B, the R44 gene product could be detected in RCMV-infected cells at 16, 24, 48, and $72 \mathrm{~h}$ post infection (p.i.) (lanes 5-8), but not at earlier time points (lanes $1-4$ ). Previously, MoAb RCMV8 has been used extensively as a tool to identify RCMV-infected cells. In accordance with the nuclear localization of the pR44 homologs from HCMV and MCMV $[10,23], R C M V 8$ was found to react with proteins in the nucleus of rat cells infected in vitro or in vivo with RCMV $[2,3]$. To further examine the subcellular localization of $p R 44$, REF were subjected to immunocytochemistry at various time points after RCMV infection. Figure 3 shows that expression of pR44 could be detected in nuclei of infected cells as early as $8 \mathrm{~h}$ p.i. (Fig. 3B). At this time point, fluorescent signals of low intensity were seen in a minority of the cells only. However, at later times ( 24 and $48 \mathrm{~h}$ p.i., Fig. $3 \mathrm{C}$ and D, respectively), pR44 is detected at high levels in the majority of the cells. Similar kinetics of expression were seen by Western analysis (Fig. 2B), although the earliest time point at which pR44 was detectable with this technique was $16 \mathrm{~h} \mathrm{p.i.} \mathrm{Apparently,} \mathrm{the} \mathrm{amount} \mathrm{of}$ pR44 that was synthesized at $8 \mathrm{~h}$ p.i. was too low for detection by Western analysis. Like its homologs from MCMV and HCMV [10,23], pR44 is likely to be expressed within viral replication centers. However, this could not be confirmed due to unavailability of appropriate replication center-specific antibodies.

In conclusion, we found that RCMV R44 encodes a $55-\mathrm{kD}$ a protein that is expressed in the nuclei of RCMV-infected cells as early as $8 \mathrm{~h}$ after infection in vitro. In addition, we identified pR44 as the target of anti-RCMV MoAb RCMV8.

\section{References}

1. Agulnick, A.D., Thompson, J.R., lyengar, S., Pearson, G., Ablashi, D., and Ricciardi, R.P. (1993). Identification of a DNA-binding protein of human herpesvirus 6 , a putative DNA polymerase stimulatory factor. J. Gen. Virol. 74, 1003-1009.

2. Beisser, P.S., Grauls, G., Bruggeman, C.A., and Vink, C. (1999). Deletion of the R78 $G$ protein-coupled receptor gene from rat cytomegalovirus results in an attenuated, syncytium-inducing mutant strain. J. Virol. 73, 7218-7230.

3. Beisser, P.S., Vink, C., van Dam, J.G., Grauls, G., Vanherle, S.J.V., and Bruggeman, C.A. (1998). The R33 G protein-coupled receptor gene of rat cytomegalovirus plays an essential role in the pathogenesis of viral infection. J. Virol. 72, 2352-2363.

4. Beuken, E., Slobbe, R., Bruggeman, and C.A., Vink, C. (1996). Cloning and sequence analysis of the genes encoding DNA polymerase, glycoprotein $\mathrm{B}, I \mathrm{CP} 18.5$ and major DNA-binding protein of rat cytomegalovirus. J. Gen. Virol. 77, 1559-1562.

5. Brown, T., and Mackey, K. (1997). Analysis of RNA by Northern and slot blot hybridization. In Current protocols in molecular biology, F.M. Ausubel, R. Brent, R.E. Kingston, D.D. Moore, J.G. Seidman, J.A. Smith, and K. Struhl, eds. (New York, USA: John Wiley \& Sons), pp 4.9.1-4.9.16.

6. Bruning, J.H., Debie, W.H.M., Dormans, P.H.J., Meijer, H., and Bruggeman, C.A. (1987). The development and characterization of monoclonal antibodies against rat cytomegalovirus induced antigens. Arch. Virol. 94, 55-70.

7. Chan, S.R., and Chandran, B. (2000). Characterization of human herpesvirus 8 ORF59 protein (PF-8) and mapping of the processivity and viral DNA polymerase-interacting domains. J. Virol. 74, 10920-10929. 
8. Chang, C.K., and Balachandran, N. (1991). Identification, characterization, and sequence analysis of a cDNA encoding a phosphoprotein of human herpesvirus $6 . \mathrm{J}$. Virol. 65, 2884-2894.

9. Chang, C.K., and Balachandran, N. (1991). Identification, characterization, and sequence analysis of a cDNA encoding a phosphoprotein of human herpesvirus $6 . \mathrm{J}$. Virol. 65, 7085 .

10. Ertl, P.F, and Powell, K.L. (1992). Physical and functional interaction of human cytomegalovirus DNA polymerase and its accessory protein (ICP36) expressed in insect cells. J. Virol. 66, 4126-4133.

11. Gallo, M.L., Jackwood, D.H., Murphy, M., Marsden, H.S., and Parris, D.S. (1988). Purification of the herpes simplex virus type 165 -kilodalton DNA-binding protein: properties of the protein and evidence of its association with the virus-encoded DNA polymerase. J. Virol. 62, 2874-2883.

12. Geballe, A.P., Leach, F.S., and Mocarski, E.S. (1986). Regulation of cytomegalovirus late-gene expression: $\gamma$ genes are controlled by posttranscriptional events. J. Virol. $57,864-874$

13. Gibson, W. (1983). Protein counterparts of human and simian cytomegaloviruses. Virology 128, 391-406.

14. Görlich, D. (1997). Nuclear protein import. Curr. Opin. Cell. Biol. 9, 412-419.

15. Görlich, D., and Mattaj, I.W. (1996). Nucleocytoplasmic transport. Science 271, 15131518.

16. Hynes, R.O. (1987). Integrins: A family of cell surface receptors. Cell 48, 549-554.

17. Johnson, P.A., Best, M.G., Friedmann, T., and Pariis, D.S. (1991). Isolation of a herpes simplex virus type 1 mutant deleted for the essential UL42 gene and characterization of its null phenotype. J. Virol. 65, 700-710.

18. Kiehl, A., and Dorsky, D.I. (1991). Cooperation of EBV DNA polymerase and EA$D(B M R F 1)$ in vitro and colocalization in nuclei of infected cells. Virology $184,330-$ 340.

19. Laemmli, U.K. (1970). Cleavage of structural proteins during the assembly of the head of bacteriophage T4. Nature 227,680-685.

20. Leach, F.S., and Mocarski, E.S. (1989). Regulation of cytomegalovirus late-gene expression: differential use of three start sites in the transcriptional activation of ICP36 gene expression. J. Virol. 63,1783-1791.

21. Lin, K., Dai, C.Y., and Ricciardi, R.P. (1998). Cloning and functional analysis of Kaposi's sarcoma-associated herpesvirus DNA polymerase and its processivity factor. J. Virol. $72,6228-6232$.

22. Loh, L.C., Balachandran, N., and Britt, W.J. (1991). Characterization of a membraneassociated phosphoprotein of murine cytomegalovirus (pp50) and its immunological cross-reactivity with a human cytomegalovirus protein. Virology 183,181-194.

23. Loh, L.C., Britt, W.J., Raggo, C., and Laferté, S. (1994). Sequence analysis and expression of the murine cytomegalovirus phosphoprotein pp50, a homolog of the human cytomegalovirus UL44 gene product. Virology 200, 413-427.

24. Marchetti, M.E., Smith, C.A., and Schaffer, P.A. (1988). A temperature-sensitive mutation in a herpes simplex virus type 1 gene required for DNA synthesis maps to coordinates 0.609 through 0.614 in $U_{1}$. J. Virol. 62, 715-721.

25. Marsden, H.S., Campbell, M.E.M., Haarr, L., Frame, M.C., Parris, D.S., Murphy, M., Hope, R.G., Muller, M.T., and Preston, C.M. (1987). The 65,000-M, DNA-binding 
and virion trans-inducing protein of herpes simplex virus type 1. J. Virol. 61, 24282437.

26. Mocarski, E.S., Pereira, L., and Michael, N. (1985). Precise localization of genes on large animal virus genomes: use of Igt11 and monoclonal antibodies to map the gene for a cytomegalovirus protein family. Proc. Natl. Acad. Sci. USA 82, 1266-1270.

27. Pande, H., Campo, K., Shanley, J.D., Creeger, E.S., Artishevsky, A., Gallez-Hawkins, G., and Zaia, J.A. (1991). Characterization of a $52 \mathrm{~K}$ protein of murine cytomegalovirus and its immunological cross-reactivity with the DNA-binding protein ICP36 of human cytomegalovirus. J. Gen. Virol. 72,1421-1427.

28. Pari, G.S., Kacica, M.A., and Anders, D.G. (1993). Open reading frames UL44, IRS1/ TRS1, and UL36-38 are required for transient complementation of human cytomegalovirus orilyt-dependent DNA synthesis. J. Virol. 67, 2575-2582.

29. Pearson, G.R., Vroman, B., Chase, B., Sculley, T., Hummel, M., and Kieff, E. (1983). Identification of polypeptide components of the Epstein-Barr virus early antigen complex with monoclonal antibodies. J. Virol. 47, 193-200.

30. Ruoslahti, E., and Pierschbacher, M.D. (1987). Nin cell adhesion: RGD and integrins. Science 238, $491-497$.

31. Stals, F.S., Bosman, F., van Boven, C.P., and Bruggeman, C.A. (1990). An animal model for therapeutic intervention studies of CMV infection in the immunocompromised host. Arch. Virol. 114, 91-107.

32. Vaughan, P.J., Purifoy, D.J.M., and Powell, K.L. (1985). DNA-binding protein associates with herpes simplex virus DNA polymerase. J. Virol. 53, 501-508.

33. Vink, C., Beuken, E., and Bruggeman, C.A. (2000). The complete DNA sequence of the rat cytomegalovirus. J. Virol. 74, 7656-7665.

34. Wu, C.A., Nelson, N.J., McGeoch, D.J., and Challberg, M.D. (1988). Identification of herpes simplex virus type 1 genes required for origin-dependent synthesis. J. Virol. 62, 435-443. 


\section{CHAPTER 3}

The Rat Cytomegalovirus R78 G Protein-Coupled Receptor Gene is Required for the Production of Infectious Virus in the Spleen

Suzanne J.F. Kaptein, Patrick S. Beisser, Yvonne K. Gruijthuijsen, Kim G.M. Savelkouls, Koen W.R. van Cleef, Erik Beuken, Gert E.L.M. Grauls, Cathrien A. Bruggeman, Cornelis Vink

Journal of General Virology 2003, 84, 2517-2530 


\begin{abstract}
The rat cytomegalovirus (RCMV) $R 33$ and $R 78$ genes are conserved within the subfamily of Betaherpesvirinae, and encode proteins ( $p R 33$ and $p R 78$, respectively) that show sequence similarity with $G$ protein-coupled receptors (GPCRs). Previously, the biological relevance of these genes was demonstrated by the finding that R33-and R78-deleted RCMV strains are severely attenuated in vivo. In addition, R78-deleted strains were found to replicate less efficiently in cell culture. In order to allow monitoring of the expression of the R33- and R78-encoded proteins, we generated recombinant RCMV strains, designated RCMV33G and RCMV78G, that express enhanced green fluorescent protein (EGFP)-tagged versions of $p R 33$ and $p R 78$ instead of native $p R 33$ and $p R 78$, respectively. Here, we report that while RCMV33C replicates as efficiently as wild-type (WT) virus in rat embryo fibroblast cultures, strain RCMV78G produces 3- to 4-fold lower virus titres than WT RCMV in the culture medium. This result indicates that the pR78-EGFP protein, as expressed by RCMV78G, does not completely functionally replace its native counterpart ( $p$ R78) in vitro. Interestingly, in infected rats, infectious RCMV33G was produced in significantly lower amounts than infectious WT RCMV, as well as RCMV78G, in the salivary glands. Conversely, although RCMV33G replicated to similar levels as WT virus in the spleen, both RCMV78G and an R78 knock-out strain (RCMV $R$ R78a) replicated poorly in this organ. Together, these data indicate that $R 78$ is crucial for the production of infectious $R C M V$ in the spleen of infected rats.
\end{abstract}

\title{
Introduction
}

Cytomegaloviruses (CMVs) employ a panoply of strategies that are aimed at subversion of antiviral defense mechanisms of their hosts. Among the CMV proteins that are likely to play a key role in some of these strategies are proteins that show sequence similarity with $G$ protein-coupled receptors (GPCRs). It is generally believed that the CMV GPCR genes have been pirated by an ancestral virus during the long coevolution of pathogen and host. GPCRs form a large family of receptors that function in signal transduction through cell membranes. These proteins invariably consist of seven transmembrane helices that are connected by three intracellular and three extracellular loops. The majority of GPCRs activate $G$ proteins and are capable of transducing a wide variety of messages. Within the genomes of all sequenced CMVs, genes have been identified that encode GPCR homologues. Human CMV (HCMV) carries four putative GPCR genes: US27, US28, UL33 and $U L 78[11,12,17]$. Only two of these, UL33 and $U L 78$, have homologues in each of the currently sequenced betaherpesvirus genomes $[1,2,11,12,17,22,28,30]$, which may reflect the biological relevance of these genes.

The biological significance of the UL33 family members has previously been demonstrated in studies using recombinant CMVs that carry either a disrupted UL33 [24], M33 [14] or R33 gene [2] in their genomes. In cell culture, each of these mutant viruses replicated with similar efficiency as the corresponding wild-type (WT) viruses $[2,14,24]$. However, during in vivo infection, significant differences were observed between animals infected with the recombinants and those infected with the WT viruses. In contrast to their WT counterparts, M33- and R33-deleted viruses could not be detected within the salivary glands of infected mice and rats, respectively $[2,14]$. This indicated that $M 33$ and 
R33 play a role in virus dissemination to or replication in the salivary glands $[2,14]$. Furthermore, it was shown in the RCMV/rat model that R33 plays an important role in the pathogenesis of RCMV disease, since a significantly lower mortality was seen among rats infected with R33-deleted RCMV (RCMV $\triangle R 33$ ) than among those infected with WT RCMV [2].

It has been firmly established that the members of the UL33 gene family encode $G$ protein-coupled receptors. The human herpesvirus type $6 \mathrm{~B}(\mathrm{HHV}-6 \mathrm{~B})$ member of the UL33 family, pU12, was reported to be a calcium-mobilizing receptor for several CC chemokines [19]. In addition, we found the RCMV R33-encoded protein to signal in a ligand-independent, constitutive fashion [18]. Recently, similar activities have also been attributed to the MCMV and HCMV counterparts of these proteins [38]. Like the UL33 family members, the UL78 gene family members were found to have important roles in the pathogenesis of infection. A significantly lower mortality was observed among rats infected with R78-deleted RCMV strains (RCMV $\triangle R 78 \mathrm{a}$ and $R C M V \triangle R 78 \mathrm{C}$ ) than among animals infected with WT RCMV [3]. Additionally, cells infected with these recombinant viruses produced 10- to 100 -fold lower virus titres than their WT counterpart. Similar observations have been made in the MCMV/murine model [29]. Despite the relatively low sequence similarity with known chemokine receptors, the HHV-6A pUL78 homologue (pU51) was reported to bind several CC chemokines, such as CCL2, CCL5 CCL7, CCL11. CCL13 as well as an HHV-8-encoded chemokine, VMIP-II [26]. These binding characteristics strongly resemble those of the HHV-6B homologue of pUL33, pU12. Nevertheless, signaling activities have hitherto not been identified for any other member of the UL78 family.

In order to monitor the expression of both $\mathrm{pR} 33$ and $\mathrm{pR} 78$ in vitro and in vivo, we set out to generate recombinant RCMV strains expressing either pR33-enhanced green fluorescent protein (EGFP) or pR78-EGFP instead of native $p R 33$ and $p R 78$, respectively. Here, we show that these recombinant viruses (RCMV33G and RCMV78G, respectively) differ from WT RCMV in various aspects of replication in vitro and in vivo. Most notably, while strain RCMV33G is defective in producing infectious virus in the salivary glands of infected rats, strain RCMV78G is incapable of producing viral progeny in the spleen. In all other organs and tissues tested, these strains replicate in a fashion indistinguishable from that of WT virus.

\section{Materials and Methods}

\section{Cells and virus}

Primary rat embryo fibroblasts (REF), rat fibroblast cell line Rat2 (Rat2 TK"; ATCC CRL-1764), and monocyte/macrophage cell line R2 were cultured as described previously $[9,13]$. REF were utilized for propagation of both WT RCMV (Maastricht strain; [9] and recombinant RCMV strains, as well as for virus titration by plaque assay [10]. Rat 2 were utilized for transfection [2] and confocal laserscan microscopy studies. RCMV DNA was isolated from culture medium as described by Vink et al. [36]. 
A

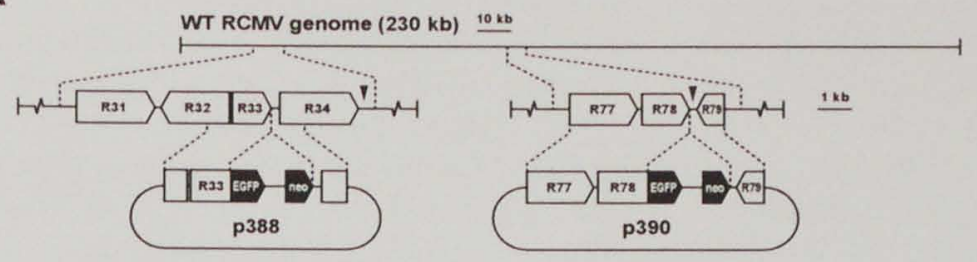

B
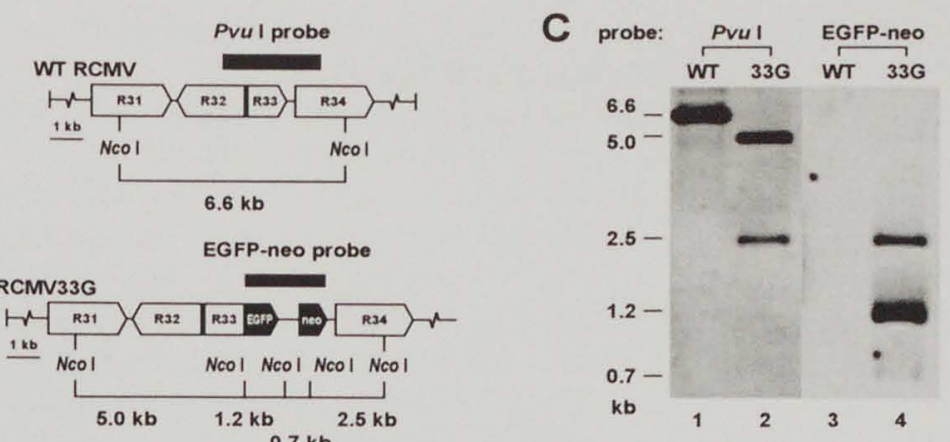

D
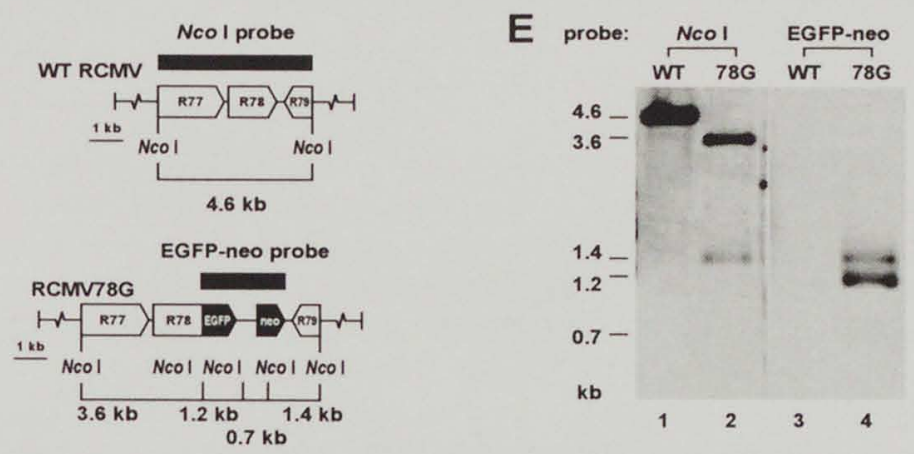

Figure 1. Construction of RCMV strains RCMV33G and RCMV78G. (A) The recombinant strains were generated by homologous recombination between RCMV genomic DNA and plasmids containing an EGFP-neo cassette. The RCMV genome is represented by a black line at the top of the diagram. Below the genome, the R33 and R78 loci are highlighted. The ORF positions, sizes and orientations are indicated by white arrow boxes. Consensus polyadenylation sequences closest to the $3^{\prime}$ end of either R33 or R78 are indicated by black triangles. Recombination plasmid diagrams are indicated below the R33 and R78 loci. ORFs within the EGFP-neo cassette are indicated by black arrow boxes. (B) Location of Ncol restriction sites at the R33 locus within the genomes of WT RCMV (top) and RCMV33G (bottom). Black boxes indicate the locations that correspond with each of the probes used for hybridisation. Ncol restriction sites and predicted lengths of restriction fragments are indicated below each of the loci. (C) Chemiluminescence exposure from a Southern blot of Ncol-treated WT RCMV DNA (lanes 1 and 3) and RCMV33G DNA (lanes 2 and 4) hybridized with either the Pvul probe (lanes 1 and 2) or the EGFP-neo probe (lanes 3 and 4). The lengths of the detected fragments are indicated on the left in kb. (D) Location of Ncol restriction sites at the R78 locus within the genomes of WT RCMV (top) and RCMV78G (bottom). (E) Chemiluminescence exposure of a Southern blot containing Ncol-treated WT RCMV DNA (lanes 1 and 3) and RCMV78G DNA (lanes 2 and 4) hybridized with either the Ncol probe (lanes 1 and 2) or the EGFPneo probe (lanes 3 and 4). 


\section{RCMV33G recombination plasmid construction}

In order to generate an RCMV strain in which the R33 open reading frame (ORF) is fused in-frame to the 5 ' end of the EGFP ORF, a recombination plasmid was generated. This plasmid, designated $p 388$ (Fig. 1A), was constructed by cloning of a 2.4-kb Nhel$X$ bal fragment, containing both the EGFP ORF and a neomycin resistance gene (neo), into the Xbal site of plasmid p384. This fragment was designated the EGFP-neo cassette. A detailed description of the construction of $p 384$ has been described previously [18]. Plasmid p384 contains the complete R33 gene with its translation termination codon changed into a leucine codon and an Xbal site. The 2.4-kb Nhel-Xbal insert of $\mathrm{p} 388$ was derived from plasmid p374, which was generated as follows. First, a 1.4-kb fragment containing the SV40 early promoter and the neomycin resistance gene was amplified by $P C R$, using primers NEO.C-F and NEO.C-R (Table 1 ) and, as template, plasmid Rc/CMV (Invitrogen). The amplified fragment was digested with EcoRI and $X$ bal and cloned into ECORI- and Xbal-digested pUC119, generating plasmid p370. Subsequently, the EGFP ORF was cloned upstream of the neo ORF. To this purpose, the EGFP ORF was amplified by PCR using primers GFP.CN-F and GFP.C-R (Table 1) and, as template, plasmid p368. Plasmid p368 was derived from vector pEGFP-N1 (Clontech-Westburg BV) by deletion of the 51-bp BamHI-Bg/ll fragment. The 1.1-kb PCR fragment containing the EGFP ORF was digested with EcoRI and cloned into EcoRI-digested p370, resulting in plasmid p374. The integrity of all DNA constructs was verified by sequence analysis.

\section{RCMV78G recombination plasmid construction}

To generate an RCMV strain in which the R78 open reading frame (ORF) is fused inframe to the $5^{\prime}$ end of the EGFP ORF, a recombination plasmid, designated p390 (Fig. $1 \mathrm{~A}$ ), was generated as follows. First, the $X b a l$ site of pUC119 was destroyed by digestion of this vector with $X b a l$, treatment of the linearized vector with the Klenow fragment of DNA polymerase I (Klenow) in the presence of deoxynucleotide triphosphates (dNTPS), followed by ligation using T4 DNA ligase. The resulting plasmid was termed pre- 377 . Next, the RCMV Xbal B fragment, which was cloned in vector PSP62-PL by Meijer et al. [25], was digested with $\mathrm{Ncol}$, and a 4.6-kb fragment, containing the complete R77, R78, and R79 ORFs (position 96996 to 101556 of the RCMV genome [37]), was treated with Klenow and cloned into the Hincll site of pre-377, generating plasmid p377. To enable the in-frame fusion of the EGFP ORF to the $3^{\prime}$ end of the R78 ORF, the R78 stop codon was altered into an $X b a l$ restriction site using the following PCR-based procedure. First, the sequence downstream of the R78 stop codon was amplified by PCR with primers R79.C-F and R79.C-R (Table 1), using $p 377$ as a template. The resulting 558-bp PCR product was treated with T4 DNA polymerase and then digested with $X b a l$. Then, the $X$ bal-blunt PCR product was cloned into pUC119, which was previously successively treated with HindllI, Klenow and Xbal. The resulting plasmid was termed pre-p382. Next, the $3^{\prime}$ end of the R78 ORF was amplified by PCR with primers R78.C-F and R78.C$R$ (Table 1), using $p 377$ as a template. The amplified 667-bp fragment was treated with T4 DNA polymerase, and then digested with $X b a l$. The resulting blunt- $X b$ al fragment was cloned into pre-p382 by using the filled-in EcoRI site of the polylinker and the newly introduced $X b a l$ site at the 3 ' end of the R78 ORF, generating plasmid $p 382$. Finally, the 682-bp Ascl-Clal fragment from p377 was exchanged for the Ascl-Clal fragment from 
$\mathrm{p} 382$, resulting in plasmid $\mathrm{p} 386$. Next, the $2.4-\mathrm{kb}$ Nhel-Xbal fragment from plasmid $\mathrm{p} 374$ (see above) was cloned into the newly introduced $X$ bal site at the $3^{\prime}$ end of ORF R78 in p386, resulting in plasmid p390. In this plasmid the EGFP ORF is fused in-frame to the $3^{\prime}$ terminus of the R78 ORF. The integrity of all DNA constructs was verified by sequence analysis.

\section{Generation of strains RCMV33G and RCMV78G}

Approximately $1 \times 10^{7}$ Rat 2 cells were trypsinized and subsequently centrifuged for 5 $\mathrm{min}$ at $500 \mathrm{~g}$. The cells were resuspended in $0.5 \mathrm{ml}$ of culture medium, after which $10 \mu \mathrm{g}$ of either plasmid p388 or p390 was added. The suspension was transferred to a $0.4-\mathrm{cm}$ electroporation cuvette (Bio-Rad) and pulsed at $0.25 \mathrm{kV}$ and $500 \mu \mathrm{F}$ in a Bio-Rad Gene Pulser electroporator. The cells were subsequently seeded in T75 culture flasks. At $14 \mathrm{~h}$ after transfection, the cells were infected with low-passage RCMV at a multiplicity of infection (moi) of 1 . The culture medium was supplemented with $50 \mu \mathrm{g}$ of $\mathrm{G} 418$ per $\mathrm{ml}$ at $16 \mathrm{~h}$ post-infection ( $\mathrm{pi}$ ). Recombinant viruses were cultured on REF monolayers and plaque purified as described earlier $[2,3,4]$.

\section{Southern blot hybridisation}

DNA isolated from wild-type (WT) RCMV, RCMV33G, and RCMV78G was digested with $\mathrm{Ncol}$, electrophoresed through a $1 \%$ agarose gel, and blotted onto a Hybond $\mathrm{N}^{+}$ nylon membrane (Amersham Pharmacia Biotech) as described previously [7]. The integrity of genomic DNA from strain RCMV33G was checked by using plasmids $p 375$ (containing R32, R33 and R34 sequences) and p374 (containing EGFP and neo sequences) as probes. The integrity of the RCMV78C DNA was verified by using $p 377$ (which contains R77, R78 and R79 sequences) and p374 as probes. Hybridisation and detection experiments were performed with digoxigenin DNA labeling and chemiluminescence detection kits (Roche).

\section{Isolation of poly $(A)^{+}$RNA and Northern blot hybridisation}

Poly $(A)^{+}$RNA was isolated from either WT RCMV-, RCMV33G- or RCMV78G-infected REF (moi $=0.01$ ) at day 6 pi using a QuickPrep Micro mRNA Purification Kit (Amersham Pharmacia Biotech), according to the manufacturer's protocol. Electrophoresis of RNA under denaturing conditions and transfer to Hybond $\mathrm{N}$ membranes (Amersham Pharmacia Biotech) has been described previously [8]. The blots were hybridized with probes specific for either R32, R33, R34, R77, R78, R79-80, EGFP, or the SV40 Early antigen promoter and neo gene. The 426-bp BamHI, 976-bp Sad, 501-bp Asp718-HindIII, 1432-bp BamHI$B g$ Il, 734-bp Ncol-EcoRl, and 1380-bp EcoRl-Xbal fragments from plasmid $p 388$ were used as R32-, R33-, R34-, R79-80-, EGFP- and neo-specific probes, respectively. R77and R78-specific probes were generated as described previously by Beisser et al. [3]. Hybridisation and detection experiments were performed with digoxigenin DNA labeling and chemiluminescence detection kits (Roche). 
REF were infected with either WT RCMV, RCMV33G or RCMV78G at an moi of 0.01 . At day $6 \mathrm{pi}$, cells were harvested and resuspended in lysisbuffer $(150 \mathrm{mM} \mathrm{NaCl}, 50$ $\mathrm{mM} \mathrm{NaF}, 25 \mathrm{mM}$ Tris/HCl pH 7.5, $2 \mathrm{mM}$ EDTA, $1 \%(\mathrm{w} / \mathrm{v}) \mathrm{NP}-40)$. Subsequently, lysates from $3 \times 10^{4}$ infected cells were separated by sodium dodecyl sulphate- $12 \%$ polyacrylamide gel electrophoresis (SDS-PAGE), essentially according to the Laemmli method [21]. The gel was transferred to a nylon filter (NYTRAN NY 12 N; Schleicher \& Schuell) and incubated successively with rabbit anti-EGFP polyclonal antiserum (Living Colors A.v. Peptide Antibody; Clontech) and peroxidase-conjugated, goat anti-rabbit immunoglobulines (Dako). The blot was developed using a luminescent detection system (ECL; Amersham Pharmacia Biotech).

\section{Confocal laserscan microscopy}

Rat2 cells were grown on glass coverslips and infected with either WT RCMV, RCMV33G or RCMV78G. At several time points pi, the cells were fixed for 20 min with $3.7 \%$ paraformaldehyde in PBS. Confocal laserscan microscopy images were collected at wavelengths of $488 \mathrm{~nm}$ using an MRC 600 confocal microscope equipped with an oil immersion objective ( $40 \times$ magnification, numerical aperture $=1 \cdot 3$; Bio-Rad) as described previously [6]. The digital images were processed using Confocal Assistance software from Bio-Rad.

\section{Dissemination of WT RCMV, RCMV33G, and RCMV78G in vivo}

Male specific-pathogen-free (spf) Lewis/M rats (Central Animal Facility, Maastricht University, Maastricht, The Netherlands) were kept under standard conditions [34]. All experimental protocols mentioned in this paper were approved by the Maastricht University Animal Experiments Committee and were consistent with the Dutch Laboratory Animal Care Act. Five groups of 12 male s.p.f. Lewis/M rats ( 7 weeks old, 250 to $300 \mathrm{~g}$ of body weight, immunosuppressed 1 day before infection) were infected with $9 \times 10^{5}$ plaqueforming units of either WT RCMV, RCMV33G, RCMV $\triangle R 33, R C M V 78 G$, or RCMV $\triangle R 78$. On days 5 and $28 \mathrm{pi}$, six rats from each group were sacrificed, and their internal organs were collected. These organs were subjected to immunohistochemical analysis, plaque assay (as was described previously by Bruggeman et al. [9]) and quantitative PCR as described below. The plaque test and PCR data were statistically analysed by applying a Mann-Whitney $U$ test using SPSS (SPSS International BV).

\section{Real-time quantitative $P C R$}

Total cellular DNA was extracted from the salivary glands, spleen, kidneys, liver, lungs, heart, pancreas, and thymus as follows. Frozen tissue (approximately $4 \mathrm{~mm}^{3}$ in size) was lysed in lysisbuffer (100 mM NaCl, $10 \mathrm{mM}$ Tris/ $\mathrm{HCl} \mathrm{pH} \mathrm{8.0,25} \mathrm{mM} \mathrm{EDTA,} 0.5 \%$ SDS) supplemented with $50 \mathrm{ng} \mathrm{ml}^{-1}$ proteinase $\mathrm{K}$ (Roche) and $5 \mu \mathrm{g} \mathrm{ml}{ }^{-1}$ RNase A (Amersham Pharmacia Biotech), followed by homogenisation, and incubation for $30 \mathrm{~min}$ at $56^{\circ} \mathrm{C}$. Next, DNA was extracted with phenol:chloroform (1:1) and ethanol-precipitated. Before the samples were subjected to real-time PCR, they were analysed by both agarose 
gelelectrophoresis, in order to establish their integrity, and spectrophotometry, to determine their DNA concentrations. The sequences of the TaqMan primers (RCMVfor and RCMVrev; Table 1) and that of the TaqMan probe (RCMVpro; Table 1) used to quantify CMV were selected from the immediate early 1 (IE1) gene with Primer Express software (version 2.0; Perkin-Elmer Biosystems). The TaqMan probe selected between the primers was fluorescently labeled at the $5^{\prime}$ end with 6-carboxyfluorescein (FAM) as the reporter dye and, at the 3 ' end, with 6-carboxytetramethylrhodamine (TAMRA) as the quencher (Table 1). PCR was performed with $12.5 \mu l$ TaqMan Universal PCR Master Mix (Perkin-Elmer Biosystems), $900 \mathrm{nM}$ forward primer, $300 \mathrm{nM}$ reverse primer, $125 \mathrm{nM}$ TaqMan probe, and $100 \mathrm{ng}$ of sample DNA in a total volume of $25 \mu \mathrm{l}$. PCR was performed in 96 -well microtitre plates under the following conditions: $2 \mathrm{~min}$ at $50^{\circ} \mathrm{C}$ and $10 \mathrm{~min}$ at $95^{\circ} \mathrm{C}$, followed by 42 cycles of $95^{\circ} \mathrm{C}$ for $15 \mathrm{~s}$ and $60^{\circ} \mathrm{C}$ for $1 \mathrm{~min}$. The data were analysed with ABI PRISM 7000 Sequence Detection System software (Perkin-Elmer Biosystems). For quantification, standard curves were generated using dilutions of RCMV DNA preparations of known concentration.

\section{Results}

Generation of RCMV strains with EGFP genes fused at the $3^{\prime}$ end of either $R 33$ or $R 78$

We previously demonstrated that RCMV pR33 is a GPCR that signals in a constitutive fashion in cells transfected with an expression construct containing R33 [18]. In addition, we found that a modified version of this protein, containing EGFP at its cytoplasmic Cterminal tail, possesses similar signaling activities as native, non-fused pR33 [18]. This indicated that the EGFP tag at the C-terminus of pR33 does not interfere with its signaling properties, and hence, that EGFP may be a suitable tag to study pR33 expression in vivo. In order to investigate the expression of both $p R 33$ and pR78 during RCMV infection, we set out to generate two recombinant RCMV strains, which express either pR33-EGFP or pR78-EGFP instead of native $p R 33$ and pR78, respectively. To create these strains, we first designed two plasmid constructs containing either the R33 or the R78 gene. Subsequently, the EGFP ORF was inserted into these plasmids at the 3 ' end of either R33 or R78, such that their ORFs were fused in-frame to the EGFP ORF. The resulting R33-EGFP and R78EGFP genes were then shuttled into the RCMV genome by homologous recombination between the plasmids containing these genes and the RCMV genome during infection in cultured fibroblasts (Fig. 1A). Recombinant virus was subsequently enriched for and plaque purified as outlined in Materials and Methods. To verify the genomic integrity of the recombinant strains, Southern blot analysis was performed. First, we analysed the R33EGFP-expressing recombinant strain, which was designated RCMV33G. DNA from both RCMV33G and WT RCMV was digested with Ncol, electrophoresed, blotted and hybridized with either an RCMV DNA-specific probe or an EGFP-specific probe. As shown in Fig. $1 \mathrm{~B}$ and $\mathrm{C}$, the hybridisation patterns observed with each of these probes were as predicted, both for WT RCMV and for RCMV33G. This indicated that (i) the R33 gene was correctly replaced by the R33-EGFP gene in the RCMV33G genome, and (ii) the RCMV33G pool is plaque pure.

The genomic integrity of the R78-EGFP-expressing strain, termed RCMV78G, was checked in a similar fashion as described above for RCMV33G. Fig. 1D and Eshow that 
hybridisation of Ncol-digested RCMV and RCMV78G DNA with either an RCMV DNAspecific or an EGFP DNA-specific probe, yielded results indicating that (i) R78 was properly replaced by R78-EGFP in the RCMV78G genome, and (ii) the RCMV78G pool is plaque pure. The correct genomic integrity of each of the recombinant strains was also confirmed by Southern blot hybridisation of Pstt-digested RCMV33G and RCMV78G DNA (data not shown).

\section{Transcription of R33-EGFP, R78-EGFP and neighboring genes}

To evaluate transcription of R33-EGFP, R78-EGFP and their neighboring genes, Northern blot analysis was performed with poly $(\mathrm{A})^{+} \mathrm{RNA}$ extracted from RCMV-, RCMV33G- and RCMV78G-infected cells. Two different sets of Northern blots were prepared. The first set contained RNA from WT RCMV-and RCMV33G-infected cells. These blots were treated with probes specific for either R32, R33, R34, EGFP or neo (Fig. 2A and B). We previously found the RCMV genomic region containing $R 33$ to be transcribed in a highly complex fashion [2]. Whereas $R 32$ was reported to be transcribed as a single, major 2.5$\mathrm{kb}$ mRNA [5], numerous cotranscripts were identified that contained both R33 and R34 sequences [2]. In light of the expression of these large, 4- to 6-kb cotranscripts, it was to be expected that insertion of both the EGFP ORF and the neo expression cassette into the RCMV genome, would have a significant impact on the transcription patterns of the R33 and R34 genes. Indeed, Fig. 2C shows clear differences between strain RCMV33G and WT RCMV in the expression of these genes. Most notably, strain RCMV33G expresses two unique transcripts, with lengths of 3.1 and $3.5 \mathrm{~kb}$, respectively, which hybridize with both the R33-and EGFP-specific probe (Fig. 2C, lanes 4 and 8). These mRNAs are likely to represent transcripts for the PR33-EGFP fusion protein. In contrast to the R33 and R34 genes, the R32 gene was transcribed by both RCMV33G and WT virus in a similar fashion (Fig. 2C, lanes 1 and 2). Given the complexity of transcription of the RCMV R33-R34 genomic region, and in the absence of antibodies directed against either pR33 or pR34, it is difficult to predict the physiological consequences of the transcriptional differences between RCMV33G and WT RCMV. Therefore, we cannot exclude the possibility that potential differences in replicative potential between RCMV33G and WT virus, either in vitro or in vivo, can be attributed to differences in transcription of genes other than, and downstream of, the R33 gene.

The second set of Northern blots contained RNA from WT RCMV- and RCMV78Ginfected cells. These blots were treated with probes specific for either R77, R78, R79R80, EGFP or neo (Fig. 2D and E). In accordance with our previous findings [3], WT $R C M V$ was found to express three different R78 transcripts, with lengths of $1.8,3.7$ and $5.7 \mathrm{~kb}$ (Fig. 2F, lane 13). Interestingly, strain RCMV78G also expresses three different R78 mRNAs, the sizes of which roughly correspond to the sum of the length of the EGFP expression cassette and the lengths of the respective WT RCMV R78 mRNAs (Fig. 2F, lane 14). Accordingly, each of the three R78 transcripts expressed by RCMV78G also hybridise with the EGFP-specific probe (Fig. 2D, lane 18). Contrary to strain RCMV33G, which expresses the neo gene predominantly as a cotranscript (Fig. 2C, lane 10), RCMV78G transcribes the neo gene into a major, monocystronic message of $1.2 \mathrm{~kb}$ (Fig. 2F, lane 20). We conclude that the transcription of genes neighboring R78 in the RCMV genome is not significantly altered by the introduction of the EGFP expression cassette at the $3^{\prime}$ terminus of the R78 ORF. 
A

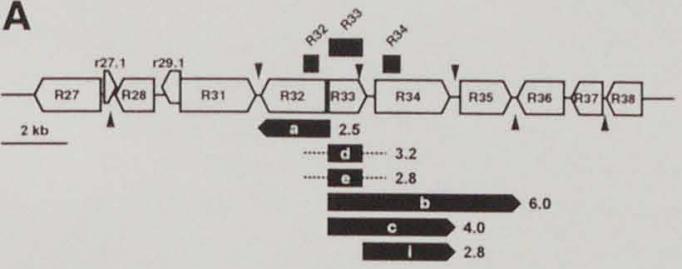

B

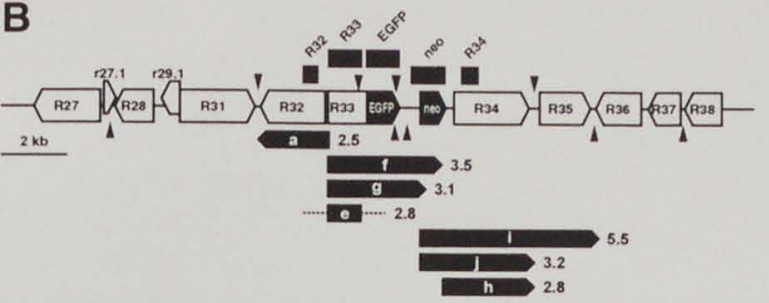

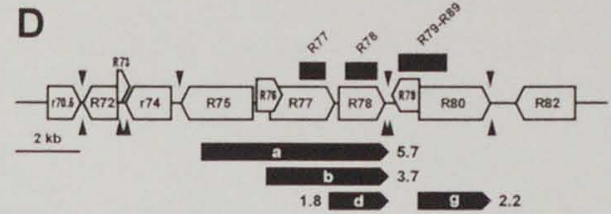
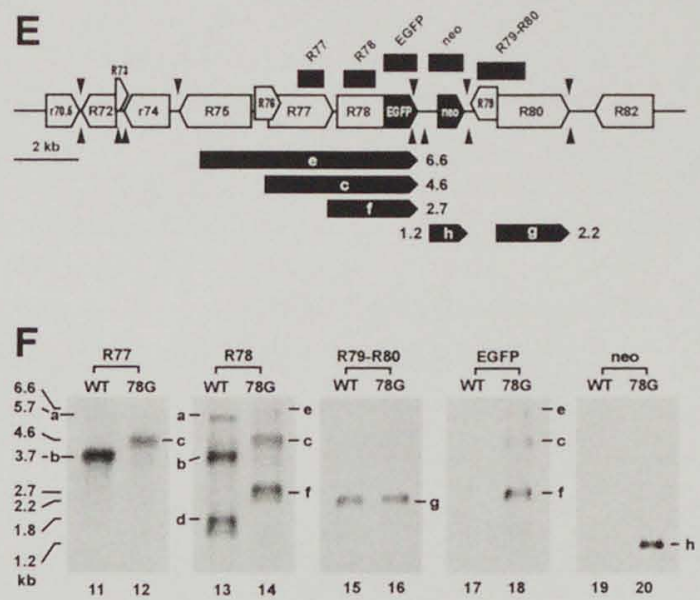

Figure 2. Transcription of genes neighboring R33 and R78, R33-EGFP and R78-EGFP in WT RCMV-infected, RCMV33Ginfected and RCMV78G-infected cells, respectively. The black boxes in each diagram delineate the positions of the probes that were used for hybridisation. White arrows indicate ORF positions, sizes and orientations. Black arrowheads indicate predicted polyadenylation sites (arrow heads pointing down: AATAAA, arrowheads pointing up: TTTATT). Black arrows indicate the predicted positions, sizes and orientations of the transcripts that were detected by Northern blot hybridisation. At the right-hand side of each black arrow, the estimated transcript size is indicated in kb. The predicted transcripts are marked with white letters that correspond to the letters which are used to denote the bands on the Northern blots in Fig. 2C. The estimated lengths of the hybridizing fragments are indicated in $\mathrm{kb}$ on the left of each panel. (A) Organisation of the WT RCMV genome and predicted transcripts of R33 and its neigbouring genes. (B) Organisation of the RCMV33G genome and predicted transcripts of R33-EGFP and its neigbouring genes. (C) Chemiluminescence exposure of Northern blots hybridized with probes specific for either R32, R33, R34, EGFP, or neo sequences. (D) Organization of the WT RCMV genome and predicted transcripts of R78 and its neigbouring genes. (E) Organization of the RCMV78G genome and predicted transcripts of R78-EGFP and its neigbouring genes. (F) Chemiluminescence exposure of Northern blots hybridized with probes specific for either R77, R78, R79-R80, EGFP, or neo sequences. WT, $33 \mathrm{G}$ and $78 \mathrm{G}$ denote poly(A)+ RNA from REF infected with WT RCMV, RCMV33G and RCMV78G, respectively. 
In previous experiments, it was shown that deletion of the R33 gene from the RCMV genome does not affect viral replication in vitro [2]. By contrast, the R78 gene was found to play a crucial role during in vitro replication, as 10-100 fold lower virus titres were recovered from cultures of cells infected with $R 78$ null mutant RCMV strains (RCMV $\triangle R 78 \mathrm{a}$ and $R C M V \triangle R 78 \mathrm{C}$ ) [3]. To determine the impact of replacing the $R 33$ and $R 78$ genes in the RCMV genome with R33-EGFP and R78-EGFP, respectively, multi-step growth curves were generated for WT RCMV, RCMV33G and RCMV78G. As a control for attenuation due to $R 78$ dysfunction, $R C M V \triangle R 78$ a was also included in these experiments. REF were infected with either of these virus strains at an moi of 0.01 . Subsequently, culture medium samples were taken at days $1,3,5$ and $7 \mathrm{pi}$, and subjected to plaque titration assays. Since R33-deleted virus was previously shown to replicate with a similar efficiency as WT RCMV in vitro, it was not surprising to find that strain RCMV33G also replicates in a similar fashion as WT virus (Fig. 3A). By contrast, strain RCMV78G was found to produce 3- to 4-fold lower virus titres than WT virus at days 5 and $7 p i$, respectively $(p<0.05$; Fig. $3 B$ ). Although the level of virus production of strain RCMV78G is significantly higher than that of RCMV $\triangle R 78 \mathrm{a}$, which produces approximately 50 -fold lower titres than WT virus at days 5 and 7 pi $(p<0.05$; Fig. 3B), these data indicate that strain RCMV78G may be attenuated, albeit moderately, in comparison with WT RCMV. It is therefore likely that the R78-EGFP gene can only partly functionally replace the R78 gene.

\section{pR33-EGFP and $p R 78-E G F P$ expression in vitro}

In order to assess the expression of the R33-EGFP- and R78-EGFP-encoded proteins (pR33-EGFP and pR78-EGFP, respectively) during infection in vitro, Rat2 cells were infected
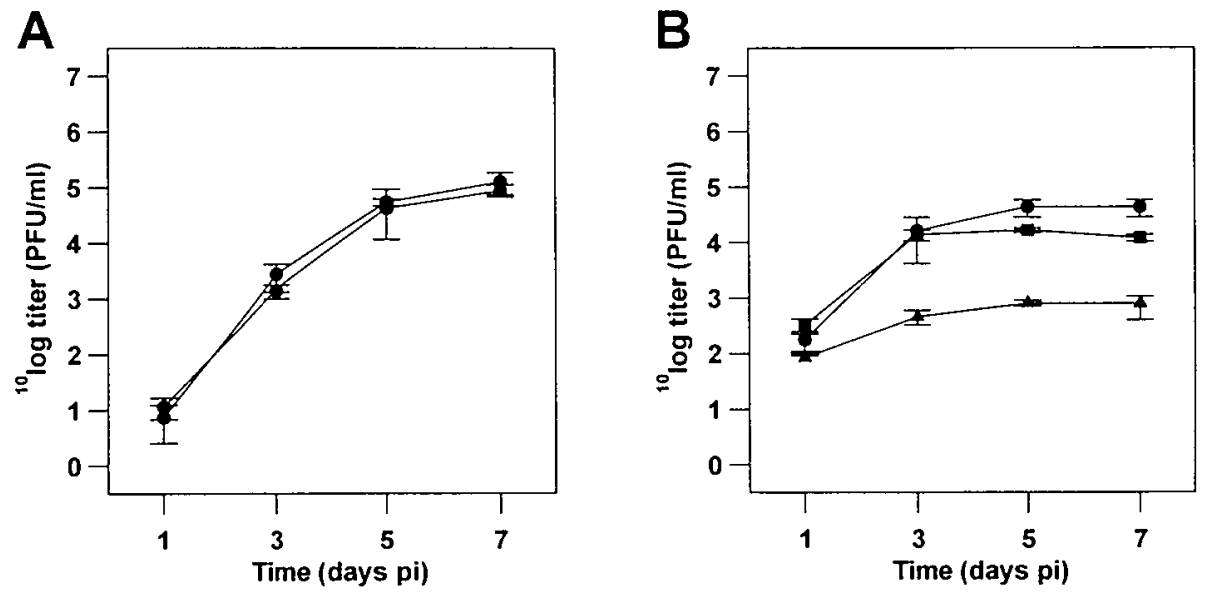

Figure 3. Strain RCMV78G replicates with a lower efficiency than WT RCMV. (A) Multi-step growth curves of WT RCMV (O) and RCMV33G(O). (B) Multi-step growth curves of WT RCMV (O), RCMV78G $(\mathbf{D})$, and RCMV $R 78 \mathrm{a}(\Delta)$. Infection of REF with either of the RCMV strains was performed at an moi of 0.01 . The graphs indicate the virus titres that were determined in samples taken from the culture media at the indicated time points pi. The error bars show the standard deviation for each of the virus titres. 
with either WT RCMV, RCMV33G or RCMV78G, and subjected to confocal laserscan microscopy at various time points pi. Upon infection of the cells with RCMV33G, a focal green fluorescent signal was observed in the cytoplasm as early as $4 \mathrm{~h}$ pi (Fig. 4). At early times after infection, between 4 and $8 \mathrm{~h}$ pi, a granular, perinuclear signal was seen in the RCMV33G-infected cells. This expression pattern is very similar to that observed in COS7 or Rat2 cells after transfection with R33-EGFP expression constructs [18]. However, a clear colocalisation of the fluorescent signal with cell membranes, as seen previously in transfected cells, could not be observed in the RCMV33G-infected cells. At late times after infection ( 24 and $48 \mathrm{~h} \mathrm{pi)}$, the fluorescence was evenly distributed throughout the cells (Fig. 4).

After infection of Rat2 cells with RCMV78G, green fluorescence was first seen at $2 \mathrm{~h}$ pi as a granular, perinuclear signal (Fig. 4). While the intensity of the signal increased between 4 and $48 \mathrm{~h}$ pi, the granular distribution of the signal remained visible up until 24 $\mathrm{h}$ pi. At $48 \mathrm{~h}$ pi, the fluorescence was more evenly distributed throughout the RCMV78Ginfected cells. As in RCMV33G-infected cells, a clear colocalisation of green fluorescence with the cell membrane is not clearly seen in RCMV78G-infected cells. Nevertheless, such a colocalisation is also absent in Rat2 cells transfected with R78-EGFP expression constructs, which give rise to an expression pattern highly similar to that seen in RCMV78Ginfected cells at $8 \mathrm{~h}$ pi (data not shown).
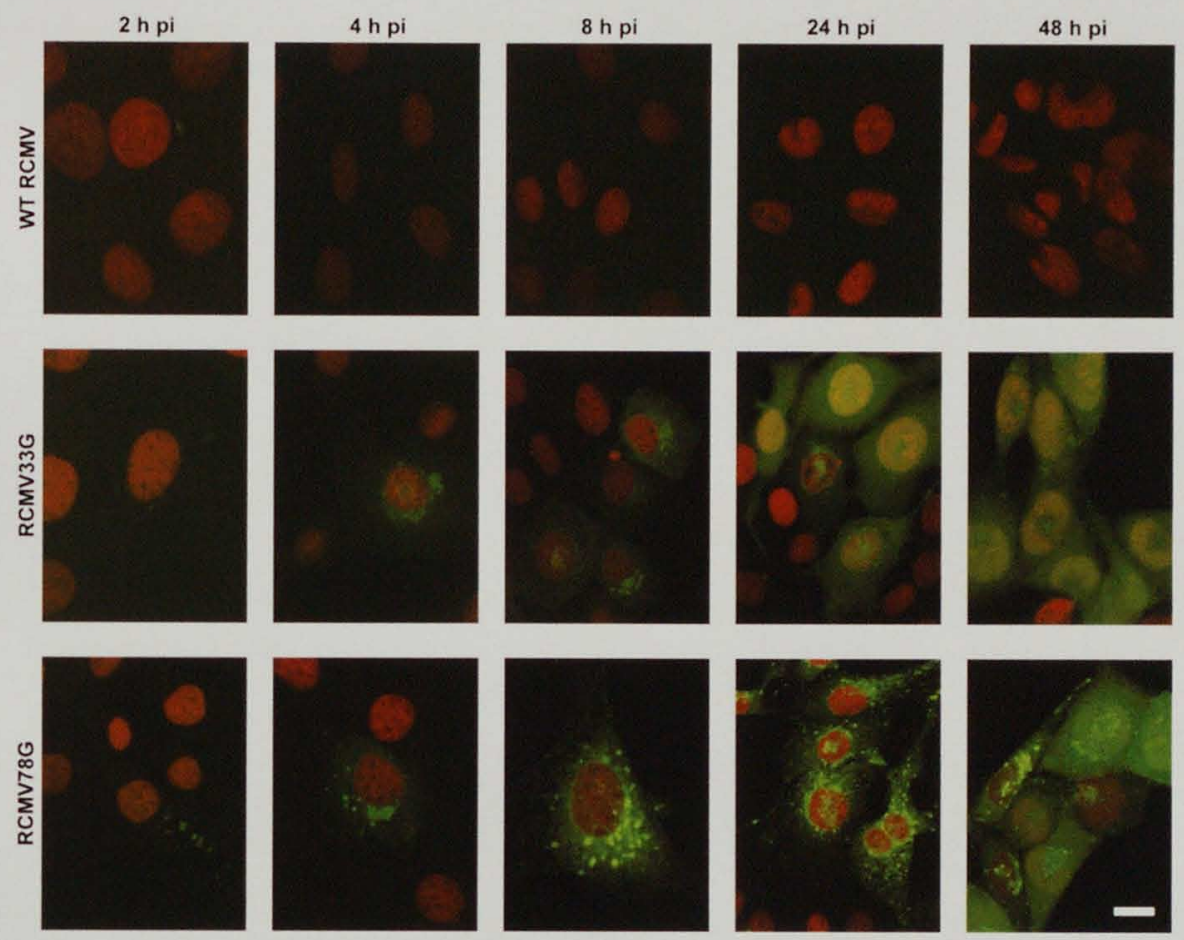

Figure 4. Confocal laserscan micrographs of Rat2 fibroblasts infected with either WT RCMV (top row), RCMV33G (middle row) or RCMV78C (lower row). Micrographs were taken at the times indicated above each column. Prior to analysis, the cells were stained with propidium iodide (red) to indicate the cell nuclei. EGFP signals are shown in green. The scale bar indicates $10 \mu \mathrm{m}$. 
To further characterize the expression of pR33-EGFP and pR78-EGFP by the recombinant viruses, Western blot analysis was performed. First, protein extracts were made from REF infected with either RCMV33G or RCMV78G. Subsequently, the extracts were electrophoresed and blotted onto nitrocellulose filters, which were developed using commercial anti-EGFP antibodies. Contrary to the evident green fluorescent signal in RCMV33G-infected cells that was seen by confocal microscopy (Fig. 4), we observed a weak EGFP-specific signal in extracts of these cells using Western blot analysis (Fig. 5 , lane 2). Accordingly, we were previously unable to detect any EGFP signal in extracts of transfected cells expressing pR33-EGFP by Western blot analysis, whereas the expression of this protein could easily be monitored microscopically [18]. We hypothesize that pR33EGFP forms large, insoluble aggregates, which do not efficiently enter the polyacrylamide gels. Nevertheless, the weak EGFP band in Fig. 5 corresponds to a protein with an estimated molecular mass of approximately $73 \mathrm{kD}$, which is similar to the predicted molecular mass of pR33-EGFP (71 kD). This suggests that the R33-EGFP fusion gene within the RCMV33C genome expresses a full-length pR33-EGFP fusion protein.

In contrast to pR33-EGFP, pR78-EGFP could readily be detected by Western blot analysis. By using anti-EGFP antibodies, a major polypeptide with an estimated molecular mass of approximately $75 \mathrm{kDa}$ was observed in extracts from RCMV78G-infected cells (Fig. 5, lane 3). The estimated molecular mass of this major protein species corresponds with the calculated molecular mass of the pR78-EGFP fusion protein $(78 \mathrm{kDa})$. Besides the $\sim 75-\mathrm{kDa}$ protein, several minor species of high molecular mass are also observed in extracts from RCMV78G-infected cells. It is likely that these polypeptides represent multimeric forms of pR78-EGFP, since multimerisation is a phenomenon common to both GPCRs and green fluorescent proteins [31, 35].

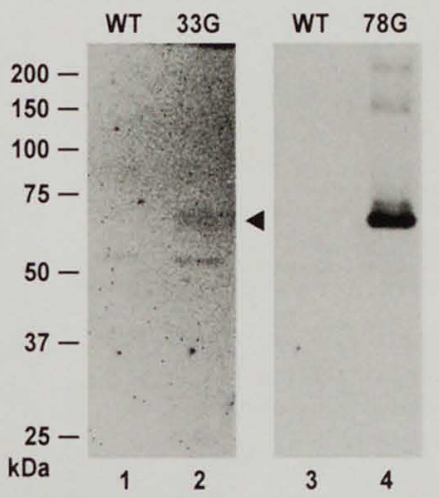

Figure 5. Expression of $p R 33-E G F P$ and $p R 78-E G F P$ in RCMV33G- and RCMV78G-infected REF, respectively. The figure shows a chemiluminescence exposure of a Western blot treated with polyclonal antibodies directed against EGFP. The samples were taken at 6 days pi from REF infected at an moi of 0.01 with either WT RCMV (lane 1), RCMV33G (lane 2) or RCMV78G (lane 3). Sizes of protein markers are shown to the left of the blot (in $\mathrm{kDa}$ ). WT, 33G and 78G denote protein extracts prepared from REF infected with WT RCMV, RCMV33G and RCMV78G, respectively. 

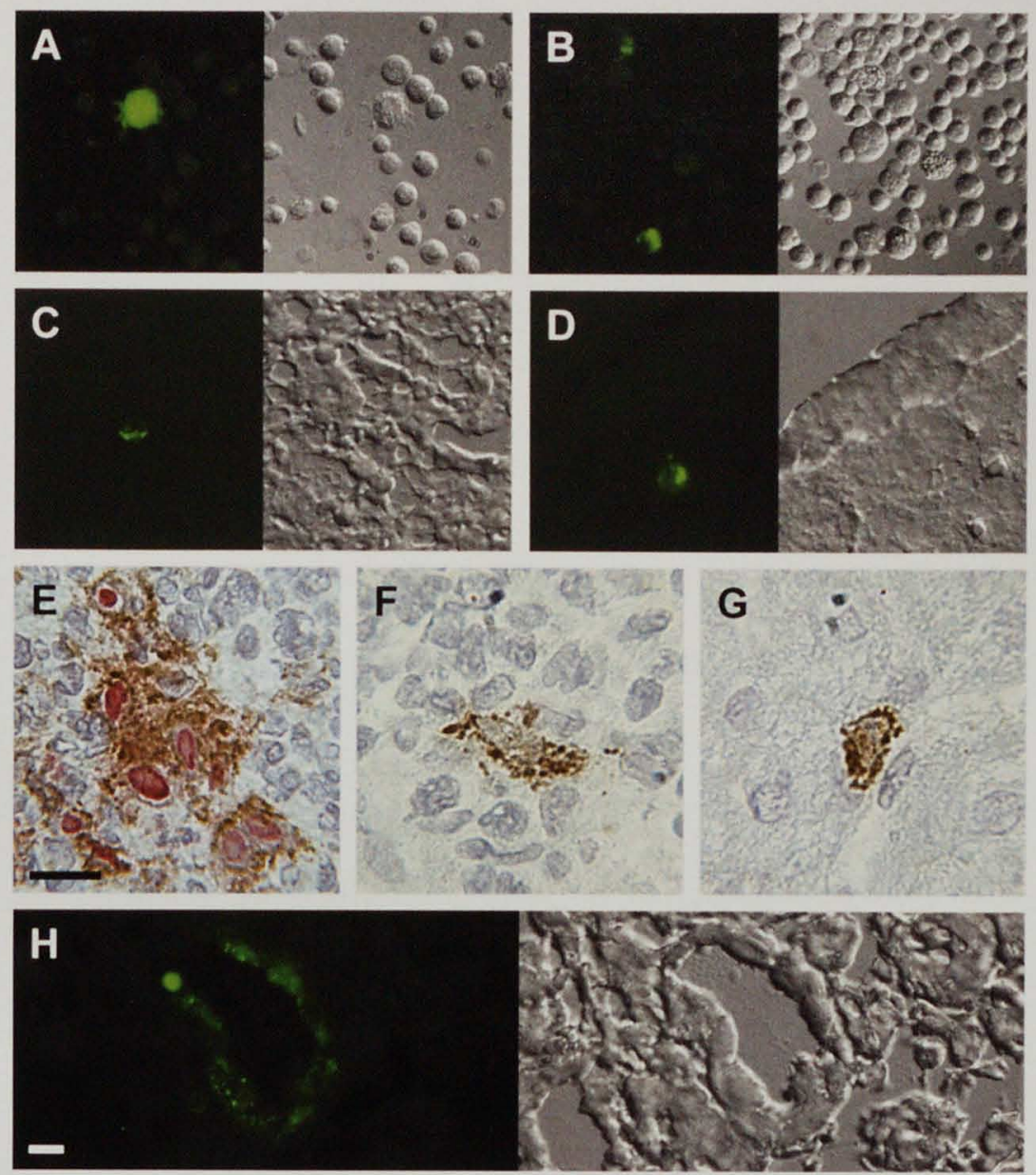

Figure 6. Expression of $p R 44, p R 33-E G F P$ and $p R 78$-EGFP in several organs from rats infected with either RCMV33G or RCMV78G. (A) Expression of pR33-EGFP in bone marrow cells from RCMV33G-infected rats. The figure shows photographs taken by fluorescence $(490 \mathrm{~nm})$ (left-hand panel) and phase contrast (right-hand panel) microscopy. (B) Expression of pR78-EGFP in bone marrow cells from RCMV78G-infected rats. Cells were photographed as described in Fig. 6A. (C) Expression of pR78-EGFP in the spleen. Sections $(6 \mu \mathrm{m})$ were photographed as described in Fig. 6A. (D) Expression of pR78-EGFP in the liver. Sections were photographed as described in Fig. 6A. (E) Expression of pR44 and pR78-EGFP in the spleen. Sections were treated with both antipR44 and anti-EGFP polyclonal antibodies. Anti-pR44 antibodies were detected using anti-mouse IgG antibodies conjugated with alkaline phosphatase (AP). Anti-EGFP antibodies were detected using anti-rabbit IgG antibodies conjugated with horseradish peroxidase (HRP). AP stainings were performed with Fast Red (red) and HRP stainings with diaminobenzidine (brown). (F) Expression of pR78-EGFP in pR44-negative cells in the spleen of RCMV78G-infected rats. Sections were stained as in Fig. 6E. (G) Expression of pR78-EGFP in pR44-negative cells in the liver of RCMV78G-infected rats. Sections were stained as described in Fig. 6E. $(\mathrm{H})$ Expression of pR78-EGFP in salivary gland ductal epithelial cells of RCMV78G-infected rats. Sections were photographed as described in Fig. 6A. The micrographs shown in Figures $(A)$ to $(G)$ were taken from samples extracted at day $5 \mathrm{pi}$, whereas the micrograph shown in $(\mathrm{H})$ was taken from material extracted at day $28 \mathrm{pi}$. The scale bars indicate $20 \mu \mathrm{m}$. The scale bar in Fig. $6 \mathrm{E}$ also applies to Fig. $6 \mathrm{~F}$ and 6G. The scale bar in Fig $6 \mathrm{H}$ also applies to Fig 6A-6D 
Dissemination and replication of RCMV33G and RCMV78G in immunocompromised rats at 5 days after infection

To monitor the dissemination and replication of strains RCMV33G and RCMV78G, the following animal experiment was performed. Five groups of 7-weeks old, immunocompromised rats were infected with either WT RCMV, RCMV33G, RCMV $\triangle R 33$, RCMV78G, or RCMV $\triangle R 78 \mathrm{a}$. At day 5 and day 28 pi, 6 rats from each group were sacrificed and dissected. The salivary glands, spleen, kidneys, liver, lungs, heart, pancreas, and thymus were extracted and analysed by immunohistochemistry, plaque assay and quantitative PCR.

First, we set out to examine expression of either pR33-EGFP of pR78-EGFP in RCMV33G-and RCMV78G-infected rats, respectively. This was done by direct fluorescence microscopy and immunohistochemical analysis using both anti-pR44 antibodies (directed against an RCMV early-phase protein; [20]) and anti-EGFP antibodies. We were unable to detect pR33-EGFP expression in solid organs, such as spleen and liver, at day 5 pi. However, pR33-EGFP fluorescence was evident in cells from femural bone marrow suspensions (Fig. 6A). These suspensions yielded $69 \pm 50$ (mean \pm standard deviation) pR33-EGFPpositive cells per $10^{6}$ bone marrow cells, similar to bone marrow suspensions from RCMV78G-infected rats, which yielded $121 \pm 72$ pR78-EGFP-positive cells per $10^{6}$ bone marrow cells. In contrast to the absence of pR33-EGFP-specific signals in spleen and liver tissue, overt expression of pR78-EGFP could be observed in these tissues in RCMV78Ginfected rats (Fig. 6C and 6D). Additionally, in double-stained sections of the spleen, pR78-EGFP could be detected in each pR44-positive cell (Fig. 6E), but also in pR44negative cells in both spleen (Fig. 6F) and liver (Fig. 6G). Similar to what was observed in RCMV78G-infected REF in vitro, the subcellular distribution of $p R 78$-EGFP in either bone marrow cells, or spleen or liver sections appeared to be granular and perdominantly perinuclear.

Next, the titters of infectious virus was determined by plaque assy. As shown in Table 2 , at day 5 pi, significant amounts of infectious virus were detected predominantly in the spleen. Interestingly, while virus was readily detectable in spleen samples from WT RCMV, RCMV33G-, or RCMV $\triangle R 33$-infected rats, virus could not be detected in spleen samples from RCMV78G-and RCMV $\triangle R 78$-infected rats (Fig. 7A and Table 2). This indicated that strains RCMV78C and RCMV $\triangle R 78 \mathrm{a}$ are unable to either enter or replicate in the spleen. To further investigate this phenomenon, the viral DNA load in the spleen was determined by quantitative PCR. Surprisingly, the viral DNA concentrations in spleen did

Table 2. The presence of infectious RCMV and viral DNA in organs from infected rats

\begin{tabular}{|c|c|c|c|c|c|c|c|c|c|c|c|c|c|c|}
\hline \multirow[b]{3}{*}{ Virus } & \multicolumn{12}{|c|}{ Day 5 p.i. } & \multicolumn{2}{|c|}{ Day 28 p.i. } \\
\hline & \multicolumn{2}{|c|}{ Spleen } & \multicolumn{2}{|c|}{ Kidney } & \multicolumn{2}{|c|}{ Liver } & \multicolumn{2}{|c|}{ Pancreas } & \multicolumn{2}{|c|}{ Thymus } & \multicolumn{2}{|c|}{$S_{\mathbf{B}}$} & \multicolumn{2}{|c|}{$S_{B}$} \\
\hline & PA & PCR & PA & PCR & PA & PCR & $P A$ & PCR & PA & $P C R$ & $P A$ & PCR & PA & PCR \\
\hline WT RCMV & $5 / 6$ & $6 / 6$ & $0 / 3$ & $2 / 3$ & $2 / 6$ & $3 / 3$ & $0 / 1$ & $3 / 3$ & $2 / 6$ & $1 / 3$ & $0 / 6$ & $3 / 6$ & $6 / 6$ & $4 / 4$ \\
\hline $\operatorname{RCMV} 336$ & $6 / 6$ & $4 / 4$ & $0 / 3$ & $3 / 3$ & $1 / 6$ & $3 / 3$ & $1 / 2$ & $2 / 3$ & $5 / 6$ & $2 / 3$ & $0 / 6$ & $4 / 6$ & $0 / 6$ & $1 / 6$ \\
\hline RCMV $\triangle 33$ & $5 / 6$ & $6 / 6$ & $0 / 3$ & $3 / 3$ & $0 / 6$ & $3 / 3$ & ND & $3 / 3$ & $1 / 6$ & $2 / 3$ & $0 / 6$ & $0 / 6$ & $0 / 6$ & $0 / 6$ \\
\hline RCMV78C & $0 / 6$ & $6 / 6$ & $0 / 6$ & $3 / 3$ & $0 / 6$ & $3 / 3$ & $2 / 5$ & $0 / 3$ & $3 / 5$ & $2 / 3$ & $0 / 6$ & $4 / 6$ & $6 / 6$ & $5 / 5$ \\
\hline$R C M V \triangle R 78 a$ & $0 / 6$ & $5 / 5$ & $0 / 3$ & $3 / 3$ & $0 / 6$ & $3 / 3$ & $4 / 6$ & $1 / 3$ & $0 / 6$ & $3 / 3$ & $0 / 6$ & $2 / 6$ & $4 / 6$ & $5 / 5$ \\
\hline
\end{tabular}

The ratios indicate the number of organs found positive for virus, relative to the total amount of organs tested (one organ per rat). Abbreviations: $P A$ $=$ plaque assay: $S_{g}=$ salivary gland; $N D=$ not determined 
not differ significantly between any of the five experimental groups (Fig. 7B). Taken together, these observations indicate that although RCMV78G and RCMV $\triangle R 78 \mathrm{a}$ disseminate to the spleen with an efficiency similar to that of WT RCMV, these recombinant strains are not as efficient as WT virus in producing infectious virus. We therefore conclude that the R78 gene is important for efficient replication of RCMV in the spleen, and that, in accordance with our previous findings, R78-EGFP is not able to functionally replace $R 78$.

Dissemination and replication of RCMV33G and RCMV78G in immunocompromised rats at 28 days after infection

Tissue sections from rat organs sampled at day 28 pi were stained with anti-pR44 and anti-EGFP antibodies. At this time point, both spleen and kidney sections from rats infected with WT RCMV or either of the mutant strains were found to be negative for $p R 44$ and either pR33-EGFP or PR78-EGFP. In contrast, salivary glands were found to harbor pR44positive cells in rats infected with WT RCMV, RCMV78G and RCMV $\triangle R 78 \mathrm{a}$, but not in rats infected with RCMV33G or RCMV $\triangle R 33$ (data not shown). Additionally, salivary gland sections from RCMV78G-infected rats were PR78-EGFP-positive by fluorescence microscopy (Fig $6 \mathrm{H}$ ). Similar to what was observed in RCMV78G-infected REF in vitro, the subcellular distribution of pR78-EGFP in salivary gland epithelial cells appeared to be granular and perdominantly perinuclear.

At day 28 pi, the salivary glands were the only sites to harbor infectious virus (Table 2). High virus titres were found in the salivary glands of WT RCMV-, RCMV78G- and RCMV $\triangle R 78 \mathrm{a}$-infected rats (Fig. 7C). These titers did not differ significantly between the

A

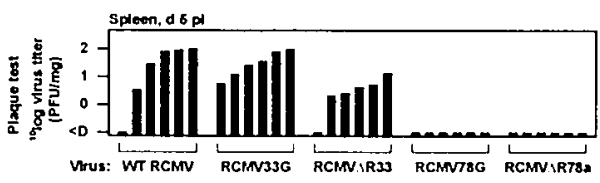

c

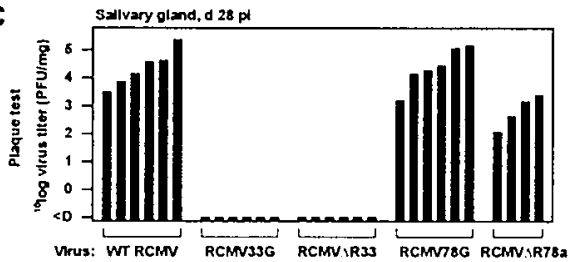

B

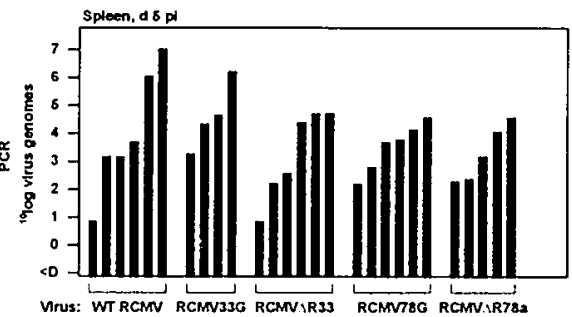

D

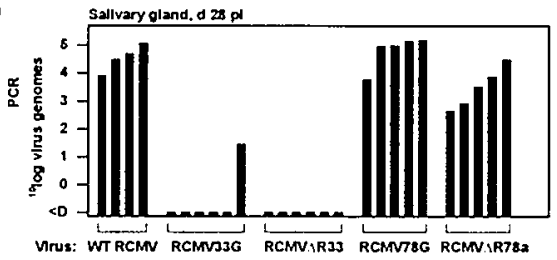

Figure 7. The $R 78$ gene is important for efficient RCMV replication in the spleen of immunocompromised infected rats. (A) Virus titres in the spleen at day 5 after infection of rats with either WT RCMV. RCMV33G, RCMV $\triangle R 33$. RCMV78G, or RCMV $\triangle R 78$ a. Each bar represents the result from a single rat. (B) Amount of viral genome copies in samples similar to those analysed in (A). (C) Virus titres in salivary glands at day 28 after infection of rats with either of the RCMV strains. (D) Amount of viral genome copies in samples similar to those analysed in (C). $\angle D$, below detection level (for the plaque assay: $10^{\prime \prime}$ $\mathrm{PFU} / \mathrm{mg}$ tissue, for PCR: $10^{-1}$ viral genome copies/ $\mu \mathrm{g}$ tissue DNA). 
three experimental groups. In accordance with previous findings [2], infectious virus could not be detected in salivary gland samples from RCMV $\triangle R 33$-infected rats (Table 2 and Fig. 7C). Surprisingly, we were also unable to detect infectious virus in salivary gland samples of RCMV33G-infected animals (Table 2 and Fig. 7C). Thus, like RCMV $\triangle$ R33, RCMV33G is unable to either enter or replicate efficiently in the salivary glands. To further study the presence of the recombinant viruses in the salivary glands, viral genomic DNA levels were assessed by quantitative PCR (Table 2 and Fig. 7D). Fig. 7D shows that approximately $4 \times 10^{5}$ copies of viral DNA per $\mu \mathrm{g}$ tissue were found in the salivary glands from WT RCMV-, RCMV78G-, and RCMVAR78a-infected rats. The viral DNA loads between the three experimental groups did not differ significantly. Interestingly, viral DNA could only be detected in one of the six RCMV33G-infected rats and none of the RCMV $\triangle$ R33infected animals (Fig. 7D). Moreover, the virus titre within the single, RCMV33G-positive salivary gland sample was very low, i.e. 27 copies of viral DNA per $\mu g$ tissue (Fig. 7D). Taken together, these data show that strain RCMV33G is defective in replication in the salivary glands.

We conclude that both strain RCMV33G and strain RCMV78G have similar in vivo replication characteristics as their corresponding null mutant viruses (RCMVR33 and RCMVR78, respectively). Although this conclusion largely disqualifies RCMV33G and RCMV78G as useful tools for studying pR33 and pR78 expression in vivo, the characterization of these recombinant strains has revealed the crucial role of the $R 78$ gene, which is conserved among all betaherpesviruses, in the production of infectious $\mathrm{RCMV}$ in the spleen. In addition, these studies have underlined the essential function of the second conserved GPCR gene of RCMV, R33, in salivary gland tropism.

\section{Discussion}

EGFP has proven a versatile fusion partner for studying expression and trafficking of a variety of proteins, both in vitro and in vivo. Among the proteins that have previously been characterized as EGFP fusions are three alphaherpesvirus proteins, i.e. herpes simplex virus 1 (HSV-1) major tegument protein VP22 [16], HSV-1 viral envelope glycoprotein gH [23] and the equine herpesvirus 1 (EHV-1) UL34 gene product [27]. The genes encoding the EGFP fusion proteins were shuttled into the viral genomes, after which the expression of the fusions was investigated in vitro. In light of our interest in the GPCR homologues of RCMV, pR33 and $p R 78$, and because antibodies against these proteins are currently lacking, we decided on pursuing an approach to study both RCMV GPCR homologues as fusions with EGFP, in a similar fashion as described for HSV-1 VP22 and gH as well as for the EHV-1 UL34 gene product. Thus, two recombinant RCMV strains were constructed. RCMV33G and RCMV78G, which express PR33-EGFP and PR78-EGFP, respectively, instead of their native counterparts. To our knowledge, RCMV33G and RCMV78G represent the first betaherpesvirus strains that express EGFP-fused versions of viral proteins.

Previously, we reported that pR33 and pR33-EGFP possess similar constitutive signaling properties in vitro [18]. Based on these results, we anticipated that the fusion of both pR33 and pR78 to EGFP would not affect the function of these proteins. However, we found strain RCMV33G to differ from WT virus in one major, but significant characteristic: this recombinant strain is unable to either enter or replicate in the salivary glands of infected rats. A similar phenotype has previously been attributed to strain RCMV $\triangle \mathrm{R} 33$, 
which lacks a functional R33 gene [2]. Our current data therefore corroborate the notion that RCMV R33, like its homologue from MCMV [14], is essential for salivary gland tropism of the virus. Additionally, we conclude that the R33-EGFP gene is not able to functionally replace its native counterpart in vivo. Putative causes for the deficit of strain RCMV33G are the following. (i) The transcription of R33-EGFP and surrounding genes may be different from that of their native counterparts. Indeed, transcriptional analysis of the genomic region of R33-EGFP and R33 indicated that there are clear differences between RCMV33G and WT virus, not only in the expression of R33(-EGFP), but also in transcription of the R34 gene, which is located downstream of R33. However, given the similarity between strains RCMV33G and RCMV $\triangle R 33$ in their in vivo phenotypes, it is unlikely that these phenotypes are caused by aberrant expression of R34. (ii) Another difference between WT RCMV and RCMV33G in salivary gland tropism may be an altered subcellular distribution of $p R 33-E G F P$ in comparison with $p R 33$. Due to the unavailability of antiPR33 antibodies, this hypothesis cannot be tested yet. (iii) In comparison with pR33, PR33-EGFP may be hindered in its interaction with cellular proteins due to the presence of the EGFP moiety at its $C$ terminus. As previously noted, we did not observe any differences in the signaling properties of pR33 and pR33-EGFP in vitro [18]. However, it is possible that these proteins carry out other, or additional, signaling activities, and bind to different protein partners, in vivo. An example of a process in which pR33 and pR33EGFP may potentially differ is desensitisation, which serves to modulate GPCR activity by modification of amino acid residues at the (intracellular) $C$ terminus [33]. The $C$-terminal EGFP tag of pR33-EGFP could mask critical residues within the pR33 sequence from regulatory proteins responsible for desensitisation of the receptor. (iv) Finally, the expression of the pR33-EGFP fusion proteins may induce immune mechanisms that do not occur during WT RCMV infection. Similar mechanisms may also be induced by the expression of the neo gene by RCMV33G. Nevertheless, while each of the recombinant RCMV strains in our laboratory has been generated using the same neo expression cassette, each of these strains exhibits clear phenotypic differences. In addition, one of these mutants, RCMVAr144 [4], could not be distinguished phenotypically from WT RCMV, both in rat survival and viral dissemination experiments. We therefore deem it unlikely that the expression of the neo gene would induce additional immune mechanisms that are not seen during WT RCMV infection.

Although RCMV33G replicates with similar efficiency as WT RCMV in spleen and liver at day 5 pi, pR33-EGFP could not be detected by immunohistochemistry using antiEGFP-antibodies in spleen or liver samples from RCMV33G-infected rats. In contrast, pR33-EGFP is markedly expressed in bone marrow cells from these rats. Based on these observations, it could be hypothesized that $R 33$ is specifically expressed in bone marrow cells at early time points of infection in vivo. Whether or not this expression reflects the expression of native R33 by the WT virus is currently unknown. Our future studies will therefore be directed at (i) the generation of anti-pR33 antibodies, which has hitherto been unsuccessful, and (ii) the construction of RCMV strains expressing GPCR homologs with alternative, smaller protein tags, such as FLAG. In these studies, an important aim will be to address how pR33 determines the salivary gland tropism of RCMV, and how this relates to RCMV virulence and putative expression of the protein in bone marrow.

The recombinant RCMV strain expressing PR78-EGFP was found to be attenuated, albeit moderately, both in vitro and in vivo. In cell culture, RCMV78G produced 3- to 4 fold lower virus titres than WT RCMV in the culture medium. By comparison, an R78- 
deleted virus strain, RCMV $\mathrm{R} 78 \mathrm{a}$, produced approximately 50 times lower virus titres than WT RCMV (this study, and [3]). Similarly, an MCMV strain with a deletion of the $M C M V$ homologue of $R 78, M 78$, was reported to be at least 50 times less effective in producing infectious virus [29]. Taken together, these results indicate that the expression of pR78-EGFP by strain RCMV78G can only partly complement the absence of the native R78 gene. The strong similarity between WT RCMV and RCMV78G in transcription of R78(-EGFP) and neighboring genes in cell culture, indicates that the differences between these strains in viral replication are not caused by differences in transcription, but rather by dissimilarities in other processes, such as translation, subcellular distribution, proteinprotein interactions and/or post-translational modification of pR78(-EGFP).

The ability of pR78-EGFP to only partially functionally replace the native $P R 78$ protein, was also observed in vivo. The most dramatic difference between WT RCMV and RCMV78G was seen at day 5 pi in the spleen of infected rats. While infectious virus was readily detectable in the spleen of all WT RCMV-infected rats, virus was not detected in the spleen of any of the RCMV78G-infected rats. Additionally, infectious virus was not found in the spleens of RCMV $R$ R78a-infected animals. Significant differences between RCMV and RCMV78G in the production of infectious virus were not seen in any of the other investigated organs. Although we previously studied the differences between WT $R C M V$ and RCMV $\triangle R 78 a$ in viral dissemination [3], the replication defect of RCMV $\triangle R 78 a$ in the spleen has hitherto remained unnoticed. Since similar viral DNA levels were found in the spleen of WT RCMV-, RCMV $\triangle R 78 \mathrm{a}$ - and RCMV78G-infected animals, we concluded that (i) R78 plays a crucial role in the production of infectious RCMV in the spleen, and (ii) R78-EGFP does not function (as efficiently) as R78 during infection in the spleen. We hypothesize that $R 78$ does not play a role in viral dissemination or viral DNA replication, but rather functions in intracellular processes following DNA synthesis, such as virion assembly or egress. Previously, we reported that a different cell morphology was seen in cultures infected with RCMV $\triangle R 78$ a as compared to cultures infected with WT virus [3]. Taken together, our findings indicate that $p R 78$ may play a role in stabilizing intra- and/or intercellular structures required for optimal release of virions from infected cells.

It is interesting to note, that our data on viral dissemination differ from those reported by Oliveira et al. in a study of an M78-deleted MCMV strain [29]. This strain was shown to replicate less efficiently than WT MCMV not only in spleen, but also in salivary glands and liver. We currently do not have an explanation for this discrepancy, although it is clear that $p R 78$ and the $M 78$ gene product may show differences in function as a consequence of differences between their predicted amino acid sequences [37]. Challenges for future studies will be (i) to elucidate the putative intracellular pathways by which pM78, and maybe also pR78, mediate the accumulation of IE transcripts, (ii) to characterize how the activities of these proteins stimulate the production of infectious virus in vitro, and (iii) to identify the processes that determine the R78-dependent spleen tropism of RCMV.

\section{Acknowledgements}

S.J.F.K. and P.S.B. contributed equally to this work. C.V. is supported by a fellowship of the Royal Netherlands Academy of Arts and Sciences (KNAW). Y.K.G. and K.W.R.V.C are supported by grants $901-02-224$ and $901-02-239$, respectively, from the Netherlands 
Organisation for Scientific Research to C.V. We thank Jos Broers for assisting with confocal laserscan microscopy, and Rien Blok and Frank Stassen for critically reading the manuscript.

\section{References}

1. Bahr, U., and Darai, G. (2001). Analysis and characterization of the complete genome of tupaia (tree shrew) herpesvirus. J. Virol. 75, 4854-4870.

2. Beisser, P.S., Vink, C., Van Dam, J.G., Grauls, G., Vanherle, S.J., and Bruggeman, C.A. (1998). The R33 G protein-coupled receptor gene of rat cytomegalovirus plays an essential role in the pathogenesis of viral infection. J. Virol. 72, 2352-2363.

3. Beisser, P.S., Grauls, G., Bruggeman, C.A., and Vink, C. (1999). Deletion of the R78 $G$ protein-coupled receptor gene from rat cytomegalovirus results in an attenuated, syncytium-inducing mutant strain. J. Virol. 73, 7218-7230.

4. Beisser, P.S., Kloover, J.S., Grauls, G.E., Blok, M.J., Bruggeman, C.A., and Vink, C. (2000). The $\mathrm{r} 144$ major histocompatibility complex class I-like gene of rat cytomegalovirus is dispensable for both acute and long-term infection in the immunocompromised host. J. Virol. 74, 1045-1050.

5. Beuken, E., Grauls, G., Bruggeman, C.A., and Vink, C. (1999). The rat cytomegalovirus R32 gene encodes a virion-associated protein that elicits a strong humoral immune response in infected rats. J. Gen. Virol. 80B, 2719-2728.

6. Broers, J.L., Machiels, B.M., Van Eys, G.J., Kuijpers, H.J., Manders, E.M., Van Driel, R., and Ramaekers, F.C. (1999). Dynamics of the nuclear lamina as monitored by GFP-tagged A-type lamins. J. Cell Sci. 112, 3463-3475.

7. Brown, T. (1993). Analysis of DNA sequences by blotting and hybridization. In Current protocols in molecular biology, pp. 4.2.1-4.2.15. Edited by F.M. Ausubel, R. Brent, R.E. Kingston, D.D. Moore, J.G. Seidman, J.A. Smith, and K. Struhl. New York, NY, USA: John Wiley \& Sons.

8. Brown, T., and Mackey, K. (1997). Analysis of RNA by Northern blot and slot blot hybridization. In Current protocols in molecular biology, pp. 4.9.1-4.9.16. Edited by F.M. Ausubel, R. Brent, R.E. Kingston, D.D. Moore, J.G. Seidman, J.A. Smith, and K. Struhl. New York, NY, USA: John Wiley \& Sons.

9. Bruggeman, C.A., Meijer, H., Dormans, P.H.J., Debie, W.H.M., Grauls, G.E.L.M., and van Boven, C.P.A. (1982). Isolation of a cytomegalovirus-like agent from wild rats. Arch. Virol. 73, 231-241.

10. Bruggeman, C.A., Meijer, H., Bosman, F, and van Boven, C.P.A. (1985). Biology of rat cytomegalovirus infection. Intervirology 24,1-9.

11. Chee, M.S., Bankier, A.T., Beck, S., Bohni, R., Brown, C.M., Cerny, R., Horsnell, T., Hutchison 3rd, C.A., Kouzarides, T., Martignetti, J.A., Preddie, E., Satchwell, S.C., Tomlinson, P., Weston, K.M., and Barrell, B.G. (1990). Analysis of the protein-coding content of the sequence of human cytomegalovirus strain AD169. Curr. Top. Microbiol. Immunol. 154, 125-169.

12. Chee, M.S., Satchwell, S.C., Preddie, E., Weston, K.M., and Barrell, B.G. (1990). Human cytomegalovirus encodes three $G$ protein-coupled receptor homologues. Nature 344, 774-777. 
13. Damoiseaux, J.G.M.C., Döpp, E.A., Calame, W., Chao, D., MacPherson, G.G., and Dijkstra, C.D. (1994). Rat macrophage lysosomal membrane antigen recognized by monoclonal antibody ED1. Immunology 83, 140-147.

14. Davis-Poynter, N.J., Lynch, D.M., Vally, H., Shellam, G.R., Rawlinson, W.D., Barrell, B.G., and Farrell, H.E. (1997). Identification and characterization of a G protein-coupled receptor homolog encoded by murine cytomegalovirus. J. Virol. 71, 1521-1529.

15. Dijkstra, C.D., Döpp, E.A., Joling, P., and Kraal, G. (1985). The heterogeneity of mononuclear phagocytes in lymphoid organs: distinct macrophage subpopulations in the rat recognized by monoclonal antibodies ED1, ED2 and ED3. Immunology 54, 589-599.

16. Elliot, E., and O'Hare, P. (1999). Live-cell analysis of a green fluorescent proteintagged herpes simplex virus infection. J. Virol. 73, 4110-4119.

17. Gompels, U., Nicholas, A.J., Lawrence, G., Jones, M., Thomson, B.J., Martin, M.E., Efstathiou, S., Craxton, M., and Macaulay, H.A. (1995). The DNA sequence of human herpesvirus-6: structure, coding content and genome evolution. Virology 209, 2951.

18. Gruijthuijsen, Y.K., Casarosa, P., Kaptein, S.J.F., Broers, J.L., Leurs, R., Bruggeman, C.A., Smit, M.I., and Vink, C. (2002). The rat cytomegalovirus R33-encoded G proteincoupled receptor signals in a constitutive fashion. J. Virol. 76, 1328-1338.

19. Isegawa, Y., Pin, Z., Nakano, K., Sugimoto, N., and Yamanishi, K. (1998). Human herpesvirus 6 open reading frame $\cup 12$ encodes a functional beta-chemokine receptor. J. Virol. 72, 6104-6112.

20. Kaptein, S.J.F., Beuken, E., Grauls, G.E.L.M., Bruggeman, C.A., and Vink, C. (2001). Rat cytomegalovirus open reading frame $R 44$ is an early-late gene that encodes a nuclear protein. Arch. Virol. 146, 2211-2218.

21. Laemmli, U.K. (1970). Cleavage of structural proteins during the assembly of the head of bacteriophage T4. Nature 227, 680-685.

22. Liu, Y., and Biegalke, B.J. (2001). Characterization of a cluster of late genes of guinea pig cytomegalovirus. Virus Genes 23, 247-256.

23. Lorentzen, E.U., Eing, B.R., Hafezi, W., Manservigi, R., and Kuhn, J.E. (2001). Replication-competent herpes simplex virus type 1 mutant expressing an autofluorescent glycoprotein $\mathrm{H}$ fusion protein. Intervirology 44, 232-242.

24. Margulies, B.J., Browne, H., and Gibson, W. (1996). Identification of the human cytomegalovirus $C$ protein-coupled receptor homologue encoded by UL33 in infected cells and enveloped virus particles. Virology 225, 111-125.

25. Meijer, H., Dreesen, J.C., and van Boven, C.P. (1986). Molecular cloning and restriction endonuclease mapping of the rat cytomegalovirus genome. J. Gen. Virol. 67,13271342.

26. Milne, R.S., Mattick, C., Nicholson, L., Devaraj, P., Alcami, A., and Gompels, U.A. (2000). RANTES binding and down-regulation by a novel human herpesvirus- 6 beta chemokine receptor. J. Immunol. 164, 2396-2404.

27. Neubauer A., Rudolph, J., Brandmüller, C., Just, F.T., and Osterrieder, N. (2002). The equine herpesvirus 1 UL34 gene product is involved in an early step in virus egress and can be efficiently replaced by a UL34-GFP fusion protein. Virology 300,189204.

28. Nicholas J. (1996). Determination and analysis of the complete nucleotide sequence of human herpesvirus. J. Virol. 70, 5975-5989. 
29. Oliveira, S.A., and Shenk, T.E. (2001). Murine cytomegalovirus M78 protein, a G protein-coupled receptor homologue, is a constituent of the virion and facilitates accumulation of immediate-early viral mRNA. Proc. Natl. Acad. Sci. USA 98, 32373242.

30. Rawlinson, W.D., Farrell, H.E., and Barrell, B.G. (1996). Analysis of the complete DNA sequence of murine cytomegalovirus. J. Virol. 70, 8833-8849.

31. Rios, C.D., Jordan, B.A., Gomes, I., and Devi, L.A. (2001). G-protein-coupled receptor dimerization: modulation of receptor function. Pharmacol. Ther. 92, 71-87.

32. Seidman, J.G. (1998). Immunohistochemistry. In Current protocols in molecular biology, pp. 14.6.1-14.6.13. Edited by F.M. Ausubel, R. Brent, R.E. Kingston, D.D. Moore, J.G. Seidman, J.A. Smith, and K. Struhl. New York, NY, U S A: John Wiley \& Sons.

33. Sibley, D.R., and Lefkowitz, R.J. (1985). Molecular mechanisms of receptor desensitization using the beta-adrenergic receptor-coupled adenylate cyclase system as a model. Nature 317, 124-129.

34. Stals, F.S., Bosman, F., van Boven, C.P., and Bruggeman, C.A. (1990). An animal model for therapeutic intervention studies of $C M V$ infection in the immunocompromised host. Arch. Virol. 114, 91-107.

35. Tsien, R.Y. (1998). The green fluorescent protein. Annu. Rev. Biochem. 67, 509544.

36. Vink, C., Beuken, E., and Bruggeman, C.A. (1996). Structure of the rat cytomegalovirus genome termini. J. Virol. 70, 5221-5229.

37. Vink C., Beuken, E., and Bruggeman, C.A. (2000). Complete DNA sequence of the rat cytomegalovirus genome. J. Virol. 74, 7656-7665.

38. Waldhoer, M., Kledal, T.N., Farrell, H., and Schwartz, T.W. (2002). Murine cytomegalovirus (CMV) M33 and human CMV US28 receptors exhibit similar constitutive signaling activities. J. Virol. 76, 8161-8168. 


\section{CHAPTER 4}

The r131 Gene of Rat Cytomegalovirus Encodes a Proinflammatory CC Chemokine Homolog which is Essential for the Production of Infectious Virus in the Salivary Glands

Suzanne J.F. Kaptein, Koen W.R. van Cleef, Yvonne K. Gruijthuijsen, Erik V.H.

Beuken, Lieve Van Buggenhout, Patrick S. Beisser, Frank R.M. Stassen, Cathrien A. Bruggeman, Cornelis Vink

Virus Genes 2004, 29, 43-61 


\section{Abstract}

Rat cytomegalovirus (RCMV) possesses two adjacent genes, $r 131$ and $r 129$, which have the potential to encode CC chemokine homologs. Interestingly, the amino acid sequences encoded by both genes show similarity to the sequence of the murine CMV (MCMV) MCK-2 protein, which is encoded by the m131/129 gene. In order to study the significance of the 131 gene in the pathogenesis of RCMV infection, we generated two different virus strains in which the 131 open reading frame is disrupted. Replication of these null mutant strains, designated RCMV $\triangle \mathrm{r} 131 \mathrm{a}$ and RCMV $\mathrm{r} 131 \mathrm{~b}$, was evaluated in vitro and in vivo. Both strains were found to replicate with a similar efficiency as wild-type (WT) RCMV in vitro. However, in contrast to WT virus, neither RCMV $\triangle$ r131a nor RCMV $\triangle$ r131b established a high-titer infection in the salivary glands of immunocompromised rats. Furthermore, in a local, rat footpad infection model, both recombinant viruses induced a significantly lower amount of paw swelling than did WT RCMV. Also, a higher number of infiltrating macrophages was observed in paws infected with WT RCMV than in those infected with the recombinants. Taken together, these results suggest that $r 131$ (i) promotes inflammation at initial sites of inoculation and, subsequently, efficient virus dissemination to or infection of the salivary glands and (ii) might be involved in the persistence of virus infection, at least in the spleen. In addition, our data indicate that $\mathrm{r} 131$ represents the functional homolog of the MCMV m131/129 gene.

\section{Introduction}

The highly host-restricted cytomegaloviruses (CMVs) are opportunistic pathogens that cause acute, lifelong persisting and latent infections. The fact that CMVs are capable of infecting their hosts for life indicates that these viruses must have evolved strategies to either evade or subvert antiviral immune responses. Since the chemokine signaling system is indispensable for proper immune system functioning, cellular chemokines and chemokine receptors constitute favourite targets for viral subversion. Indeed, betaherpesviruses, like CMV, have been shown to encode homologs of cellular chemokines and chemokine receptors that potentially mimic or modulate key immune regulatory proteins $[2,22,23]$.

Genes encoding chemokine homologs have been identified in all sequenced CMV genomes. Chemokines are small ( 8 to $10 \mathrm{kDa}$ ) chemoattractant cytokines that are classified into four classes on the basis of the arrangement of four conserved cysteine (C) residues within their amino acid sequences. Within the $C X C$ or $\alpha$ chemokines, the first two conserved cysteine residues are interrupted by a single, non-conserved amino acid $(X)$, whereas this intervening amino acid is lacking in $C C$ or $\beta$ chemokines. $C$ or $\gamma$ chemokines contain only two of the four conserved cysteines and in $\mathrm{CX}_{3} \mathrm{C}$ or $\delta$ chemokines, the first two conserved cysteine residues are separated by three non-conserved amino acids. In the HCMV genome, two putative CXC chemokine genes have been identified: UL146 and UL147 [10]. The proteins encoded by these genes were designated $V C X C-1$ and VCXC-2, respectively, and show similarity with IL-8 [25]. Only vCXC-1 was demonstrated to be functional. It is a very potent chemokine, inducing calcium mobilization, chemotaxis and degranulation of peripheral blood neutrophils in vitro [25]. Furthermore, vCXC-1 was found to specifically bind to IL-8 receptor CXCR2. It was hypothesized that the trafficking 
of neutrophils mediated by $\mathrm{v} C X \mathrm{C} 1$ promotes efficient virus dissemination during acute CMV infection [25].

In the genome of murine CMV (MCMV), a single gene was identified that has the ability to encode a chemokine [20]. This gene, $\mathrm{m} 131 / 129[13,19]$, is conserved in sequence as well as position with rat CMV (RCMV) $\mathrm{r} 131$ [37]. MCMV m131/129 is transcribed as a spliced $m R N A$ that contains sequences derived from both open reading frames (ORF) m131 and m129 [13, 19, 28]. Only the $5^{1}$-terminal, m131-derived part of this spliced transcript encodes CC chemokine-like sequences. The 3'-terminal, m129-derived part encodes sequences that do not resemble any known protein motifs. The m131/129encoded protein, which was designated MCK-2 (MCMV-encoded chemokine 2) [19], is considerably larger than cellular CC chemokines [13, 19]. A synthetic polypeptide containing m131-encoded sequences (MCK-1 peptide) was found to induce calcium signaling and adherence in murine peritoneal macrophages, indicating that the $\mathrm{m} 131$ / m129-encoded polypeptide may indeed have chemokine activity [31]. Furthermore, human chemokine receptor CCR3-expressing cells as well as the human macrophage cell line THP1 are responsive to MCK-1 [31]. In addition, MCK-2 was shown to promote inflammation at initial sites of infection, and dissemination of virus to the salivary glands, a major site of virus replication $[13,30,31]$.

As mentioned above, the RCMV genome carries a homolog of the MCMV m131/ 129 gene, $r 131$ [37]. It was recently hypothesized, however, that RCMV may contain yet another gene encoding a CC chemokine homolog [1]. This gene, which was designated RCK- 3 , is localized immediately downstream of the $r 131$ gene and was predicted to consist of two exons [1]. Interestingly, RCK-3, which will be referred to here as 1129 , displays similarity with the UL128 gene, which was recently identified in the genomes of HCMV and chimpanzee CMV [1]. Thus, RCMV r129 and HCMV UL128 may represent the first putative chemokine genes that are conserved between rodent and primate $C M V$ s. The finding of a tandem of putative CC chemokine genes in the RCMV genome is intriguing and raises a number of questions. Are $r 131$ and $r 129$ the result of a gene duplication event? Is $\mathrm{r131}$ the true homolog of MCMV m131/129? Do both genes encode functional chemokines? And, do these proteins have similar functions? To begin and address these questions, we have initiated a study to determine the biological significance of the RCMV r131 gene. Here, we report the sequence similarities among the various CC chemokine homologs of the CMVs, transcription of the $r 131$ and $r 129$ genes, and the characterization of RCMV r131-knockout strains, both in vitro and in vivo.

\section{Materials and Methods}

\section{Cells and Virus}

Primary rat embryo fibroblasts (REF) and rat fibroblast cell line Rat2 (Rat2 TK; ATCC CRL-1764) were cultured as described previously $[9,36]$. REF were utilized for propagation of (recombinant) RCMV (Maastricht strain), as well as for virus titration plaque assay [8]. Rat2 cells were used for transfection experiments with recombination plasmid DNA [5]. RCMV DNA was isolated from culture medium as described by Vink et al. [35]. 


\section{Construction of RCMVAr131a and RCMVAr131b recombination plasmids}

In order to generate RCMV strains in which the 131 ORF is disrupted by the neomycine resistance (neo) ORF, two recombination plasmids, designated $p 407$ and $p 408$, were generated as follows. Previously, the 4.2-kb RCMV Xbal J fragment (position 181,505 to 185,751 of the RCMV genome [37]) had been cloned in vector pSP62-PL by Meijer et al. [21], resulting in plasmid 025 . The Xbal J fragment contains ORFs $r 137, \mathrm{r} 136, \mathrm{r} 135$, $\mathrm{r133}, \mathrm{r} 131$, and $\mathrm{r} 129$. The $0.1-\mathrm{kb} B s p \mathrm{H}$ fragment within the 131 ORF of plasmid $\mathrm{c025}$ was exchanged for a 1.8-kb BspHI fragment containing the neo gene. The 1.8-kb BspHI fragment was derived from vector pEGFP-N1 (Becton Dickinson Biosciences, Alphen aan den Rijn, The Netherlands). The neo ORF is flanked by an SV40 early promoter and a herpes simplex virus (HSV) thymidine kinase (TK) polyadenylation (poly(A)) signal. Replacement of the $B s p H I$ fragment within 131 resulted in two different recombination plasmids (Fig. 3), one in which the orientation of the neo ORF is opposite to that of the r131 ORF (p407), and one in which the orientations of the neo and $\mathrm{r} 131$ ORF are similar (p408). The integrity of all plasmid constructs was verified by sequence analysis.

\section{Generation of RCMV 131 deletion mutants}

Approximately $1 \times 10^{7}$ Rat 2 cells were trypsinized and subsequently centrifuged for 5 $\mathrm{min}$ at $500 \times \mathrm{g}$. The cells were resuspended in $0.5 \mathrm{ml}$ of culture medium, after which 10 $\mu \mathrm{g}$ of either plasmid $\mathrm{p} 407$ or p 408 was added. The suspension was transferred to a $0.4-$ $\mathrm{cm}$ electroporation cuvette (Bio-Rad, Veenendaal, The Netherlands) and pulsed at 0.25 $\mathrm{kV}$ and $500 \mu \mathrm{F}$ in a Bio-Rad Gene Pulser electroporator. The cells were subsequently seeded in T75 culture flasks. At $14 \mathrm{~h}$ after transfection, the cells were infected with lowpassage RCMV at a multiplicity of infection (moi) of 1 . The culture medium was supplemented with $50 \mu \mathrm{g}$ of $\mathrm{G} 418$ per $\mathrm{ml}$ at $16 \mathrm{~h}$ post infection (pi). Recombinant viruses were cultured on REF monolayers and plaque purified as described earlier $[3,5]$. Finally, two plaque-purified recombinant strains were selected for further study: (i) RCMV $\triangle \mathrm{r} 131 \mathrm{a}$, which was generated using plasmid p407, and (ii) RCMV $\mathrm{r} 131 \mathrm{~b}$, which was generated using plasmid $\mathrm{p} 408$.

\section{Southern blot hybridization}

DNA isolated from wild-type (WT) RCMV, RCMV $\triangle \mathrm{r} 131 \mathrm{a}$, and RCMV $\triangle \mathrm{r} 131 \mathrm{~b}$ was digested with $B a$, electrophoresed through a $1 \%$ agarose gel, and blotted onto a Hybond $\mathrm{N}^{+}$nylon membrane (Amersham Pharmacia Biotech, Roosendaal, The Netherlands) as described previously [6]. The blots were hybridized with digoxygenin-labeled DNA derived from either plasmid $\mathrm{c025}$ (see above) or $\mathrm{p} 369$ (containing neo-specific sequences). Plasmid p369 was constructed as follows. A 0.8-kb fragment containing the neo ORF was amplified by PCR, using primers NEO.N-F and NEO.N-R (Table 1) and, as template, plasmid Rc/ CMV (Invitrogen, Breda, The Netherlands). The amplified fragment was then digested with BamHI and Xbal and cloned into BamHI- and Xbal-digested pUC119, resulting in plasmid $p 369$. Hybridization and detection experiments were performed with digoxigenin DNA labeling and chemiluminescence detection kits (Roche, Almere. The Netherlands). 
Table 1. PCR primers ised in this stixty

\begin{tabular}{|c|c|c|c|c|c|}
\hline Primer & Sequence $(5 \rightarrow 3)^{4}$ & Restriction site & Source & Position & Orientation \\
\hline NEON.F & ATAACSAICCIIICICAISA TCAACAACATCCATITC & BmH BspH & $\mathrm{PRC} / \mathrm{CMN}$ & $2.235 \cdot 2.277$ & + \\
\hline NEO.N.R & GITALCIASAACCCCCACAGICCCCCTCACAAC & $x a x$ & PRC/OMN & $3.039 \cdot 3.070$ & - \\
\hline ITORACE.F & GTCCGSATCCGTCATTCAATACGTICT & Bunt & RCMV genorre & $182.012 \cdot 182.038$ & + \\
\hline INORACER & GAICAGTTAAGTCAACCCACCCCATCC & & RCNN genorre & $181.454-181,480$ & - \\
\hline IMTRACEF & GAICTGTGTCCCCCCTAAACGTICO & & RCMV genome & $182.652-182,676$ & + \\
\hline NBIRACBR & AATACGIACCAACCITACCCCCGACACACAIC & $A s p 718$ & RCMV genome & $182.644 \cdot 182.676$ & - \\
\hline$n 31-F$ & AAIICTACAICATTAATTACACAACGTCCCACGTG & $x+1$ & RCMV genome & $182,178-182,209$ & + \\
\hline$n 31-R$ & AATICTAGATCACCCCTCCCCACACAACACAC & $x h$ & RCMV genome & $182,865 \cdot 182,899$ & - \\
\hline RCMVfor & TIACCCATCATGTTCCAATTI & & RCMV ginome & $172,731-172,751$ & + \\
\hline RCMVIEV & TICCAACCCCCACACACA & & RCMV genome & $172,859 \cdot 172.876$ & - \\
\hline RCMVirode & FAM TCICTACCACCCACCCICCACCOTI- TANRA & & RCMV genome & $172,826 \cdot 172,850$ & - \\
\hline
\end{tabular}

"Underlined serpences indicate restriction enzyme recogrition sites; sequences in boldface type differ from that of the arignal sequence as described in the columrs for souce and positions. Reporter dye (FAW) and quencher (TAWRA) elements are indicated in italics.

$" t$, arientation of the sequerce is identical to the published RCMV sequence [37] between indicated positions: -- seruence is complementary to the published sequence between the indicated positions.

Isolation of poly $(A)+R N A$ and amplification of CDNA ends

$R C M V$ poly $(A)^{+} R N A$ was isolated at immediate early (IE), early $(E)$, and late $(L)$ times of RCMV infection of REF as described earlier [5]. To obtain mRNA from mock-infected cells, a procedure similar to that described for the purification of $L$ mRNA was used, except that RCMV infection was omitted. In a separate experiment, poly(A)+RNA was isolated from either mock-, WT RCMV-, RCMV $\triangle$ r131 a- or RCMV $\triangle$ r131b-infected REF. Poly $(A)^{+}$RNA was purified using a QuickPrep Micro mRNA Purification Kit (Amersham Pharmacia Biotech), according to the manufacturer's protocol.

To determine the $5^{\prime}$ and $3^{\prime}$ ends of the $r 129$ and $r 131$ transcripts, approximately $3 \mu \mathrm{g}$ of the purified L-phase mRNA was used for the synthesis of CDNA and amplification of CDNA ends using either gene specific primer r129RACE.F, r1 29RACE.R, I131RACE.F or 131RAC3.R (Table 1) and the 5' RACE System for Rapid Amplification of CDNA ends (Invitrogen) as well as the SMART RACE CDNA Amplification Kit (Becton Dickinson Biosciences) according to the manufacturer's protocols. The resulting PCR products were cloned into vector pGEM-T Easy (Promega, Amsterdam, The Netherlands) and sequenced.

\section{Northern blot hybridization}

Electrophoresis of RNA under denaturing conditions, and transfer to Hybond $\mathrm{N}$ membranes (Amersham Pharmacia Biotech) were performed essentially as described by Brown and Mackey [7]. The blots were hybridized with either single-stranded DNA probes (for $r 131$ ) or double-stranded DNA probes (for $r 128, r 129, r 131, r 133$, or neo). The strand-specific 131 probes were constructed as follows. The r131 3'-RACE product (see above) was treated successively with T4 DNA polymerase and T4 polynucleotide kinase, and then cloned into the Hincll site of pUC119, generating plasmid p344. After digestion of $\mathrm{p} 344$ with BamHI, which resulted in deletion of approximately $700 \mathrm{bp}$ at the $3^{\prime}$ end of the 1131 cDNA including the poly $(A)$ tail, the plasmid was circularized using T4 DNA ligase, generating plasmid p346. Then, plasmid p346 was linearized with either BamHI or Pstl and used in a 'run off' linear amplification reaction by incubation with Taq DNA 
polymerase, either the reverse or forward universal sequencing primer, deoxynucleotide triphosphates dNTPs and [ $\alpha{ }^{-32}$ P]dATP (ICN Biomedicals, Zoetermeer, The Netherlands) for 35 cycles $\left(1 \mathrm{~min}\right.$ at $95^{\circ} \mathrm{C}, 30 \mathrm{sec}$ at $55^{\circ} \mathrm{C}$, and $30 \mathrm{sec}$ at $72^{\circ} \mathrm{C}$ ).

The 971-bp BgNl-Xbal, 525-bp BamHI-Xbal and 442-bp Asp718-BgNl fragments from the RCMV ECoRI E fragment (position 17,3541 to 18,7480 of the RCMV genome [37]), which was previously cloned in vector PSP62-PL [21], were used as $r 128-, 129$ - and 1133-specific probes, respectively. The 829-bp BamHI-Xbal fragment from plasmid p369 and the 525-bp BamHI-Xbal fragment from plasmid p521 were used as neo- and $\mathrm{r} 129$ specific probes, respectively. A 700-bp r131-specific probe, containing the complete $\mathrm{r} 131 \mathrm{ORF}$, was generated using a PCR-based procedure with primers $\mathrm{r} 131-\mathrm{F}$ and $\mathrm{r} 131-\mathrm{R}$ (Table 1), and plasmid $\mathrm{c025}$ as template. The various DNA fragments were labeled with $\left[\alpha-{ }^{32} \mathrm{P}\right] \mathrm{dATP}$ (ICN Biomedicals) using a Random Primed DNA labeling kit (Roche). Hybridization and autoradiography were performed as described earlier [7].

\section{Dissemination of WT RCMV, RCMVAr131a and RCMVAr131b}

Male specific-pathogen-free (spf) Lewis/M rats (Central Animal Facility, Maastricht University, Maastricht, The Netherlands) were kept under standard conditions [33]. Three groups of twelve seven-weeks-old rats ( 250 to $300 \mathrm{~g}$ of body weight) were immunosuppressed by exposure to 5 Gy of total body Röntgen irradiation 1 day before infection. Intraperitoneal infection was carried out with $1 \times 10^{6}$ plaque-forming units (PFU) of either WT RCMV RCMV $\triangle \mathrm{r} 131 \mathrm{a}$ or RCMV $\triangle \mathrm{r} 131 \mathrm{~b}$. Virus stocks that were used for inoculation were derived from the supernatant of sonicated virus-infected REF. On days 4 and 28 pi, six rats from each group were sacrificed, and their internal organs (salivary glands, spleen, kidneys, liver, thymus, blood and bone marrow) were collected. These organs were subjected to plaque assay, immunohistochemistry, and real-time, quantitative PCR as described below. The plaque test and PCR data were statistically analyzed by applying a Chi-Square test using SPSS (SPSS International BV). P values of $<0.05$ were considered to indicate statistical significance.

\section{Infection of rat footpads with WT RCMV, RCMVAr131a and RCMVAr131b}

Six-weeks-old, immunosuppressed rats were subcutaneously inoculated with $1 \times 10^{5}$ PFU of either WT RCMV, RCMV $\triangle \mathrm{r} 131 \mathrm{a}$ or RCMV $\mathrm{r} 131 \mathrm{~b}$ in the dorsum of the left hind paw, essentially as described by Persoons et al. [27]. As a control, supernatant from sonicated, mock-infected REF cultures was injected in the right hind paw of the same animal. Both hind paws were evaluated daily and paw thicknesses were measured using a digital micrometer Digimatic type ID-110M; Mitutoya, Tokyo, Japan). Each determination was performed 10 times. In a separate, similar experiment, rats were sacrificed at either day 3 or day 10 pi and tissue was prepared from the dorsum of the hind paws, snap frozen and mounted in Tissue-Tec (Sakuro Finetek Europe BV, Zoeterwoude, The Netherlands). Subsequently, $5 \mu \mathrm{m}$ frozen sections were subjected to immunohistochemistry (see below). Also, the spleen and salivary glands were collected and subjected to both plaque titer determination and quantitative PCR. The paw thickness data were statistically analyzed by applying a Paired Samples T test using SPSS (SPSS International BV). P values of $<0.05$ were considered to indicate statistical significance. 
Total cellular DNA was extracted from the salivary glands, spleen, kidneys, liver, pancreas, and thymus as follows. Frozen tissue (approximately $4 \mathrm{~mm}^{3}$ in size) was lysed in lysis buffer ( $10 \mathrm{mM}$ Tris- $\mathrm{HCl}$ pH 8.0,100 $\mathrm{mM} \mathrm{NaCl}, 25 \mathrm{mMEDTA}, 0.5 \%$ SDS) supplemented with $50 \mathrm{ng} / \mathrm{ml}$ proteinase $\mathrm{K}$ (Roche) and $5 \mu \mathrm{g} / \mathrm{ml}$ RNAse A (Amersham Pharmacia Biotech), followed by homogenization, and incubation for $30 \mathrm{~min}$ at $56^{\circ} \mathrm{C}$. Next, DNA was extracted with phenol:chloroform (1:1) and ethanol-precipitated. Before the samples were subjected to real-time PCR, they were analyzed by both agarose gel electrophoresis, in order to establish their integrity, and spectrophotometry, to determine DNA concentrations. The sequences of the TaqMan primers (RCMVfor and RCMVrev) and TaqMan probe (RCMVprobe; Table 1) were selected from the immediate early 1 (IE1) gene with Primer Express software (version 2.0; Perkin-Elmer Biosystems, Nieuwerkerk aan de IJssel, The Netherlands). The TaqMan probe that was selected between the primers, was fluorescently labeled with 6-carboxyfluorescein (FAM) at the $5^{\prime}$ end as the reporter dye, and with 6carboxytetramethylrhodamine (TAMRA) at the $3^{\prime}$ end as the quencher (Table 1). PCR was performed in a total volume of $25 \mu \mathrm{l}$, containing $12,5 \mu \mathrm{l}$ TaqMan Universal PCR Master Mix (Perkin-Elmer Biosystems), $900 \mathrm{nM}$ forward primer, $300 \mathrm{nM}$ reverse primer, $125 \mathrm{nM}$ TaqMan probe, and $100 \mathrm{ng}$ of sample DNA. PCR was performed using the ABI PRISM 7000 Sequence Detection System (SDS) (Perkin-Elmer Biosystems) under the following conditions: $2 \mathrm{~min}$ at $50^{\circ} \mathrm{C}$ and $10 \mathrm{~min}$ at $95^{\circ} \mathrm{C}$, followed by 42 cycles of $95^{\circ} \mathrm{C}$ for $15 \mathrm{~s}$ and $60^{\circ} \mathrm{C}$ for $1 \mathrm{~min}$. The data were analyzed with ABI PRISM 7000 SDS software (PerkinElmer Biosystems). For quantification, standard curves were generated using dilutions of RCMV DNA preparations of known concentration.

\section{Immunohistochemistry}

Frozen tissue sections $(4 \mu \mathrm{m})$ of the salivary glands, spleen, kidneys, liver, lungs, heart, pancreas, and thymus were stained with mouse monoclonal antibody (MAb) RCMV8, which is directed against the RCMV R44-encoded nuclear protein [18]. Also, frozen sections $(5 \mu \mathrm{m})$ of the dorsum of infected hind paws were stained with either mouse MAb RCMV8, mouse anti-rat MAb CD49d (directed against VLA-4; clone P12520; Pharmingen, San Diego, California), mouse anti-rat MAb CD4 (directed against CD4+ cells; clone W3/25; Harlan Sera-Lab Ltd., Sussex, United Kingdom), MAb 323 (directed against natural killer cells [11]), mouse MAb ED1 (directed against inflammatory macrophages, peripheral blood monocytes, and dendritic cells [12]), or mouse anti-rat MAb ED2 (directed against resident tissue macrophages and liver Kupfer cells [12]). The different MAbs were detected with goat anti-mouse immunoglobulins conjugated with horse radish peroxidase (HRP; DakoCytomation, Heverlee, The Netherlands). Specific antigen-antibody binding was visualized using diaminobenzidine (DAB) substrate [32]. Sections were counterstained with haematoxylin and embedded in immu-mount (Thermo Shandon, Pittsburg, PA). 


\section{A.

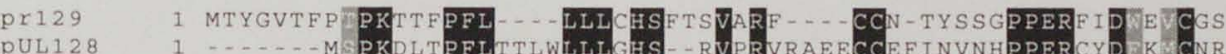

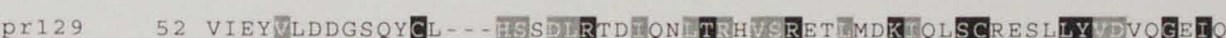

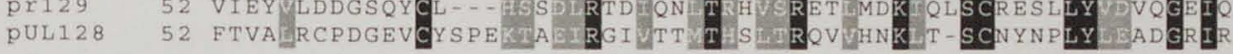

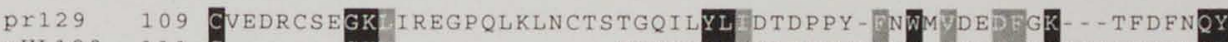

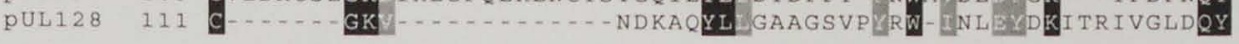

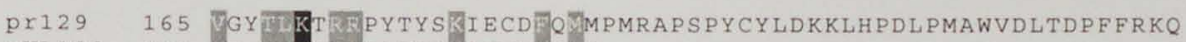

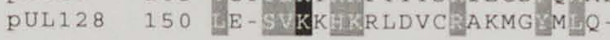

B.

pri31

pm131/129

pUL130

pr131

pm131/129

PUL130

pr131

pm131/129

PUL130

pr131

$\mathrm{pm} 131 / 129$

pUL130

pr131

pm131/129

pUL130

pr131

pm131/129

pUL130

c.

pUL1 28

pr129

pm131/129

pUL 128

pr129

pm131/129

pUL 128

pri29

pm131/129

pUL 128

pr129

pm131/129

pUL 128

pr129

pm131/129

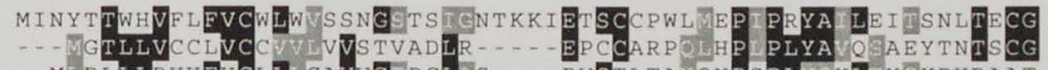

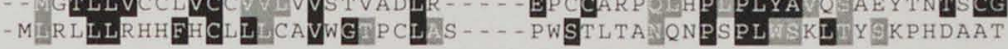

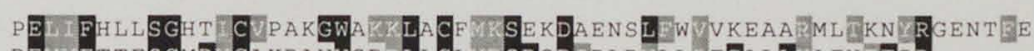
RE FTTESGMR CAKRAWWSD LLCL SRSD SRLR LLIFGALLAFN T IR.....

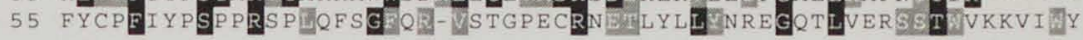

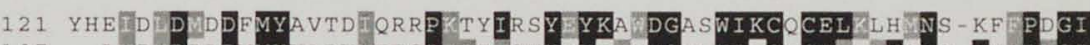
107 - LGP DPADMMYVADV MTESERTT VKYPYEVKGENWIECVCE T VGNG -TN P GI 114 LSGRNQTILQRMPRTASKPSDGNVEISVEDAK BGAHMPKQTKLL V VNDGTR Q

\section{GAGR - ...-SKASISYTLD TFS IT NGD TRCTHN}

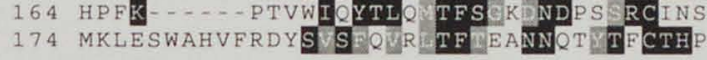

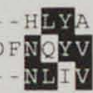

215 QDVLSRLPIPN

218 ATLLSSASPETGAAKTLTPTAVECEFKNASETLRTPYYCMPLTSGEP

215

278 SDE

\section{-.}

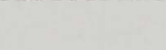

E P P PRVFYRLQRL 
D

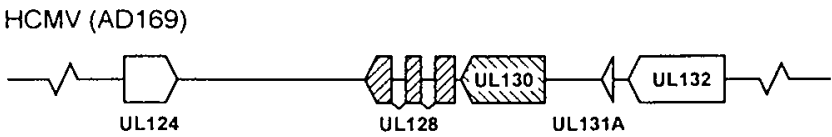

RCMV
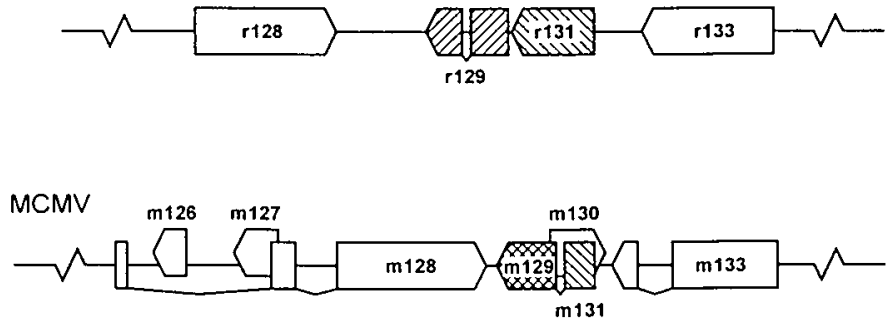

$\mathbf{k b}$

Figure 1. Amino acid sequence alignments of the $C C$ chemokine homologs encoded by RCMV, MCMV and $\operatorname{HCMV}(A, B$ and $C)$. The alignments were carried out by using either a Pairwise Global Alignment Algorithm program (http://www.ebi.ac.uk/emboss/ align) or a Clustal W Multiple Sequence Alignment Program [34] at the European Bioinformatics Institute, UK (http://www.ebi.ac.uk/clustalw). Blocks of identical (black boxes with a white font) and similar (grey boxes with a white font) amino acid residues were generated with program BOXSHADE (version 3.21; The EMBnet Foundation. The Netherlands [http://www.ch.embnet.org/ software/ BOX_form.html]), with the fraction of sequences that must agree for shading set to either 0.8 (A) or 0.5 ( $B$ and $C$ ). Numbers to the left of the sequences indicate the positions of the amino acid residues within the polypeptides. The MCK-2 (m131/129)- and UL128-encoded amino acid sequences were taken from MacDonald et al. [19] and Akter et al. (GenBank accession number NP 783797) [1], respectively. (D) The CMV CC chemokine genes correspond in orientation and location within their genomes. The HCMV (top), RCMV (middle), and MCMV (bottom) genomes are represented by black lines. The ORF positions, sizes and orientations are indicated by white arrow boxes. Those putatively encoding $C C$ chemokines are indicated by white shaded arrow boxes.

\section{Results}

\section{Characterization of the r129 and r131 gene}

The RCMV r131 ORF is localized between nucleotides 182,187 and 182,891 of the RCMV genome [37]. It has the capacity to encode a 234-amino acid polypeptide with a predicted molecular mass of $26.8 \mathrm{kDa}$. Search of the PSORT database (http:// psort.nibb.ac.jp/) revealed the presence of a potential signal peptide at the $\mathrm{N}$ terminus of pr131. The putative cleavage site is situated between the glycine residue at position 22 (G-22) and the serine residue at position 23 (S-23) (data not shown). Additionally, the predicted pr131 amino acid sequence contains four conserved cysteine (C) residues, all residing in the amino-terminal part of pr 131 , with the first two C's being adjacent. Other conserved residues with in the pr131 sequence that are characteristic for $C \mathrm{C}$ chemokines are a tyrosine at position 47 ( $Y-47)$, a phenylalanine at position 65 (F-65), and a tryptophan at position 80 (W-80) (data not shown). As with MCMV MCK-2 [19], the carboxyl terminus of pr131 lacks significant homology to known cellular chemokines. 
Table 2. Amino acid identity percentage between the CC chemotone homologs encoded by RCMV 131 and $129 . \mathrm{MCMV}$ $\mathrm{m} 131 / 129$, and HCMV UL 128 and UL 130

\begin{tabular}{|c|c|c|c|c|}
\hline & \multicolumn{4}{|c|}{ CC chemokine identities (\%) } \\
\hline & 131 & $\mathrm{~m} / 31 / 120$ & UL128 & UL130 \\
\hline 1129 & 12.9 & 11.9 & 17.7 & 11.9 \\
\hline$n 31$ & 100 & 20.5 & 16.1 & 17.3 \\
\hline $\mathrm{m} / 31 / 129$ & 20.5 & 100 & 12.4 & 10.8 \\
\hline UL128 & 16.1 & 12.4 & 100 & 13.9 \\
\hline
\end{tabular}

Percentages of identity were calculated according to the global alignment algorithm described by Myers and Miller [24].

Recently, a second gene encoding a CC chemokine homolog was identified in the RCMV genome, immediately downstream of $r 131$ [1]. This gene, $r 129$, was hypothesized to consist of two exons, located between RCMV nucleotides 181,434 to 181,749 and 181,832 to 182,181 , respectively. The predicted amino acid sequence of the protein encoded by the spliced $r 129$ transcript, designated pr129, contains four conserved $C$ residues, the first two of which are arranged in a CC chemokine-like manner (data not shown). Like with pr131 and MCK-2, the chemokine-like portion of pr129 is located entirely within the $\mathrm{N}$-terminal part of the protein. Besides the $\mathrm{C}$ residues, the pr129 sequence contains two other conserved amino acids: a phenylalanine at position 43 (F43) and a tyrosine at position 55 (Y55) (data not shown). Finally, the $N$ terminus of pr1 29 is predicted to harbour a signal peptide with the cleavage site located between amino acid residues 28 (A28) and 29 (R29) (data not shown).

The amino acid sequences of pr1 29 and pr131 were compared to sequences in the protein databases using BLAST. As expected from data reported by Akter and coworkers [1], pr1 29 displays the highest level of similarity with the CC chemokine homolog encoded by the HCMV UL128 gene (17.7\% identity; Table 2). A comparison of the amino acid sequences of pr129 and pUL128 nicely aligns the CC chemokine-common conserved C residues within these proteins (Fig. 1A), which underlines the notion that 129 and UL128 may represent counterparts which may be derived from a common ancestral chemokine gene.

The pr131 protein shows the highest level of similarity with MCMV pm131/m129 $(20.5 \%)$. Interestingly, pr131 also shows similarity to the protein predicted to be encoded by the recently identified UL130 gene of HCMV (17.3\% identity; Table 2 and Fig. 1B). Although the amino acid sequence encoded by UL130 includes a putative $\mathrm{N}$-terminal signal peptide, it does not seem to contain additional features typical of chemokines [1]. It is remarkable that the regions within pr131,pm131/129 and pUL130 that show the highest level of conservation are situated in the non-chemokine-like, carboxyl-terminal parts of these proteins.

Like pr131, pr129 shows similarity, albeit at a relatively low level, with pm131/129 (Table 2). However, the strongest similarities between these proteins are not seen in their chemokine-like $\mathrm{N}$ termini, but rather in their $\mathrm{C}$ termini (Fig. 1C). As seen in Table 2 and Fig. 1, pr131 bears resemblance to pm131/129, pUL130 as well as pUL128. By contrast, the similarity between pr131 and pr129 is very low, indicating that these genes are not likely to have arisen from a relatively recent gene duplication event.

In addition to amino acid similarity, HCMV UL128 and RCMV r129 on the one hand and HCMV UL130, RCMV M 31 and MCMV m131/129 on the other, display resemblance in both orientation and location within their genomes (Fig. 1D). Moreover, genes 
immediately down- and upstream of the RCMV and MCMV CC chemokine genes, i.e. $\mathrm{r} 128$ and $\mathrm{m} 128$, and $\mathrm{r} 133$ and $\mathrm{m} 133$, respectively, also correspond in amino acid sequence, orientation and approximate location, although they do not have apparent counterparts in the HCMV genome. Taken together, we conclude that pr131 most likely represents the RCMV counterpart of the MCMV m131/129-encoded chemokine, whereas pr129 probably represents the RCMV homolog of the HCMV UL128-encoded protein.

\section{Transcription of 129 and $r 131$}

In order to investigate the transcription of the $\mathrm{r} 131$ and $\mathrm{r} 129$ gene at $I E, E$, and $L$ times of viral replication in REF, Northern blot analysis was performed. As shown in Fig. 2B and 2C, r131- and r129-specific transcripts could be detected only in the L phase of infection. Similar expression patterns have been reported for the m131/129 and UL128 genes, which were both transcribed exclusively during the L phase of MCMV and HCMV infection, respectively $[1,20]$. Two major 131 -specific transcripts could be distinguished (Fig. 2B). These transcripts have an estimated size of 1.6 and $0.9 \mathrm{~kb}$, respectively. An

A

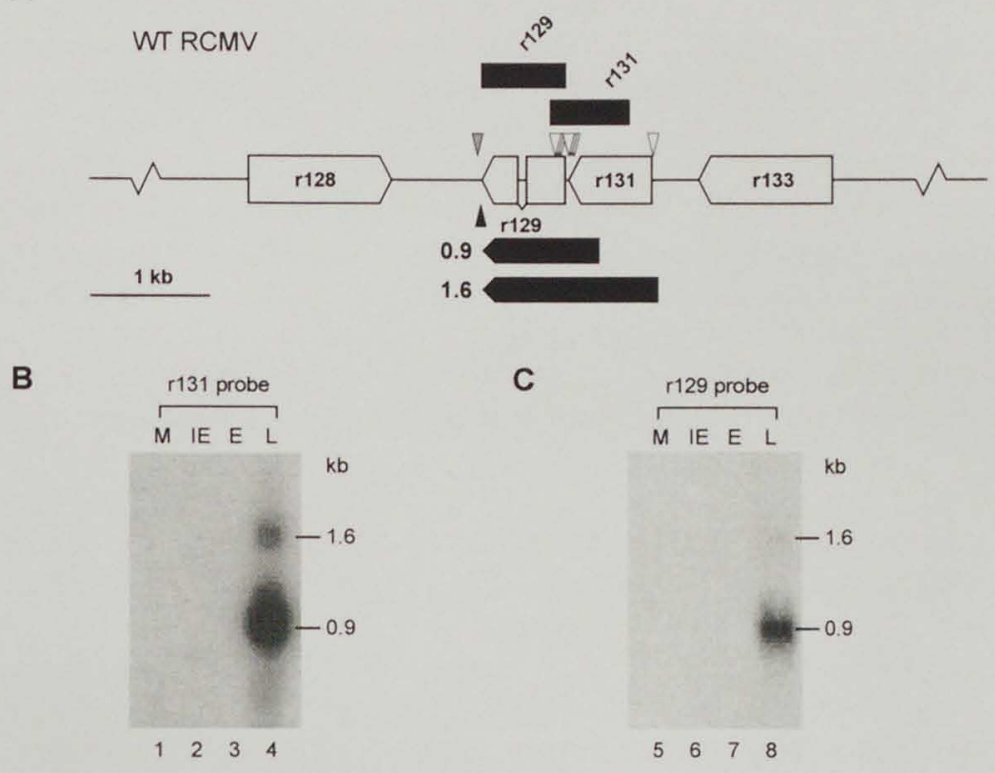

Figure 2. Transcription of the $r 129$ and $r 131$ gene. (A) Organization of the WT RCMV genome and predicted transcripts of $\mathrm{r} 129$ and $\mathrm{r} 131$. A consensus polyadenylation sequence is indicated by a black triangle. The putative $5^{\prime}$ ends of the transcripts are represented by white triangles. The putative $3^{\prime}$ end of both the r129 and $r 131$ transcript is depicted by a grey triangle. The black boxes in each diagram delineate the positions of the probes that were used for hybridization. Black arrows indicate the predicted positions, sizes and orientations of the transcripts that were detected by Northern blot hybridization. At the left-hand side of each black arrow, the predicted transcript size is depicted in kilobases (kb). Autoradiography exposures of Northern blots hybridized with probes specific for either $r 131$ (B) or $r 129$ (C) sequences. Lanes 1 and 5 represent poly $(A)+$ RNA from mock-infected $(M)$ cells, whereas lanes 2 and 6 , lanes 3 and 7 , and lanes 4 and 8 represent poly(A)+ RNA from the IE, E, and $L$ phases of infection, respectively. The estimated lengths (in $\mathrm{kb}$ ) of the different transcripts are depicted at the right of each panel. 
identical expression pattern was observed with the 129 probe, i.e. a major transcript of $0.9 \mathrm{~kb}$ and a less intense one of $1.6 \mathrm{~kb}$ (Fig. 2C). Since the $\mathrm{r} 131$ probe also contained $\mathrm{r} 129$ sequences (Fig. 2A), it is likely that the $0.9-\mathrm{kb}$ species seen with the $r 131$ probe is identical to that seen with the 129 probe. Similarly, the $1.6-\mathrm{kb}$ transcript observed with the $r 129$ probe is probably identical to that detected with the $r 131$ probe.

To further characterize the structure of the $r 131$ and $r 129$ transcripts, reverse transcriptase (RT)-PCR and rapid amplification of CDNA ends (RACE) was performed on transcripts that were generated at $L$ times of RCMV infection. The $5^{\prime}$ and $3^{\prime}$ ends of the transcripts were determined using two different amplification techniques (see Materials and Methods), after which the RACE products were cloned into vector pGEM-T Easy (Promega). Subsequently, several independent recombinant clones were sequenced. Sequencing of four independent clones mapped the $5^{\prime}$ end of the $r 131$ mRNA only 7 or 8 nucleotides upstream of the predicted start codon of the r131 ORF (Fig. 2A). The $3^{\prime}$ end of the 131 transcript was mapped 15 nucleotides downstream of a putative polyadenylation signal at the $3^{\prime}$ end of the 129 ORF (AATAAA; position 181,433 to 181,438 of the RCMV genome; Fig. 2A). Sequencing of the 3 '-RACE products of $r 131$ revealed that the r131 mRNA contains not only the $r 131$ ORF, but also the complete, unspliced $r 129$ sequence. Combining the overlapping sequences of the $5^{\prime}$ - and $3^{\prime}$-RACE products of $r 131$ indicates that this transcript has a total length of 1482 nucleotides, which corresponds to the length of the 1.6-kb transcript that was seen by Northern analysis.

The $5^{\prime}$ end of the 129 mRNA could not be determined precisely. Sequencing of nine independent clones all mapped the transcriptional start site of $r 129$ at a different location at the $5^{\prime}$ end of $r 129$. More specifically, the $5^{\prime}$ end of the $r 129$ transcript was mapped at position 182,121,182,125, 182,174, 182,214,182,224, 182,233, 182,236, 182,252 and 182,254 , respectively, of the RCMV genome (Fig. 2A). Similarly, heterogeneity of the 5 end was also observed for the m131/129 and UL128 transcripts of MCMV and HCMV. respectively $[1,19,20]$. It is unclear whether the heterogeneity of the 5 -RACE products of $r 129$ is due to degradation of the $r 129$ mRNA or reflects true heterogeneity of the $r 29$ mRNA. The 129 3'-RACE showed that the $3^{\prime}$ end of the 129 transcript is identical to that of the $1.6-\mathrm{kb} r 131 \mathrm{mRNA}$. This was to be expected, since the $\mathrm{r} 131$ transcript also contains the complete 129 sequence.

As described above, the RCMV r129 gene was hypothesized to consist of two exons, separated by a small intron [1]. To investigate this hypothesis, an RT-PCR was performed which would overlap the predicted exons. As shown in Fig. $2 \mathrm{~A}$, the sequence of the RTPCR products confirmed splicing of the $129 \mathrm{mRNA}$, and the presence of an 82-bp intron within the 129 gene (position 181,750 to 181,831 of the RCMV genome). By combining the RT-PCR and RACE data, we conclude that $r 129$ is transcribed as a 690-nucleotides mRNA. The length of this transcript corresponds to the length of $r 29$ transcript as estimated by Northern analysis $(0.9 \mathrm{~kb})$.

\section{Generation of RCMV r131 null mutants}

To address the roles of the RCMV chemokine homologs, we decided to focus first on characterization of the physiological significance of the $\mathrm{r}^{131}$ gene. To this purpose, two different RCMV 131 -knockout strains were generated by using a classical procedure based on homologous recombination between plasmids and the viral genome (see Materials and Methods). In both recombinant RCMV strains, a part of the $r 131$ gene was replaced 
A
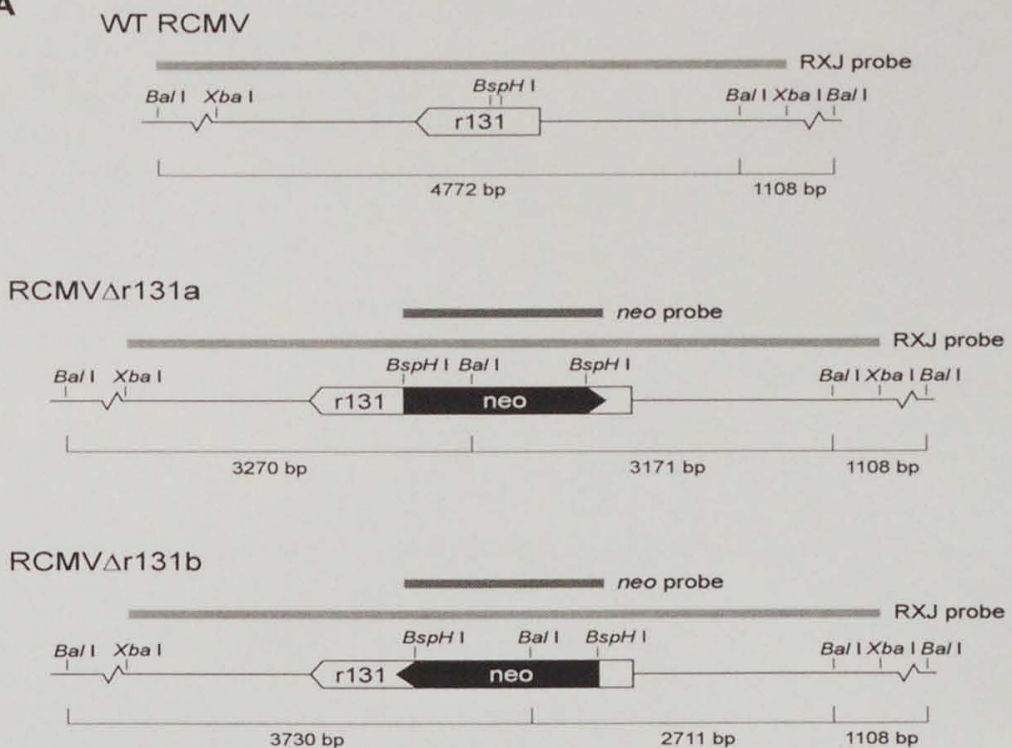

B

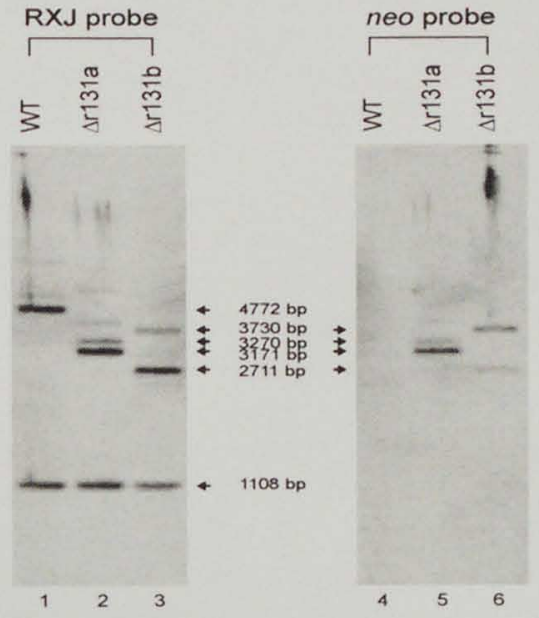

Figure 3. Construction of RCMV knockout strains in which the 1131 gene is disrupted. (A) The RCMV genome, of which the part containing the $\mathrm{r} 131 \mathrm{ORF}$ is shown, was modified by homologous recombination with recombination plasmids resulting in recombinant strains RCMV $\triangle \mathrm{r} 131 \mathrm{a}$ and $R C M V \Delta r 131 \mathrm{~b}$. The ORF positions, sizes and orientations are indicated by white arrow boxes. The neo ORF disrupting the 131 ORF is represented by a black arrow box. Location of Ball restriction sites at the $r 131$ locus within the genomes of WT RCMV (top), RCMV $\triangle \mathrm{r} 131 \mathrm{a}$ (middle), and RCMV $\triangle \mathrm{r} 131 \mathrm{~b}$ (bottom) are depicted above the genomes. Bal restriction sites and predicted lengths of restriction fragments are indicated below each of the loci. Black boxes indicate the locations that correspond with each of the probes used for hybridization. (B) Chemiluminescence exposure from a Southern blot of Ball-treated WT RCMV DNA (lanes 1 and 4), RCMV $\triangle 131$ a DNA (lanes 2 and 5), and RCMV $\triangle r 131 b$ (lanes 3 and 6) hybridized with either the RXJ probe (lanes 1 to 3 ) or the neo probe (lanes 4 to 6 ). The lengths of the detected fragments are indicated in $\mathrm{kb}$ in between the two Southern blots. WT, $\Delta r 131 a$ and $\triangle r 131 b$ denote poly(A)+ RNA from REF infected with WT RCMV, RCMVAr131a and RCMV $\triangle \mathrm{r} 131 \mathrm{~b}$, respectively. 
A
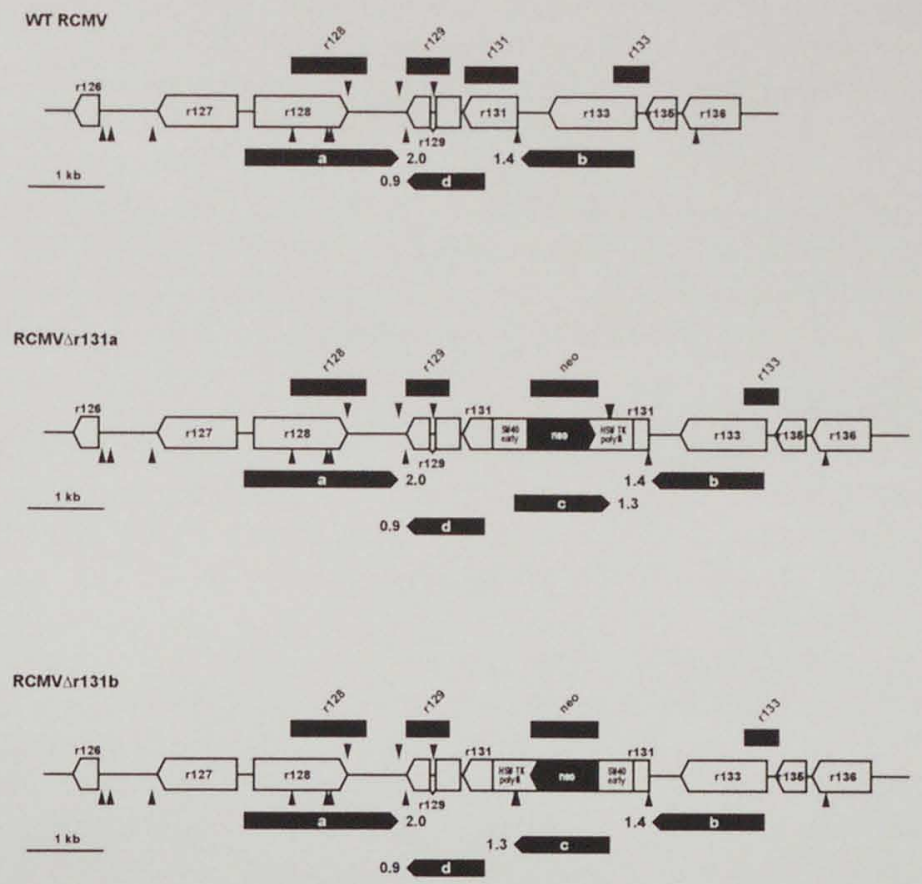

B

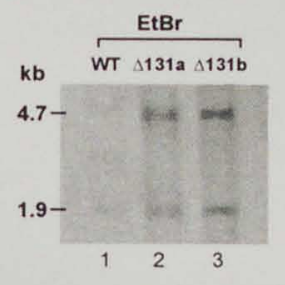

C

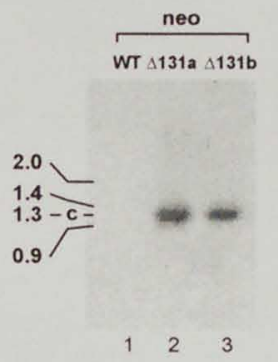

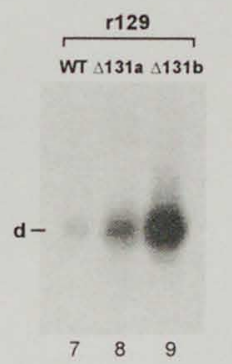

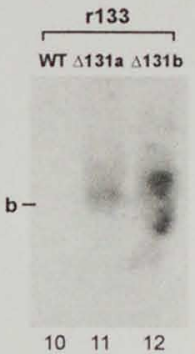

Figure 4. Transcription of genes neighbouring $r 131$ in WT RCMV-, RCMV $\triangle 1131 \mathrm{a}$ - and RCMV $\mathrm{r} 131 \mathrm{~b}$ infected cells, respectively. Black boxes indicate the locations that correspond with each of the probes used for hybridization. White arrows indicate ORF positions, sizes and orientations. Black arrowheads indicate predicted polyadenylation sites (arrowheads pointing down, AATAAA; arrowheads pointing up, TTTATT). Black arrows indicate the predicted positions, sizes and orientations of the transcripts that were detected by Northern blot hybridization. At either the left-hand or right-hand side of each black arrow, the estimated size is indicated in $\mathrm{kb}$. The predicted transcripts are marked with white letters that correspond to the letters which are used to denote the bands on the Northern blots in (C). The estimated lengths of the hybridizing fragments are indicated in $\mathrm{kb}$ on the left of each panel. (A) Organization of the WT RCMV (top), RCMV $\triangle \mathrm{r} 131 \mathrm{a}$ (middle) and RCMV $\triangle \mathrm{r} 131 \mathrm{~b}$ (bottom) genome and predicted transcripts of the neighbouring genes of $\mathrm{M} 131$. (B) $18 \mathrm{~S}$ and $28 \mathrm{~S}$ ribosomal bands on an ethidium bromide-stained agarose gel from WT RCMV-infected (lane 1), RCMVAr131a-infected (lane 2) or RCMVAr131b-infected (lane 3) cells. (C) Autoradiography exposures of Northern blots hybridized with probes specific for $1128, r 129,1133$ or neo sequences. Lanes 1, 4, 7 and 10 represent poly(A)+RNA from WT RCMV-infected cells, whereas lanes 2 , 5, 8 and 11, and lanes 3, 6, 9 and 12 represent poly(A) + RNA from RCMVAr131a- and RCMVAr131binfected cells, respectively. 
by the neomycin (neo) expression cassette, with the neo gene either in the opposite (in strain RCMV $\Delta r 131$ a) or the same orientation (in RCMV $\Delta r 131 b$ ) as the r131 gene (Fig. $3 A$ ). To verify the genomic integrity and purity of both recombinant strains, Southern blot analysis was carried out. DNA from WT RCMV, RCMV $\triangle \mathrm{r} 131 \mathrm{a}$ and RCMV $\triangle \mathrm{r} 131 \mathrm{~b}$ was digested with $B a l l$, electrophoresed, blotted, and hybridized with either an RCMV DNAspecific or a neo-specific probe. As demonstrated in Fig. 3A and B, the hybridization patterns observed with each of the probes were as predicted. This indicated that the 131 gene was correctly disrupted by the neo gene in the genomes of both RCMV $\triangle \mathrm{r} 131 \mathrm{a}$ and $R C M V \Delta r 131 b$, and that each of the recombinant virus pools are plaque pure.

\section{Transcription of neighbouring genes}

To evaluate the effect of disruption of the 131 gene on transcription of neighbouring genes, Northern blot analysis was performed with poly $(A)^{+}$RNA extracted from WT RCMV-, RCMV $\triangle$ r131a- and RCMVAr131b-infected cells. Blots were hybridized with probes specific for either $r 128, r 129, r 133$ or neo (Fig. 4). As expected, neo-specific transcripts were seen exclusively in RNA purified from RCMVAr131 a- and RCMV $\triangle \mathrm{r} 131 \mathrm{~b}$ infected cells. In both cases the neo gene was expressed as a single mRNA of approximately $1.3 \mathrm{~kb}$ (Fig. 4C). The $\mathrm{r} 128, \mathrm{r} 129$, and $\mathrm{r} 133$ genes are also expressed as single transcripts with estimated sizes of 2.0, 0.9 and $1.4 \mathrm{~kb}$, respectively (Fig. $4 \mathrm{C}$ ). Differences in lengths of these transcripts were not seen when comparing RNA purified from WT RCMV-, RCMV $\triangle \mathrm{r} 131 \mathrm{a}-$ and RCMV $\mathrm{r} 131 \mathrm{~b}$-infected cells. Although differences in intensities of the hybridizing transcripts are seen, this does not reflect differences in expression, but rather different amounts of RNA that were loaded on the gel, as indicated by the photograph of the ethidium bromide-stained agarose gel in Fig. 4B. Therefore, we conclude that transcription of the $r 128, r 129$ and $r 133$ genes is not significantly altered by disruption of the 131 gene. Consequently, it is not likely that putative phenotypic differences between WT RCMV and the recombinant strains can be attributed to genes other than r131.

\section{Replication characteristics of the RCMV r131 null mutant strains}

To examine whether disruption of the 131 gene in the RCMV genome affects virus replication in vitro, multi-step growth curves were generated for WT RCMV, RCMV $\triangle 131$ a and RCMV $\Delta r 131 b$ as follows. REF were infected with either WT RCMV, RCMV $\triangle r 131 \mathrm{a}$ or RCMV $\Delta \mathrm{r} 131 \mathrm{~b}$ at an moi of 0.01 . Subsequently, culture medium samples were taken at $1,3,5$ and 7 days pi, and subjected to plaque titer determination. Both strain RCMVAr131a and RCMV $\triangle \mathrm{r} 131 \mathrm{~b}$ were shown to replicate with similar efficiency as WT RCMV (Fig. 5). Therefore, the 131 gene is not important for efficient virus replication in vitro

Dissemination and replication of RCMV r131-knockout strains in immunocompromised rats

To study the role of $r 131$ in the pathogenesis of RCMV disease, virus dissemination and replication was monitored in rats infected with either WT RCMV or the 131 -knockout strains. At day 4 and $28 \mathrm{pi}$, rats were sacrificed and their internal organs were collected and analyzed by plaque assay and real-time, quantitative PCR. In addition, frozen sections were stained using MAb RCMV8. 


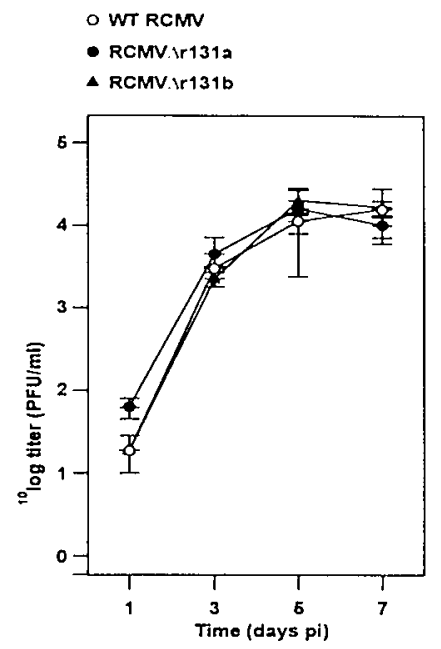

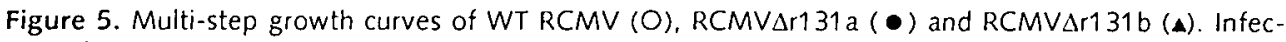
tion of REF with either of the RCMV strains was performed at an moi of 0.01 . The graphs indicate the virus titers that were determined by plaque assay in samples taken from the culture media at the indicated time points pi. The error bars show the standard deviation for each of the virus titers.

By using quantitative $P C R$, viral DNA could be detected in the majority of the organs of both WT RCMV-, RCMV $\triangle$ r131a- and RCMV $\triangle \mathrm{r} 131 \mathrm{~b}$-infected rats at day 4 pi (Table 3). The viral DNA load was found to be the highest in the spleen (data not shown). Similarly, the spleen was also found to contain the highest titers of infectious virus at day 4 pi (data not shown). Infectious virus could further be detected in thymus samples and in some liver and kidney samples early after infection (Table 3). Neither viral DNA loads nor virus titers differed significantly in the examined organs of rats infected with either of the three RCMV strains (data not shown).

Interestingly, at day $28 \mathrm{pi}$, a significant difference was found between WT RCMVand recombinant virus-infected rats $(p<0.05$; Table 3 and Fig. 6A). Although viral DNA could be detected in the spleens of WT virus-infected animals, viral DNA was not detected in the spleens from recombinant virus-infected rats. Infectious virus, however, was found in none of the spleens from the three experimental groups. This may be explained by relatively low viral DNA loads that were found in the spleens from WT RCMV-infected animals (Fig. 6A). Taken together, our data indicate that both RCMV $\triangle \mathrm{r} 131 \mathrm{a}$ and RCMV $\triangle \mathrm{r} 131 \mathrm{~b}$ are cleared more rapidly from the spleen than WT virus.

Table 3. The presence of infectious RCMV and viral DNA in organs from infected rats

\begin{tabular}{|c|c|c|c|c|c|c|c|c|c|c|c|c|c|c|}
\hline \multirow[b]{3}{*}{ Virus } & \multicolumn{10}{|c|}{ Day 4 pit' } & \multicolumn{4}{|c|}{ Day 28 pi.t } \\
\hline & \multicolumn{2}{|c|}{ Spleen } & \multicolumn{2}{|c|}{ Kidney } & \multicolumn{2}{|c|}{ Liver } & \multicolumn{2}{|c|}{ Thymus } & \multicolumn{2}{|c|}{$\mathrm{Sg}^{\prime}$} & \multicolumn{2}{|c|}{ Spleen } & \multicolumn{2}{|c|}{$\mathrm{Sg}^{\prime}$} \\
\hline & Plaque & $\mathrm{PCR}$ & Plaque & PCR & Plaque & PCR & Plaque & PCR & Plaque & PCR & Plaque & PCR & Plaque & PCR \\
\hline WT RCMV & $5 / 6$ & $5 / 6$ & $2 / 6$ & $6 / 6$ & $1 / 6$ & $6 / 6$ & $2 / 6$ & $5 / 6$ & $0 / 6$ & $4 / 6$ & $0 / 6$ & $5 / 6$ & $6 / 6$ & $6 / 6$ \\
\hline RCMVAr131a & $3 / 6$ & $5 / 6$ & $0 / 6$ & $4 / 6$ & $0 / 6$ & $4 / 6$ & $2 / 6$ & $3 / 6$ & $0 / 6$ & $3 / 6$ & $0 / 6$ & $0 / 6$ & $2 / 6$ & $1 / 6$ \\
\hline RCMVAr $131 b$ & $5 / 6$ & $6 / 6$ & $0 / 6$ & $3 / 6$ & $0 / 6$ & $5 / 6$ & $1 / 6$ & $5 / 6$ & $0 / 6$ & $1 / 6$ & $0 / 6$ & $0 / 6$ & $0 / 6$ & $0 / 6$ \\
\hline
\end{tabular}


A

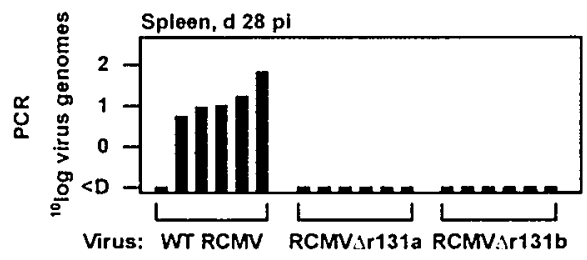

B

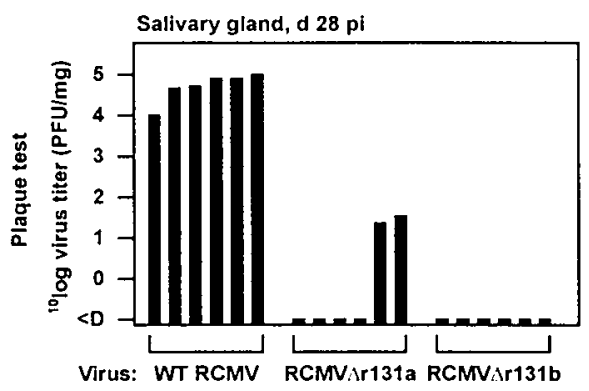

C

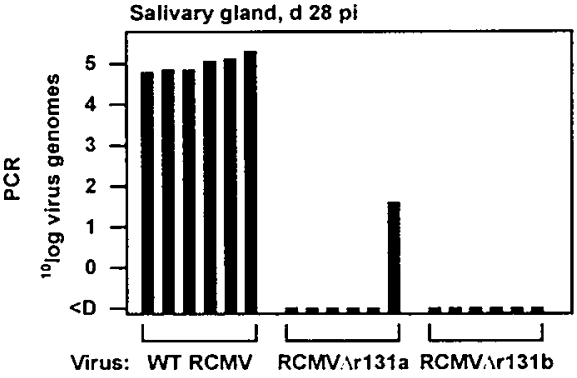

Figure 6. Dissemination of virus to the spleen and salivary glands of immunocompromised rats from the intraperitoneal infection route. (A) Amount of viral genome copies in spleen samples at day 28 after infection of rats either with WT RCMV, RCMVAr131a or RCMV $\triangle 131 \mathrm{~b}$. Each bar represents the result from a single rat. (B) Virus titers in salivary glands at day 28 after infection of rats with either one of the RCMV strains. (C) Amount of viral genome copies in samples similar to those analyzed in (B). $\angle D$, Below detection level (for the plaque assay, $10^{-1} \mathrm{PFU} \mathrm{mg}^{\cdot 1}$ tissue; for $\mathrm{PCR}, 10^{-1}$ viral genome copies $\mathrm{mg}^{-1}$ tissue DNA).

Additionally, a striking difference between WT virus and the recombinants was found in the salivary glands at day 28 pi. Both $\mathrm{r} 131$ recombinant strains were detected at significantly lower levels than WT RCMV in this organ ( $p<0.05$; Table 3 and Fig. 6B). These differences were also reflected by the viral DNA loads in the salivary glands: viral DNA loads were significantly lower in the salivary glands from recombinant virus-infected rats than in those from WT virus-infected animals ( $p<0.05$; Table 3 and Fig. 6C). Salivary glands from WT RCMV-infected rats contained an average of approximately $1 \times 10^{5}$ viral DNA copies per $\mu \mathrm{g}$ tissue, whereas viral DNA could only be detected in one out of six salivary gland samples from RCMV $\mathrm{r} 131 \mathrm{a}$-infected rats and in none from RCMV $\Delta \mathrm{r} 131 \mathrm{~b}$ infected rats. Moreover, the RCMV $\triangle 131$ a DNA-positive salivary gland sample only had a very low load of 22 viral DNA copies per $\mu$ g tissue (Fig. $6 \mathrm{C}$ ). Taken together, these data show that, in contrast to WT RCMV, both 131 -knockout strains do not replicate efficiently in the salivary glands of infected rats.

\section{Infection of rat footpads with RCMVAr131a and RCMVAr131b}

To investigate the replication of the 131 -knockout viruses in a local infection model [27], six-week-old, immunosuppressed rats were subcutaneously inoculated with either WT RCMV, RCMV $\mathrm{r} 131 \mathrm{a}$ or RCMV $\mathrm{r} 131 \mathrm{~b}$ in the dorsum of the left hind paw. As a control, the rats were mock-infected in the right paw. Paw thickness was measured daily 
A

O WT RCMV

- RCMV $\triangle \mathrm{r} 131 \mathrm{a}$

$\triangle R C M V \triangle r 131 b$

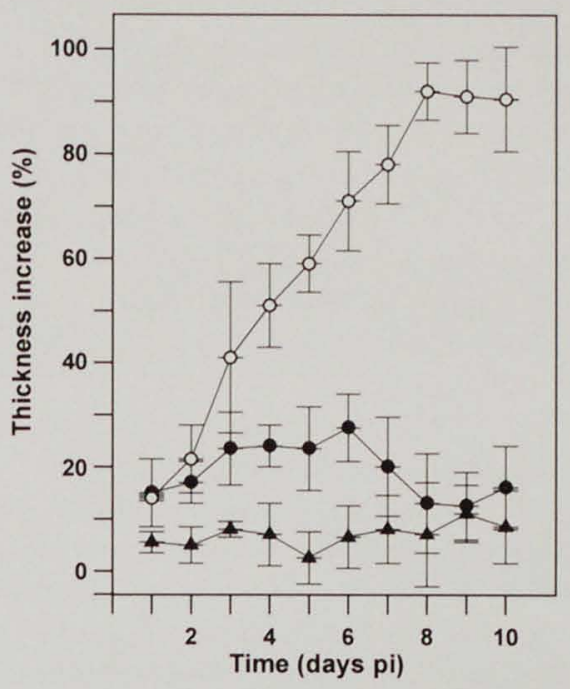

B

RCMV $\triangle \mathrm{r} 131 \mathrm{a}$

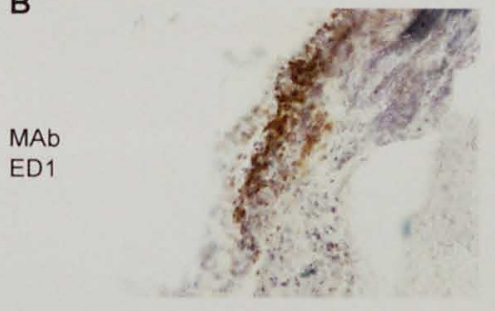

C

MAb RCMV8

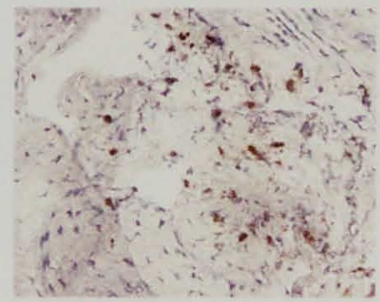

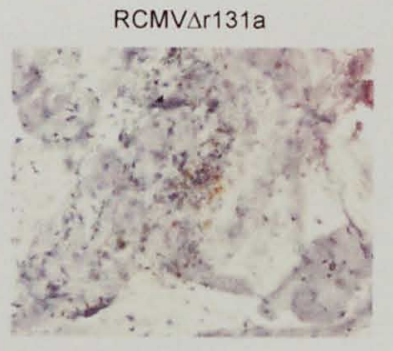
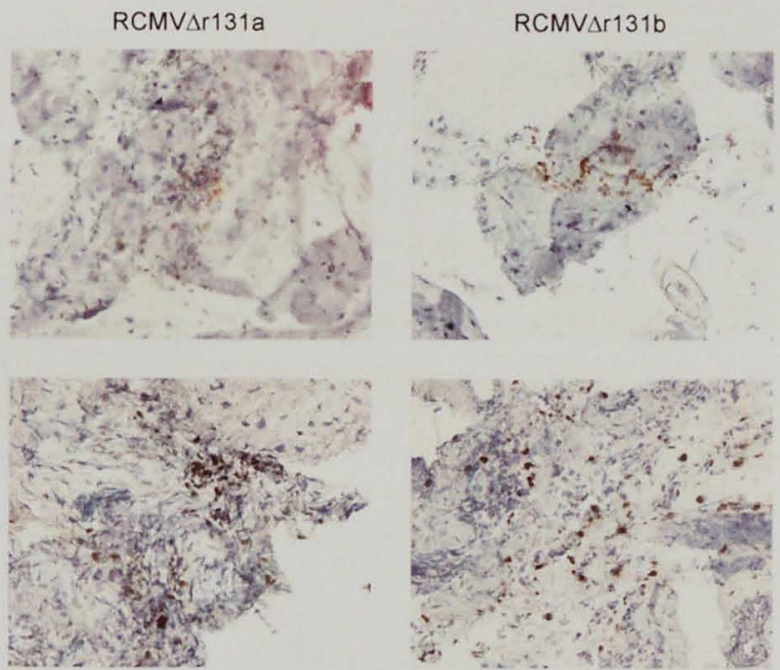

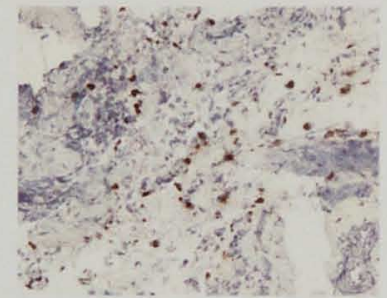

Figure 7. Inoculation of rat footpads with either WT RCMV, RCMV $\Delta r 131$ a or RCMV $\triangle r 131 b$. (A) Thickness increase of rat hind paws at the indicated time points after subcutaneous inoculation with either WT RCMV (O), RCMV $\Delta \mathrm{r} 131 \mathrm{a}(\bullet)$ or RCMV $\triangle \mathrm{r} 131 \mathrm{~b}(\boldsymbol{\Delta})$ in the dorsum of the left hind paw. Mock infection was established in the right hind paw. Thickness values are expressed as the percentage of increase in relation to day 0 and mock-infected paws. Sections $(5 \mu \mathrm{m})$ of tissue extracted from the hind paws were investigated by indirect immunohistochemistry using either MAb ED1 (B) directed against inflammatory macrophages [12] or MAb RCMV8 (C) directed against RCMV pR44 [18]. Anti-pR44 and anti-ED1 antibodies were detected using anti-mouse $\operatorname{lgC}$ antibodies conjugated with HRP. HRP stainings were performed with DAB (brown). The micrographs shown in figure $B$ and $C$ were taken from samples extracted at day 3 pi. The tissue sections were photographed at a magnification of $\times 400$. 
until 10 days pi and swelling was defined as the percentage thickness increase relative to the preinoculation measurement and the measurement in mock-infected paws. In a separate, similar experiment, rats were sacrificed at either day 3 or day 10 pi and sections of the dorsum of the hind paws were subjected to immunohistochemistry using leukocyte subsetspecific monoclonal antibodies in order to study the presence of infiltrating leukocytes.

As shown in Fig. 7A, infection of rat footpads with WT RCMV resulted in a dramatic increase in paw thickness as demonstrated previously [4, 27]. In comparison with WT virus, both r131-knockout strains induced a significantly lower amount of paw thickening (Fig. 7A). The swelling induced by WT RCMV increased markedly at day 3 pi and continued until a peak level was reached at day $8 \mathrm{pi}$ (92\% over preinoculation levels). The highest level of swelling induced by the recombinant viruses was approximately $21 \%$ over preinoculation levels at day $6 \mathrm{pi}$ (for RCMV $\Delta \mathrm{r} 131 \mathrm{a}$; Fig. 7A). The paw swelling induced by mock infection was not significantly different from that induced by each of the recombinants (data not shown). Together, these results indicate that the 1131 gene plays a crucial role in the pathology induced by local RCMV infection.

To further investigate the pathology induced upon infection with the different RCMV strains, sections of the paws were subjected to immunohistochemistry by using several cell-type specific antibodies. At day $3 \mathrm{pi}$, a lower number of inflammatory macrophages were detected in recombinant virus-infected paws than in WT RCMV-infected paws (ED1; Fig. 7B). Differences in the number of various other leukocyte subsets were not found, either at day 3, or at day 10 pi (data not shown). To check for the presence of virus in the paws, we detected the RCMV pR44 protein using MAb RCMV8. As shown in Fig. $7 C$, the numbers of infected cells within sections from either WT or recombinant virusinfected paws were roughly similar. This indicates that replication of each of these viruses within the infected paws does not differ significantly. To investigate whether the recruited inflammatory macrophages were infected with RCMV, we performed double stainings using both MAb ED1 and RCMV8. However, we were not able to unequivocally demonstrate cells to be positive for both ED1 and RCMV8. Taken together, these results indicate that a higher number of inflammatory macrophages infiltrate in wild-type virusinfected paws than in recombinant virus-infected paws, suggesting an important role for the 1131 -encoded chemokine, either directly or indirectly, in the interaction with macrophages.

Finally, to study whether the footpad inoculation route leads to a similar virus dissemination pattern as was observed for the intraperitoneal infection route, the spleen and salivary glands of the animals from the footpad infection experiment $(n=4$ for each rat group) were collected, and subjected to both plaque titer determination and quantitative PCR. As anticipated, a productive RCMV infection was established in the salivary glands at day 10 after footpad inoculation (Fig. 8A). By contrast, the 131 - knockout viruses could not be detected in these glands by plaque assay. In accordance with these results, salivary glands from recombinant virus-infected rats were found to harbour significantly lower levels of viral DNA than WT RCMV-infected salivary glands $(p<0.05$ for both recombinant strains compared to WT RCMV; Fig. 8B). A similar observation was made for the spleen at day 10 pi: a significantly higher viral DNA load was detected in animals infected with WT RCMV than in those infected with either of the two recombinants $(p<0.05$ for both recombinant strains compared to WT RCMV; Fig. 8C). Although a 10- to 100-fold difference in viral DNA load can sometimes be seen between rats within a single experimental group, such a difference represents the normal, natural variation, which was also seen in 
A

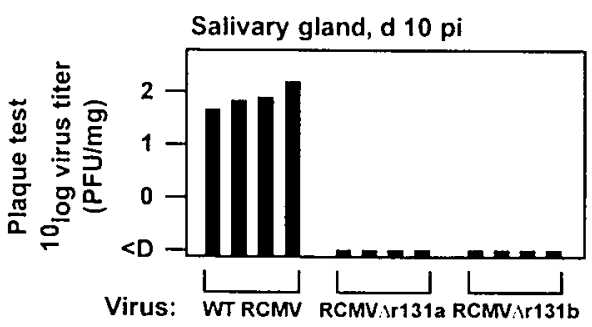

B

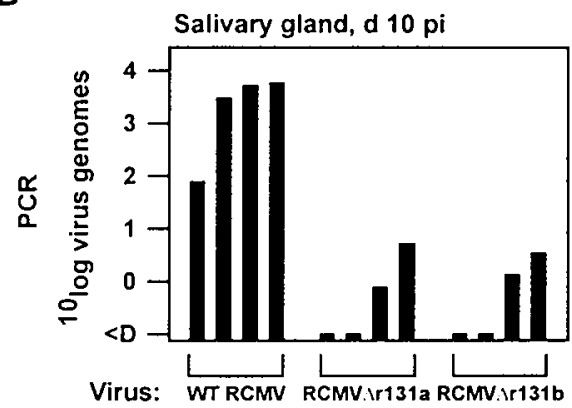

C

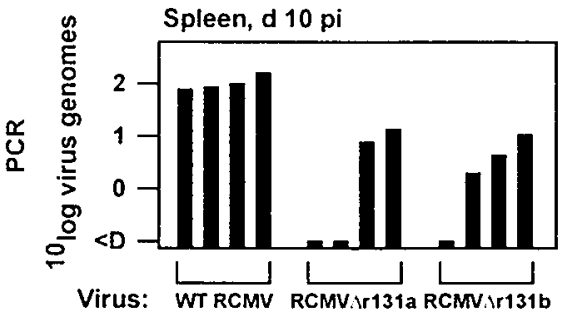

Figure 8. Dissemination of virus to the spleen and salivary glands of immunocompromised rats from the footpad inoculation route. (A) Virus titers in salivary glands at day 10 after infection of rats either with WT RCMV, RCMVAr131a or RCMVAr131b. Each bar represents the result from a single rat. (B) Amount of viral genome copies in samples similar to those analyzed in (A). (C) Amount of viral genome copies in spleen samples at day 10 after infection of rats with either of the RCMV strains. $\angle D$, Below detection level.

previous experiments [17]. At day 3 pi, neither viral DNA loads nor virus titers differed significantly in the salivary glands and spleens from WT RCMV-, RCMV $\triangle$ r131a- and $R C M V \triangle r 131 \mathrm{~b}$-infected rats (data not shown). These findings indicate that the recombinant virus strains are cleared more rapidly from salivary glands and spleen and/or that these viruses are impaired in dissemination to these organs, possibly resulting from the reduced recruitment of inflammatory macrophages which may serve as virus vehicles.

\section{Discussion}

Hitherto, RCMV is the only rodent $C M V$ possessing two genes putatively encoding $C C$ chemokines, i.e. $r 131$ and $r 129$. In view of the fact that these genes are contiguous, one might question whether they originated from a single, ancestral gene after a gene duplication event as was suggested for HCMV UL146 and UL147 [25]. However, based on the rather low level of amino acid similarity between $r 129$ and $r 131$, we deem it unlikely that they originated from a single gene. Moreover, alignments of several CMVencoded CC chemokines do not render support to the gene duplication hypothesis, since pr129 was found to have the highest level of similarity with HCMV pUL128, whereas pr131 showed the highest levels of similarity with the proteins encoded by MCMV m131/ 
129 (pm131/129 or MCK-2) and HCMV UL130. Therefore, we concluded that pr131 most likely represents the RCMV counterpart of both MCK-2 and pUL130, and pr129 probably constitutes the RCMV counterpart of HCMV pUL128. In light of these relationships, it is tempting to speculate that an ancestral CMV genome contained two adjacent CC chemokine homologs, i.e. a UL128/r129 predecessor and a UL130/r131 predecessor. Subsequently, in contrast to its $r 131$ counterpart, the UL130 predecessor within the HCMV genome may have lost its CC chemokine signature characteristics during evolution. In an ancestral MCMV genome, however, the UL128/r129 and UL130/ r131 predecessor genes may have recombined into a single CC chemokine gene, which evolved in gene $m 131 / 129$, which bears resemblance to both the UL128/r129 genes, particularly at its $C$ terminus, and the UL130/r131 genes, at its $N$ terminus. The present report focuses on the characterization of one of the two CC chemokine genes of RCMV. $\mathrm{r131}$. We found this gene to be expressed during the late phase of viral RCMV infection in cell culture. In order to investigate the function of $r 131$, two different recombinant virus strains, which were designated RCMV $\triangle \mathrm{r} 131 \mathrm{a}$ and RCMV $\triangle \mathrm{r} 131 \mathrm{~b}$, were generated in which the $r 131$ open reading frame was disrupted. Although both $\mathrm{r} 131$ - knockout strains did not differ from WT RCMV in their replication characteristics in vitro, marked differences between the knockout strains and the WT strain were seen in the pathogenesis of infection in vivo. Briefly, results from the in vivo studies indicate that pr131 promotes the influx of macrophages at the initial sites of inoculation and, subsequently, efficient virus dissemination to or infection of the salivary glands. Additionally, pr131 might be involved in RCMV persistence in the spleen. Similar data were previously reported for the MCMV m131/129 gene [13, 30, 31]. MCMV m131/129-knockout strains were unable to replicate efficiently in the salivary glands of infected mice. In addition, mck-expressing viruses induced a profound increase in the inflammatory response at the footpad inoculation site, as is evident from a higher level of foot thickness as well as substantially larger amounts of neutrophils in feet infected with mck-expressing viruses compared to those infected with mck-knockout strains. On the basis of the similarities in the phenotypes of the 131 - and $m 131 / 129-k n o c k o u t$ viruses, we concluded that the RCMV r131 gene may represent the functional homolog of the MCMV m131/129 gene.

As was suggested for MCK- $2[30,31]$, one of pr131's prominent roles in RCMV pathogenesis appears to be the modification of leukocyte homeostasis in order to recruit susceptible target cells which, in turn, could serve as vehicles that disseminate virus throughout the body. This notion, however, leaves us with the question what the function is of the r129 gene and its homolog from HCMV, UL128. Both $\mathrm{r} 129$ and UL128 have characteristics of proper CC chemokine genes. Therefore, it seems likely that they both represent functional genes. Although the function of UL128 is not known, this gene might be associated with endothelial cell as well as leukocyte tropism. Endothelial cell tropism (or endotheliotropism) is defined as the ability of virus to grow in endothelial cells, whereas leukocyte tropism (or leukotropism) concerns the capacity of virus to be transferred to peripheral blood leukocytes, either to polymorphonuclear leukocytes (PMNL) or to monocytes. Both endothelio- and leukotropism have been linked to HCMV dissemination in immunocompromised patients $[14,15,16,26,29]$. Interestingly, results from unpublished studies indicate that the HCMV locus containing the UL128 gene (the UL131-128 locus) is required for both endothelial cell and leukocyte tropism, although this locus may not be the sole determinant for this characteristic (G. Gerna, personal communication). To address the role of the $r 129$ gene (and possibly the UL128 gene), we 
are currently generating $129-k n o c k o u t$ viruses. The study of these viruses will be particularly interesting with regard to the question whether or not $r 129$ has a unique function among the virus-encoded and host chemokines.

\section{Acknowledgments}

C.V. is supported by a fellowship of the Royal Netherlands Academy of Arts and Sciences (KNAW). Y.K.G. and K.W.R.V.C. are supported by grants $901-02-224$ and $901-$ 02-239, respectively, from the Netherlands Organization for Scientific Research to C.V.

\section{References}

1. Akter, P., Cunningham, C., McSharry, B.P., Dolan, A., Addison, C., Dargan, D.J., Hassan-Walker, A.F., Emery, V.C., Griffiths, P.D., Wilkinson, G.W.G., and Davison, A.J. (2003). Two novel spliced genes in human cytomegalovirus. J. Gen. Virol. 84, $1117-1122$.

2. Alcami, A., and Koszinowski, U.H. (2000). Viral mechanisms of immune evasion. Trends Microbiol. 8, 410-418.

3. Beisser, P.S., Grauls, G., Bruggeman, C.A., and Vink, C. (1999). Deletion of the R78 $G$ protein-coupled receptor gene from rat cytomegalovirus results in an attenuated, syncytium-inducing mutant strain. J. Virol. 73, 7218-7230.

4. Beisser, P.S., Kloover, J.S., Grauls, G.E.L.M., Blok, M.J., Bruggeman, C.A., and Vink, C. (2000). The 144 major histocompatibility complex class I-like gene of rat cytomegalovirus is dispensable for both acute and long-term infection in the immunocompromised host. J. Virol. 74, 1045-1050.

5. Beisser, P.S., Vink, C., van Dam, J.G., Grauls, G., Vanherle, S.J., and Bruggeman, C.A. (1998). The R33 G protein-coupled receptor gene of rat cytomegalovirus plays an essential role in the pathogenesis of viral infection. J. Virol. 72, 2352-2363.

6. Brown, T. (1993). Analysis of DNA sequences by blotting and hybridization. In Current protocols in molecular biology, F.M. Ausubel, R. Brent, R.E. Kingston, D.D. Moore, J.G. Seidman, J.A. Smith, and K. Struhl, eds. (New York, USA: John Wiley \& Sons), pp. 4.2.1-4.2.15.

7. Brown, T. and Mackey, K. (1997). Analysis of RNA by Northern and slot blot hybridization. In Current protocols in molecular biology, F.M. Ausubel, R. Brent, R.E. Kingston, D.D. Moore, J.G. Seidman, J.A. Smith, and K. Struhl, eds. (New York, USA: John Wiley \& Sons), pp. 4.9.1-4.9.16.

8. Bruggeman, C.A., Meijer, H., Bosman, F., and van Boven, C.P.A. (1985). Biology of rat cytomegalovirus infection. Intervirology 24,1-9.

9. Bruggeman, C.A., Meijer, H., Dormans, P.H.J., Debie, W.H.M., Grauls, G.E.L.M., and van Boven, C.P.A. (1982). Isolation of a cytomegalovirus-like agent from wild rats. Arch. Virol. 73, 231-241.

10. Cha, T.A., Tom, E., Kemble, G.W., Duke, G.M., Mocarski, E.S., and Spaete, R.R. (1996). Human cytomegalovirus clinical isolates carry at least 19 genes not found in laboratory strains. J. Virol. 70, 78-83. 
11. Chambers, W.H., Vujanovic, N.L., Deleo, A.B., Olszowy, M.W., Herberman, R.B., and Hiserodt, J.C. (1989). Monoclonal antibody to a triggering structure expressed on rat natural killer cells and adherent lymphokine-activated killer cells. J. Exp. Med. 169.1373-1389.

12. Dijkstra, C.D., Döpp, E.A., Joling, P., and Kraal, G. (1985). The heterogeneity of mononuclear phagocytes in lymphoid organs: distinct macrophage subpopulations in the rat recognized by monoclonal antibodies ED1, ED2 and ED3. Immunology 54, 589-599.

13. Fleming, P., Davis-Poynter, N., Degli-Esposti, M., Densley, E., Papadimitriou, J., Shellam, $G$., and Farrell, H. (1999). The murine cytomegalovirus chemokine homolog, $m 131 /$ 129, is a determinant of viral pathogenicity. J. Virol. 73, 6800-6809.

14. Gerna, G., Percivalle, E., Baldanti, F., Sozzani, S., Lanzarini, P., Genini, E., Lilleri, D., and Revello, M.G. (2000). Human cytomegalovirus replicates abortively in polymorphonuclear leukocytes after transfer from infected endothelial cells via transient microfusion events. J. Virol. 74, 5629-5638.

15. Grefte, A., van der Giessen, M., van Son, W., and The, T.H. (1993). Circulating cytomegalovirus (CMV)-infected endothelial cells in patients with an active CMV infection. J. Infect. Dis. 167, 270-277.

16. Grundy, J.E., Lawson, K.M., MacCormac, L.P., Fletcher, J.M., and Yong, K.L. (1998). Cytomegalovirus-infected endothelial cells recruit neutrophils by the secretion of $C$ $X-C$ chemokines and transmit virus by direct neutrophil-endothelial cell contact and during neutrophil transendothelial migration. J. Infect. Dis. 177, 1465-1474.

17. Kaptein, S.J.F., Beisser, P.S., Gruijthuijsen, Y.K., Savelkouls, K.G.M., van Cleef, K.W.R., Beuken, E., Grauls, G.E.L.M., Bruggeman, C.A., and Vink, C. (2003). The rat cytomegalovirus $\mathrm{R} 78 \mathrm{G}$ protein-coupled receptor gene is required for the production of infectious virus in the spleen. J. Gen. Virol. 84, 2517-2530.

18. Kaptein, S.J.F., Beuken, E., Grauls, G.E.L.M., Bruggeman, C.A., and Vink, C. (2001). Rat cytomegalovirus open reading frame $R 44$ is an early-late gene that encodes a nuclear protein. Arch. Virol. 146, 2211-2218.

19. MacDonald, M.R., Burney, M.W., Resnick, S.B., and Virgin IV, H.W. (1999). Spliced mRNA encoding the murine cytomegalovirus chemokine homolog predicts a beta chemokine of novel structure. J. Virol. 73, 3682-3691.

20. MacDonald, M.R., Li, X.-Y., and Virgin IV, H.W. (1997). Late expression of a $\beta$ chemokine homolog by murine cytomegalovirus. J. Virol. 71, 1671-1678.

21. Meijer, H., Dreesen, J.C., and van Boven, C.P. (1986). Molecular cloning and restriction endonuclease mapping of the rat cytomegalovirus genome. J. Gen. Virol. 67,13271342.

22. Mocarski, E.S. (2002). Immunomodulation by cytomegaloviruses: manipulative strategies beyond evasion. Trends Microbiol. 10, 332-339.

23. Murphy, P.M. (2001). Viral exploitation and subversion of the immune system through chemokine mimicry. Nat. Immunol. 2,116-122.

24. Myers, E.W., and Miller, W. (1988). Optimal alignments in linear space. Comput. Appl. Biosci. 4, 11-17.

25. Penfold, M.E.T., Dairaghi, D.J., Duke, G., Saederup, N., Mocarski, E.S., Kemble, G.W., and Schall, T.J. (1999). Cytomegalovirus encodes a potent $\alpha$ chemokine. Proc. Natl. Acad. Sci. USA 96, 9839-9844. 
26. Percivalle, E., Revello, M.G., Vago, L., Morini, F., and Gerna, G. (1993). Circulating endothelial giant cells permissive for human cytomegalovirus (HCMV) are detected in disseminated HCMV infections with organ involvement. J. Clin. Invest. 92, 663670.

27. Persoons, M.C.J., Stals, F.S., van Dam Mieras, M.C., and Bruggeman, C.A. (1998). Multiple organ involvement during experimental cytomegalovirus infection is associated with disseminated vascular pathology. J. Pathol. 184, 103-109.

28. Rawlinson, W.D., Farrell, H.E., and Barrell, B.G. (1996). Analysis of the complete DNA sequence of murine cytomegalovirus. J. Virol. 70, 8833-8849.

29. Revello, M.G., Percivalle, E., Arbustini, E., Pardi, R., Sozzani, S., and Gerna, G. (1998). In vitro generation of human cytomegalovirus pp65 antigenemia, viremia, and leukoDNAemia. J. Clin. Invest. 101, 2686-2692.

30. Saederup, N., Aguirre, S.A., Sparer, T.E., Bouley, D.M., and Mocarski, E.S. (2001). Murine cytomegalovirus CC chemokine homolog MCK-2 (m131-129) is a determinant of dissemination that increases inflammation at initial sites of infection. J. Virol. 75 , 9966-9976.

31. Saederup, N., Lin, Y.C., Dairaghi, D.J., Schall, T.J., and Mocarski, E.S. (1999). Cytomegalovirus-encoded beta chemokine promotes monocyte-associated viremia in the host. Proc. Natl. Acad. Sci. USA 96, 10881-10886.

32. Seidman, J.G. (1998). Immunohistochemistry. In Current protocols in molecular biology, F.M. Ausubel, R. Brent, R.E. Kingston, D.D. Moore, J.G. Seidman, J.A. Smith, and K. Struhl, eds. (New York, USA: John Wiley \& Sons), pp. 14.6.1-16.6.13.

33. Stals, F.S., Bosman, F., van Boven, C.P., and Bruggeman, C.A. (1990). An animal model for therapeutic intervention studies of CMV infection in the immunocompromised host. Arch. Virol. 114, 91-107.

34. Thompson, J.D., Higgins, D.G., and Gibson, T.J. (1994). CLUSTAL W: improving the sensitivity of progressive multiple sequence alignment through sequence weighting, positions-specific gap penalties and weight matrix choice. Nucleic Acids Res. 22, 4673-4680.

35. Vink, C., Beuken, E., and Bruggeman, C.A. (1996). Structure of the rat cytomegalovirus genome termini. J. Virol. 70, $5221-5229$.

36. Vink, C., Beuken, E., and Bruggeman, C.A. (1997). Cloning and functional characterization of the origin of lytic-phase DNA replication of rat cytomegalovirus. J. Gen. Virol. 78, 2963-2973.

37. Vink, C., Beuken, E., and Bruggeman, C.A. (2000). The complete DNA sequence of the rat cytomegalovirus. J. Virol. 74, 7656-7665. 


\section{CHAPTER 5}

Summary and General Discussion

Samenvatting en Algehele Discussie 


\section{Summary and General Discussion}

Human cytomegalovirus (HCMV) constitutes a major cause of morbidity and mortality amongst immunocompromised subjects, particularly in transplant recipients and patients suffering from AIDS. Additionally, HCMV was reported to be implicated in various vascular disease processes, as reviewed in Chapter 1 . Evidence regarding a potential involvement of CMV in the development or exacerbation of vessel wall pathologies was provided by experiments using the RCMV (Maastricht strain)/rat model (Chapter 1). Moreover, this animal model has also proven to be a highly suitable model to examine whether or not (novel) antiviral agents are efficacious in controlling CMV infections.

HCMV infections are generally treated using antiviral agents that inhibit viral DNA synthesis, such as ganciclovir, cidofovir, or foscarnet. Ganciclovir (GCV) or 9-(1,3dihydroxy-2-propoxymethyl)guanide (DHPG) represents an acyclic analogue of the natural nucleoside 2-deoxyguanoside. Following intracellular phosphorylation of ganciclovir to ganciclovir-triphosphate by the HCMV-encoded protein kinase pUL97. the compound competes with deoxyguanoside triphosphate, resulting in an inhibition of viral DNA synthesis $[11,25,29]$. Cidofovir (CDV) forms an acyclic analogue of the corresponding monophosphate of deoxycytidine. In contrast to GCV, CDV does not require CMV-mediated initial phosphorylation. In fact, CDV is directly converted to the active triphosphate, after which it competes with deoxycytosine-5'-triphosphate in the incorporation process during viral DNA synthesis [23]. Lastly, foscarnet (FOS) or trisodium phosphonoformic acid (PFA) constitutes a pyrophosphate analogue. Contrarily to the mechanism of action of GCV and CDV. FOS directly inhibits the viral DNA polymerase by reversibly associating to the pyrophosphate binding site of DNA polymerases of herpesviruses, including the DNA polymerase encoded by HCMV [7]. However, current antiviral drug therapy was reported to concomitantly cause considerable toxic side effects, such as a deteriorated function of the central nervous system, renal function impairment, bone marrow hypoplasia, and leukopenia [17, 21, 33]. Moreover, the increased emergence of (multiple) drug resistant CMV strains nowadays represents a major menace to a successful treatment of CMV infections $[9,14,24,40]$. Resistance to current antiviral compounds is associated with the occurrence of mutations in either the HCMV UL97 and/or the UL54 gene, which encodes the catalytic subunit of the viral DNA polymerase $[2,15,22,41,42,46]$. Therefore, finding novel targets for the generation of antiviral agents is considered to be one of the main priorities in CMV research to date.

An interesting target for antiviral drug therapy development concerns the essential HCMV UL44-encoded DNA polymerase accessory protein (DPAP), also designated infected cell protein 36 (ICP36). This protein represents the other subunit of the CMVencoded DNA polymerase $[15,22]$. DPAP was reported to bind double-stranded DNA, to interact specifically with pUL54, to promote long-chain DNA synthesis, and to be required for viral replication $[10,26,35,37,45]$. Interestingly, it was recently demonstrated that pUL44 is phosphorylated by HCMV pUL97, implying that pUL97 might play a coregulatory role in CMV genome replication [28]. Like all sequenced herpesvirus genomes to date, the RCMV genome was also found to harbour a cognate UL44 gene [43]. This so-called R44 gene is expressed during the early and late phases 
of RCMV infection in vitro, yielding a potentially highly phosphorylated protein that localizes to the nucleus of RCMV-infected cells both in vitro and in vivo [19; Chapter 2]. Due to the relatively high overall identity between pR44 and pUL44 (Chapter 2), the RCMV/rat model may be employed to investigate the effectiveness of novel antiviral drugs which are directed against the pUL44 protein.

As a consequence of the increased emergence of $C M V$ strains that are resistant to the viral replication inhibitors GCV, CDV and/or FOS, it may be critical to develop antiviral compounds that, in contrast to current antiviral agents, do not seize the viral DNA polymerase but, instead, act at different targets. Hence, the membrane-associated and, thus, readily accessible CMV-encoded GPCRs may constitute more attractive antiviral targets. As to the putative GPCR genes present within the genome of HCMV, UL33 forms a highly eligible drug target, since this gene is conserved within the genomes of all known betaherpesviruses, suggestive of its biological relevance. Indeed, the UL33encoded homologues expressed by RCMV and MCMV (pR33 and pM33, respectively) were found to exert pivotal roles in virus replication in vivo. This was established by studying recombinant viruses in which either the R33 or M33 gene was disrupted or in which the R33 gene was fused to the EGFP (enhanced green fluorescent protein) gene. Unlike the wild type virus, these recombinants were unable to establish a high-titer infection in the salivary glands of infected animals [4, 8, 18; Chapter 3]. Furthermore, both pR33 and pM33 were reported to play an important role in the pathogenesis of CMV infection $[4,8]$. Intriguingly, it has recently become clear that the R33 gene as well as its counterparts within the genome of HCMV and MCMV indeed encode functionally active GPCRs, which are capable of triggering several signal transduction pathways in an agonist-independent, constitutive fashion $[5,12,13,44]$. Also, when cells were transfected with EGFP-tagged versions of above-mentioned proteins, these proteins were found to co-localize with the cell membrane $[13,44]$. Moreover, UL33like genes present within the genomes of human herpesvirus 6 (HHV-6) and 7 (HHV7 ), both designated $U 12$, were reported to encode proteins capable of binding various $C C$ (or $\beta$ ) chemokines, such as RANTES, MIP-1 $\alpha$, MIP-1 $\beta$, MCP-1, MIP-3 $\beta[16,32]$.

In addition to UL33, the HCMV genome contains yet another GPCR-like gene, termed $U L 78$, that is conserved in the genomes of all currently known betaherpesviruses, and, hence, may serve as a candidate for targeting anti-CMV drug therapy. However, contrarily to UL33, direct proof regarding UL78's GPCR nature is still lacking. Hitherto, researchers have been unsuccessful in their attempts to demonstrate that pUL78, or either one of its rodent CMV homologues, is capable of activating signaling pathways. The assumption that the UL78-like genes might putatively encode GPCRs was based on the following structurally conserved features that are present within the predicted amino acid sequences: (i) a central core domain consisting of seven transmembrane helices; (ii) two conserved cysteine residues within the predicted first and second extracellular loop, which may be involved in proper folding of the alleged GPCR; and (iii) a conserved $(D / E) R(L / I)$ motif within the predicted second intracellular loop that is thought to be required for $G$ protein-coupling [3]. Indirectly, however, there are indications that the UL78-like genes found in the different CMV genomes may indeed represent GPCR genes. The UL78-like protein encoded by HHV-6 U51, denoted pU51, was expressed in and transported to the cell surface of productively infected cord blood mononuclear cells as well as in several T-lymphocytic cell lines [30]. Additionally, when stably expressed in K562 cells, pU51 was shown to specifically bind RANTES [31]. 
Moreover, in competitive binding assays, the host chemokines MCP-1, MCP-3, MCP4 , and eotaxin, as well as the HHV-8 expressed chemokine VMIPII were capable of competing for RANTES binding by pU51 [31]. Altogether, these data imply that, analogous to the putative HHV-6 pU51 GPCR, the pUL78 homologues may display similar properties.

In order to monitor the expression of pR78 in vitro and in vivo, and because antibodies against this protein were lacking, a recombinant RCMV strain was generated that expresses an EGFP-tagged version of pR78 instead of its native counterpart [18; Chapter 3]. This recombinant virus strain was denoted RCMV78G. Interestingly, the R78-EGFP gene was able to only partially functionally replace its native R78 gene in vitro as well as in vivo. RCMV78G as well as strain RCMV $\triangle R 78 \mathrm{a}$, which carries a disrupted R78 gene, replicated with a lower efficiency than WT RCMV in vitro. When spleens were examined for the presence of infectious virus, virus could not be detected in spleen samples from any of the RCMV78G-or RCMV $\triangle R 78 \mathrm{a}$-infected rats at day 5 post infection (p.i.), whereas virus replicated productively in the spleen from wildtype (WT) RCMV-infected rats. Similarly, in spleen samples from RCMV $\triangle R 78 \mathrm{a}$-infected rats, the titers of infectious virus were also below detection level. Intriguingly, contrarily to the virus titers, the viral genomic DNA levels in the spleen were not found to differ significantly between either RCMV78G- and RCMV $\triangle R 78 \mathrm{a}$-infected rats on the one hand and WT RCMV-infected rats on the other, as determined by real-time, quantitative PCR. Moreover, expression of pR78-EGFP could easily be detected in the spleen (as well as the liver) of RCMV78G-infected rats. Altogether, these data suggest that, although both R78 mutant strains appear to enter the spleen as efficiently as WT RCMV, neither RCMV78G nor RCMV $\triangle R 78 \mathrm{a}$ is capable of replicating with an efficiency similar to that of WT RCMV. Correspondingly, an M78-deleted MCMV strain was also reported to be defective in replication in the spleen [34]. In contrast to both RCMV78G and $R C M V \triangle R 78 \mathrm{a}$, however, this strain was also demonstrated to replicate less efficiently than WT MCMV in the salivary glands as well as liver of infected mice [34]. In conclusion, the UL78-like genes in RCMV and MCMV play an important role in the production of infectious virus, at least in the spleen. Moreover, these genes likely also fulfil other important, more general functions in the pathogenesis of CMV infection. This was inferred from the observation that R78- and M78-deleted mutant strains induced a significantly lower mortality amongst infected animals than did their respective WT viruses $[3,34]$. Thus, these CMV-encoded GPCRs indeed constitute very attractive drug targets.

Additionally, the HCMV-encoded chemokines may represent yet other interesting targets for anti-CMV drug development, since chemokines represent one of the major constituents of the immune system. Initially, HCMV was reported to harbour two genes, UL146 and UL147, that both encode homologues of CXC (or $\alpha)$ chemokines and show the highest level of similarity with the host chemokine IL-8 $[6,36]$. To date, homologues of UL146 and UL147 have not been found within the genomes of the rodent CMVs. Instead, the MCMV genome encloses a gene, denoted m131/129, that expresses a putative CC chemokine [27]. As expected, the RCMV genome was shown to possess a gene that was conserved in sequence as well as in position with the MCMV m131/129 gene, which was designated 131 [43]. Furthermore, it was recently predicted that RCMV may harbour an additional gene encoding a CC chemokine homologue. This gene, which was termed $r 129$, is localized immediately downstream of $r 131$ [1]. 
Intriguingly, the amino acid sequence predicted to be encoded by 129 was demonstrated to display the highest level of similarity with the sequence encoded by the recently identified UL128 gene of HCMV. UL128 represents the only HCMV gene that has currently been identified as a gene encoding a CC chemokine homologue [1]. Thus, RCMV 129 and HCMV UL128 constitute the first putative chemokine genes that may have been conserved between rodent and primate CMVs.

A study was initiated to further characterize the two adjacent $C C$ chemokine-like genes that are present within the RCMV genome [20; Chapter 4]. As discussed above, the RCMV 131 - and 129 -encoded proteins were found to show the highest level of similarity with MCMV pm131/129 and HCMV pUL128, respectively. Furthermore, RCMV pr131 also showed similarity with a protein potentially encoded by the recently discovered HCMV UL130 gene. Although the UL130-encoded amino acid sequence is predicted to possess an $\mathrm{N}$-terminal signal peptide, it does not contain additional features typical of chemokines.

To determine the biological relevance of the CC chemokine genes of RCMV, we have first focused our attention to the elucidation of the role of the 131 gene in the pathogenesis of RCMV infection. For this purpose, two different knockout strains were created in which the 1131 gene was disrupted by a neomycin expression cassette (Chapter 4). These were designated RCMVAr131a, containing the neo gene in the opposite orientation as the 131 gene, and RCMV $\triangle \mathrm{r} 131 \mathrm{~b}$, containing the neo gene in the same orientation as the $r 131$ gene. In vitro, the $r 131$ gene was found to be dispensable for replication, as exemplified by the similarities in growth characteristics of WT RCMV, RCMV $\mathrm{r} 131 \mathrm{a}$ and RCMV $\triangle \mathrm{r} 131 \mathrm{~b}$ in REF cells. In vivo, however, pronounced differences were observed between WT RCMV on the one hand, and RCMV $\triangle \mathrm{r} 131 \mathrm{a}$ and RCMV $\triangle \mathrm{r} 131 \mathrm{~b}$ on the other. Neither RCMV $\Delta \mathrm{r} 131 \mathrm{a}$, nor RCMV $\mathrm{r} 131 \mathrm{~b}$ managed to replicate efficiently in the salivary glands of infected rats, whereas WT RCMV replicated productively in this organ. Similar results were found when virus was subcutaneously administered in the hind paw of rats. Interestingly, an additional difference was observed in the spleen from locally infected rats. Although infectious virus could not be detected in the spleen from any of the wild-type or recombinant virus-infected rats, a significantly higher viral DNA load was detected in the spleen from rats infected with WT RCMV than in those infected with either of the 1131 knockout viruses. Moreover, during local infection, RCMV $\Delta$ r131a as well as RCMV $\triangle \mathrm{r} 131 \mathrm{~b}$ induced significantly less paw swelling than did WT RCMV. Finally, when paws were examined further using immunohistochemistry, a higher number of inflammatory macrophages were observed in the WT RCMV-infected paws than in the r131 null mutant-infected paws. Similar data were previously reported for the MCMV m131/129 gene $[27,38,39]$, which indicates that RCMV r131 and MCMV m131/129 indeed represent functional homologues. Both genes appear to enhance the inflammation process at the initial sites of inoculation, and, subsequently, efficient virus dissemination to or infection of the salivary glands. Also, these chemokine genes might be involved in the persistent replication of virus in the spleen.

This leaves us with the question regarding the function of the 129 gene and its HCMV counterpart, UL128. It was suggested that UL128, and thus possibly $r 129$, might be involved in endothelial cell and leukocyte tropism (Chapter 4). To investigate this issue, and to determine the general role of the r129 CC chemokine gene in the pathogenesis of RCMV infection, we are currently generating 1129 -knockout viruses. 
In light of the homology between the 129 and UL128 genes, it is likely that the study of these recombinant viruses will also allow us to propose a function for the HCMV UL128 gene. Once again, this demonstrates the strength of the availability of the RCMV/ rat model, which allows us to study specific HCMV-like functions that can otherwise only be investigated in in vitro model systems. 


\section{Samenvatting en Algehele Discussie}

Het humaan cytomegalovirus (HCMV) is een belangrijke veroorzaker van morbiditeit en mortaliteit onder immuungecompromitteerde personen, in het bijzonder in transplantatie- en AIDS-patiënten. Daarnaast is gemeld dat HCMV betrokken is bij verscheidene vasculaire ziekteprocessen, hetgeen uitvoerig besproken is in Hoofdstuk 1. Bewijs betreffende een mogelijke betrokkenheid van CMV in de ontwikkeling of verergering van vaatwandpathologieën is onder andere geleverd in experimenten waarbij gebruik is gemaakt van het RCMV (Maastricht stam)/rat model (Hoofdstuk 1). Bovendien is bewezen dat dit diermodel een zeer geschikt model is om te onderzoeken of (nieuwe) antivirale agentia al dan niet doeltreffend zijn in het bedwingen van CMVinfecties

HCMV-infecties worden normaliter behandeld met antivirale middelen die de virale DNA-synthese inhiberen, zoals ganciclovir, cidofovir, of foscarnet. Ganciclovir (GCV), ookwel 9-(1,3-dihydroxy-2-propoxymethyl)guanide (DHPG) genoemd, is een acyclische analoog van het in de natuur voorkomende nucleoside 2-deoxyguanoside. $\mathrm{Na}$ de intracellulaire fosforylering van ganciclovir naar ganciclovir-trifosfaat, welke gemedieerd wordt door het HCMV-gecodeerde proteïne kinase pUL97, gaat de verbinding een competitie aan met deoxyguanoside trifosfaat, resulterend in een remming van de virale DNA-synthese $[11,25,29]$. Cidofovir (CDV) vertegenwoordigt een acyclische analoog van de overeenkomende monofosfaatvorm van deoxycytidine. In tegenstelling tot GCV vereist CDV geen CMV-gemedieerde initiële fosforylering. In feite wordt CDV rechtstreeks omgezet in de actieve trifosfaatverbinding, waarna het een competitie aangaat met deoxycytosine- 5 '-trifosfaat in het incorporatieproces tijdens de virale DNAsynthese [23]. Ten slotte vormt foscarnet (FOS) of trisodium fosfonoformaat (PFA) een pyrofosfaat-analoog. In tegenstelling tot het werkingsmechanisme van GCV en CDV inhibeert FOS rechtstreeks het virale DNA-polymerase door een reversibele binding aan te gaan met de pyrofosfaat-bindingsplaats van de DNA-polymerases van herpesvirussen, inclusief het DNA-polymerase dat gecodeerd wordt door HCMV [7]. Echter, van de huidige antivirale therapie is bekend dat deze gepaard gaat met aanzienlijke toxische bijwerkingen, zoals een verslechterde functie van het centraal zenuwstelsel, een aangetaste nierfunctie, beenmerg hypoplasie en leukopenie [17, 21 , 33]. Bovendien vormt de alsmaar toenemende hoeveelheid (meervoudig) resistente CMV-stammen tegenwoordig een grote bedreiging voor een succesvolle behandeling van CMV-infecties $[9,14,24,40]$. Resistentie tegen de huidige antivirale middelen is geassocieerd met het voorkomen van mutaties in het HCMV UL97 en/of UL54 gen, welke codeert voor de katalytische subeenheid van het virale DNA-polymerase [2, 15, $22,41,42,46]$. Aldus wordt het vinden van nieuwe aangrijpingspunten voor de ontwikkeling van antivirale middelen heden ten dagen beschouwd als één van de voornaamste prioriteiten in het CMV-onderzoek.

Een interessant aangrijpingspunt voor de ontwikkeling van antivirale therapie vormt het essentiële HCMV UL44-gecodeerde DNA-polymerase 'accessory protein' (DPAP), ookwel 'infected cell protein 36' (ICP36) genoemd. Dit eiwit vertegenwoordigt de andere subeenheid van het CMV-gecodeerde DNA-polymerase $[15,22]$. Van DPAP is gerapporteerd dat het dubbelstrengs-DNA bindt, een specifieke interactie aangaat met pUL54, lange-keten DNA-synthese bevordert en vereist is voor de virale replicatie [10. $26,35,37,45]$. Interessant is dat recentelijk is aangetoond dat pUL44 gefosforyleerd 
wordt door HCMV pUL97, wat inhoudt dat pUL97 een co-regulerende rol zou kunnen spelen in de CMV-genoomreplicatie [28]. Net als alle herpesvirusgenomen waarvan de basenvolgorden op dit moment bepaald zijn, is aangetoond dat het RCMV-genoom ook een homoloog van het UL44-gen bevat [43]. Dit zogenaamde R44-gen komt tot expressie tijdens de vroege en late fases van een RCMV-infectie in vitro, waarbij een mogelijk sterk gefosforyleerd eiwit ontstaat dat gelokaliseerd is in de kern van RCMVgeïnfecteerde cellen, zowel in vitro als in vivo [19; Hoofdstuk 2]. Omdat pR44 in relatief sterke mate identiek is aan pUL44 (Hoofdstuk 2), kan het RCMV/rat model aangewend worden om de werkzaamheid van nieuwe antivirale middelen die gericht zijn tegen het pUL44-eiwit te bestuderen.

Als gevolg van de toegenomen hoeveelheid CMV-stammen die resistent zijn tegen de virale replicatieremmers GCV, CDV en/of FOS kan het van belang zijn om antivirale middelen te ontwikkelen die, in tegenstelling tot de huidige antivirale agentia, niet op het virale DNA-polymerase aangrijpen, maar in plaats daarvan op andere aangrijpingspunten inwerken. Vandaar dat de membraan-geassocieerde en dus direct toegankelijke CMV-gecodeerde GPCR's aantrekkelijkere antivirale aangrijpspunten kunnen vormen. Wat betreft de vermeende GPCR-genen die aanwezig zijn in het genoom van HCMV vertegenwoordigt UL33 een zeer geschikt aangrijpingspunt, aangezien dit gen geconserveerd is in de genomen van alle bekende betaherpesvirusen, wat erop wijst dat dit gen biologisch relevant is. Van de UL33-gecodeerde homologen die door RCMV en MCMV tot expressie worden gebracht (respectievelijk pR33 en pM33), is inderdaad aangetoond dat ze een voorname rol vervullen in de virusreplicatie in vivo. Dit is vastgesteld aan de hand van studies met recombinantvirussen waarin hetzij het R33- of M33-gen verstoord is, hetzij het R33-gen gefuseerd is met een 'enhanced green fluorescent protein' (EGFP) -gen. In tegenstelling tot het wildtype virus waren deze recombinanten niet in staat om een hoge titer-virusinfectie tot stand te brengen in de speekselklieren van geïnecteerde dieren [4, 8, 18; Hoofdstuk 3]. Bovendien is er gerapporteerd dat zowel pR33 als pM33 een belangrijke rol spelen in de pathogenese van een CMV-infectie $[4,8]$. Intrigerend is dat recentelijk duidelijk is geworden dat het R33-gen, alsook equivalenten van het R33-gen in het HCMV- en MCMV-genoom, inderdaad coderen voor functioneel actieve GPCR's die in staat zijn om verscheidene signaaltransductieroutes op een ligand-onafhankelijke, constitutieve manier te activeren $[5,12,13,44]$. Bovendien, wanneer cellen getransfecteerd worden met EGFP-gelabelde versies van bovengenoemde eiwitten, blijken deze eiwitten te colokaliseren met de celmembraan $[13,44]$. Daarnaast is gemeld dat de UL33-achtige genen die zich bevinden in de genomen van humaan herpesvirus 6 (HHV-6) en 7 (HHV-7), beiden aangeduid met U12, coderen voor eiwitten die in staat zijn verscheidene CC - (of $\beta$-) chemokines te binden, zoals RANTES, MIP- $1 \alpha$, MIP-1 $\beta$, MCP-1, en MIP-3 $\beta$ $[16,32]$.

Naast UL33 bevat het HCMV-genoom nog een GPCR-achtig gen, UL78 genoemd, dat geconserveerd is in de genomen van alle tot nu toe bekende betaherpesvirussen en aldus zou kunnen dienen als een kandidaat waartegen men anti-CMV therapie zou kunnen richten. Echter, in tegenstelling tot UL33 is er een gebrek aan direct bewijs betreffende de GPCR-aard van UL78. Tot dusver zijn onderzoekers zonder resultaat geweest in hun pogingen om aan te tonen dat pUL78 of een van de knaagdier-CMV homologen in staat is om signaaltransductieroutes te activeren. De aanname dat de UL78-achtige genen mogelijkerwijs zouden kunnen coderen voor GPCR's was gebaseerd 
op de volgende structureel geconserveerde kenmerken die aanwezig zijn in de voorspelde aminozuursequenties: (i) een centraal kerndomein bestaande uit zeven transmembraanhelixen; (ii) twee geconserveerde cysteïne-residuen in de voorspelde eerste en tweede extracellulaire lus, die betrokken kunnen zijn bij de juiste vouwing van de zogenaamde GPCR; en (iii) een geconserveerd (D/E)R(L/I)-motief in de voorspelde tweede intracellulaire lus, waarvan gedacht wordt dat het vereist is voor $G$ eiwit-koppeling [3]. Echter, indirect zijn er aanwijzingen dat de UL78-achtige genen, die gevonden zijn in de verschillende CMV-genomen, inderdaad GPCR-genen kunnen vertegenwoordigen. Het UL78-achtige eiwit dat gecodeerd wordt door HHV-6 U51. aangeduid met pU51, wordt tot expressie gebracht in en naar het celoppervlak getransporteerd van productief geïnfecteerde 'cord blood' mononucleaire cellen en in verscheidene cellijnen van T-lymfocyten [30]. Daarnaast is aangetoond dat pU51 specifiek RANTES bindt wanneer het stabiel tot expressie wordt gebracht in K562cellen [31]. Bovendien waren de gastheerchemokines MCP-1, MCP-3, MCP-4 en eotaxine, alsook het door HHV-8 tot expressie gebrachte chemokine VMIPII, in staat om met RANTES een competitie aan te gaan voor binding met pU51 [31]. Over het geheel genomen houden deze gegevens in dat, in analogie met de vermeende HHV-6 pU51 GPCR, de pUL78-homologen soortgelijke eigenschappen kunnen vertonen.

Ten einde de expressie van PR78 in vitro en in vivo kritisch te volgen en omdat antilichamen tegen dit eiwit ontbreken, is er een recombinante RCMV-stam gegenereerd die een EGFP-gelabelde versie van pR78 tot expressie brengt in plaats van z'n natuurlijke equivalent [18; Hoofdstuk 3]. Deze recombinant virusstam wordt aangeduid met RCMV78G. Interessant is dat het R78-EGFP-gen slechts gedeeltelijk in staat is $z$ ' $n$ natuurlijke equivalent functioneel te vervangen zowel in vitro als in vivo. RCMV78G, alsook stam RCMV $\triangle R 78$ a dat een verstoord R78-gen bevat, vermenigvuldigde zich met een lagere efficiëntie dan het wildtype (WT) RCMV in vitro. Wanneer de milt onderzocht werd op de aanwezigheid van infectieus virus kon er geen virus gedetecteerd worden in miltmonsters van elk van de RCMV78G- of RCMV $\triangle R 78 \mathrm{a}$-geïnfecteerde ratten op dag 5 na infectie (n.i.), terwijl virus zich productief vermenigvuldigde in de milt van WT RCMV-geïnfecteerde ratten. Evenzo, in miltmonsters van RCMV $\triangle R 78 \mathrm{a}-$ geïnfecteerde ratten bevonden de virustiters zich onder het detectieniveau. Opmerkelijk is dat, in tegenstelling tot de virustiters, de niveaus van virale genomisch-DNA in de milt niet significant bleken te verschillen tussen hetzij RCMV78G-, of RCMV $\triangle R 78 \mathrm{a}$ geïnfecteerde ratten aan de ene kant en WT RCMV-geïnfecteerde ratten aan de andere kant, zoals vastgesteld door middel van een 'real-time', kwantitatieve PCR. Bovendien kon de expressie van PR78-EGFP gemakkelijk gedetecteerd worden in de milt (alsook in de lever) van RCMV78G-geïnfecteerde ratten. Alles samengenomen, wijzen deze gegevens erop dat, ofschoon beide R78-muntantstammen net zo efficiënt de milt binnendringen als het WT RCMV, noch RCMV78G, noch RCMV $\triangle R 78 \mathrm{a}$ in staat is zich met een soortgelijke efficiëntie als WT RCMV te vermenigvuldigen. In overeenstemming hiermee is de rapportage van een $M 78$-gedeleteerde MCMV-stam met een gebrekkige replicatie in de milt [34]. Echter, in tegenstelling tot zowel RCMV78G als RCMV $\triangle R 78 \mathrm{a}$, is aangetoond dat deze stam minder efficiënt repliceert in de speekselklieren, alsook de lever van geïnfecteerde muizen dan WT MCMV [34]. Concluderend, de UL78-achtige genen in het RCMV- en MCMV-genoom spelen een belangrijke rol in de productie van infectieus virus, ten minste in de milt. Bovendien vervullen deze genen waarschijnlijk ook andere belangrijke, meer algemene functies in de pathogenese van een CMV- 
infectie. Dit is afgeleid uit de waarneming dat R78- en M78-gedeleteerde mutantstammen een significant lagere mortaliteit onder geïnfecteerde dieren veroorzaakten dan hun respectievelijke WT-virussen [3, 34]. Aldus vormen deze CMVgecodeerde GPCR's inderdaad zeer aantrekkelijke aangrijpingspunten voor antivirale therapie.

Daarnaast vormen de HCMV-gecodeerde chemokines mogelijk nog andere interessante aangrijpingspunten voor de ontwikkeling van anti-CMV therapie, aangezien chemokines één van de voornaamste bestanddelen vertegenwoordigen van het immuunsysteem. Aanvankelijk is gemeld dat HCMV twee genen herbergt, UL146 en UL147, die beiden coderen voor homologen van CXC- (or $\alpha-$ ) chemokines en de meeste overeenkomst vertonen met het gastheerchemokine IL-8 $[6,36]$. Tot op heden zijn er geen homologen van UL146 en UL147 gevonden in de genomen van de knaagdierCMV's. In plaats daarvan bevat het MCMV-genoom een gen, aangeduid met $\mathrm{m} 131$ / 129, dat een vermeend CC-chemokine tot expressie brengt [27]. Zoals verwacht, is er aangetoond dat het RCMV-genoom een gen bevat, $r 131$ genaamd, dat zowel in sequentie als in positie geconserveerd is met het m131/129-gen [43]. Bovendien is er recentelijk voorspeld dat het $R C M V$-genoom nog een gen zou kunnen herbergen dat codeert voor een CC-chemokine homoloog. Dit gen, dat 129 is genoemd, is onmiddellijk stroomafwaarts van $r 131$ gelegen [1]. Opmerkelijk is dat de voorspelde aminozuursequentie die door 129 gecodeerd wordt de hoogste mate van overeenkomst laat zien met de sequentie die gecodeerd wordt door het recentelijk geïndentificeerde UL128-gen van HCMV. UL128 vertegenwoordigt het enige HCMV-gen dat thans geïndentificeerd is als een gen dat codeert voor een CC-chemokine homoloog [1]. Dus, RCMV r1 29 en HCMV UL1 28 vormen de eerste veronderstelde chemokine-genen die mogelijk geconserveerd zijn gebleven tussen de knaagdier- en primaat-CMV's.

Om de twee aangrenzende CC-chemokine-achtige genen, die in het RCMV-genoom aanwezig zijn, verder te karakteriseren, is er een studie geïnitieerd [20; Hoofdstuk 4]. Zoals hierboven beschreven, laten de RCMV r131- en r129-gecodeerde eiwitten de hoogste mate van overeenkomst zien met respectievelijk MCMV m131/129 en HCMV UL128. Daarnaast vertoonde RCMV pr131 ook een overeenkomst met een eiwit dat mogelijk gecodeerd wordt door het recentelijk ontdekte HCMV UL130-gen. Ofschoon voorspeld is dat de UL130-gecodeerde aminozuursequentie een $\mathrm{N}$-terminaal signaalpeptide bevat, bezit het geen additionele eigenschappen die kenmerkend zijn voor chemokines.

Ten einde de biologische relevantie van de CC-chemokine genen van het RCMV vast te stellen, hebben we onze aandacht eerst gericht op de rol van het 131 -gen in de pathogenese van een RCMV-infectie. Met dit doel werden er twee verschillende 'knockout'-stammen gecreëerd waarin het r131-gen verstoord wordt door een neomycine expressie cassette (Hoofdstuk 4). Ze worden aangeduid met RCMVAr131a, waarbij de oriëntatie van het neo-gen tegengesteld is aan die van het $\mathrm{r} 131$-gen, en RCMV $\Delta \mathrm{r} 131 \mathrm{~b}$, met het neo-gen in dezelfde oriëntatie als het $\mathrm{r} 131$-gen. In vitro is aangetoond dat het $\mathrm{r} 131$-gen ontbeerlijk is voor de replicatie, zoals de overeenkomsten in de groeikarakteristieken van WT RCMV, RCMV $\triangle 131 \mathrm{a}$ en RCMV $\triangle \mathrm{r} 131 \mathrm{~b}$ in REFcellen lieten zien. Echter, in vivo zijn er uitgesproken verschillen waargenomen tussen WT RCMV aan de ene kant en RCMV $\triangle$ r131 a en RCMV 1 r131b aan de andere kant. Noch RCMV $\triangle$ 131a, noch RCMV $\triangle$ r131b slaagde er in om zich efficiënt te vermenigvuldigen in de speekselklieren van geïnfecteerde ratten, terwijl WT RCMV 
zich produktief vermenigvuldigde in dit orgaan. Soortgelijke resultaten werden gevonden wanneer het virus subcutaan werd toegediend in het achterpootje van ratten. Nog een interessant verschil werd waargenomen in de milt van lokaal-geïnfecteerde ratten. Ofschoon infectieus virus niet gedetecteerd kon worden in de milt van elk van de wildtype- of recombinantvirus-geïnfecteerde ratten, werd er een significant hogere virale 'DNA-load' gevonden in de milt van ratten geïnfecteerd met WT RCMV dan in die van ratten geïnfecteerd met een van de 1131 -knockoutvirussen. Bovendien veroorzaakte zowel RCMV $\Delta \mathrm{r} 131 \mathrm{a}$ als RCMV $\Delta \mathrm{r} 131 \mathrm{~b}$ tijdens een plaatselijke infectie significant minder zwelling van het pootje dan WT RCMV. Ten slotte, wanneer de pootjes met behulp van immuunhistochemie verder onderzocht werden, werd er een groter aantal inflammatoire macrofagen geobserveerd in de WT RCMV-geïnfecteerde pootjes dan in de 1 131-deletiemutant-geïnfecteerde pootjes. Soortgelijke data zijn eerder gerapporteerd voor het MCMV m131/129-gen [27, 38, 39], wat erop wijst dat RCMV r131 en MCMV m131/129 inderdaad elkaars functionele homologen vertegenwoordigen. Beide genen lijken het ontstekingsproces op de initiële plaasten van inoculatie te bevorderen met daaruit volgend een efficiëntere virusdisseminatie naar of infectie van de speekselklieren. Ook zouden deze chemokine-genen betrokken kunnen zijn bij de aanhoudende vermenigvuldiging van virus in de milt.

Dat brengt ons bij de kwestie betreffende de functie van het 1129 -gen en z'n HCMV-equivalent, UL128. Er is gesuggereerd dat UL128, en dus mogelijk 1129 , betrokken zou kunnen zijn bij endotheelcel- en leukocyttropisme (Hoofdstuk 4). Om deze kwestie te onderzoeken en om de algemene rol van het 129 CC-chemokine gen in de pathogenese van een RCMV-infectie vast te stellen, worden er op dit moment r129-knockoutvirussen gegenereerd. In het licht van de homologie tussen de r129-en UL128-genen is het waarschijnlijk dat het bestuderen van deze recombinantvirussen ons in staat stelt om een suggestie te doen omtrent de functie van het HCMV UL128gen. Dit toont wederom de kracht van de bruikbaarheid van het RCMV/rat model, dat ons in staat stelt om specifieke HCMV-achtige functies te bestuderen die anders alleen in in vitro modelsystemen onderzocht kunnen worden.

\section{References}

1. Akter, P., Cunningham, C., McSharry, B.P., Dolan, A., Addison, C., Dargan, D.J., Hassan-Walker, A.F., Emery, V.C., Griffiths, P.D., Wilkinson, G.W.G., Davison, A.J. (2003). Two novel spliced genes in human cytomegalovirus. J. Gen. Virol. 84, 1117-1122.

2. Baldanti, F., Underwood, M.R., Talarico, C.L., Simoncini, L., Sarasini, A., Biron, K.K., Gerna, G. (1998). The Cys607 $\rightarrow$ Tyr change in the UL97 phosphotransferase confers ganciclovir resistance to two human cytomegalovirus strains recovered from two immunocompromised patients. Antimicrob. Agents Chemother. 42, 444-446.

3. Beisser, P.S., Grauls, G.E.L.M., Bruggeman. C.A., Vink, C. (1999). Deletion of the $R 78 \mathrm{G}$ protein-coupled receptor gene from rat cytomegalovirus results in an attenuated, syncytium-inducing mutant strain. J. Virol. 73, 7218-7230.

4. Beisser, P.S., Vink, C., van Dam, J.G., Grauls, G.E.L.M., Vanherle, S.J.V., Bruggeman, C.A. (1998). The R33 G protein-coupled receptor gene of rat 
cytomegalovirus plays an essential role in the pathogenesis of viral infection. J. Virol. 72, 2352-2363.

5. Casarosa, P., Gruijthuijsen, Y.K., Michel, D., Beisser, P.S., Holl, J., Fitzsimons, C.P., Verzijl, D., Bruggeman, C.A., Mertens, T., Leur, R., Vink, C., Smit, M.J. (2003). Constitutive signaling of the human cytomegalovirus-encoded receptor UL33 differs from that of its rat cytomegalovirus homolog R33 by promiscuous activation of $\mathrm{G}$ proteins of the $\mathrm{Gq}, \mathrm{Gi}$, and Gs classes. J. Biol. Chem. 278, 50010-50023.

6. Cha, T.A., Tom, E., Kemble, G.W., Duke, G.M., Mocarski, E.S., Spaete, R.R. (1996). Human cytomegalovirus clinical isolates carry at least 19 genes not found in laboratory strains. J. Virol. 70, 78-83.

7. Chrisp. P., Clissold, S.P. (1991). Foscarnet. A review of its antiviral activity, pharmacokinetic properties and therapeutic use in immunocompromised patients with cytomegalovirus retinitis. Drugs 41, 104-129.

8. Davis-Poynter, N.J., Lynch, D.M., Vally, H., Shellam, G.R., Rawlinson, W.D., Barrell, B.G., Farrell, H.E. (1997). Identification and characterization of a G protein-coupled receptor homolog encoded by murine cytomegalovirus. J. Virol. $71,1521-1529$.

9. Erice, A., Chou, S., Biron, K.K., Stanat, S.C., Balfour Jr, H.H., Jordan, M.C. (1989). Progressive disease due to ganciclovir-resistant cytomegalovirus in immunocompromised patients. N. Engl. J. Med. 320, 289-293.

10. Ertl, P.F., Powell, K.L. (1992). Physical and functional interaction of human cytomegalovirus DNA polymerase and its accessory protein (ICP36) expressed in insect cells. J. Virol. 66, 4126-4133.

11. Faulds, D., Heel, R.C. (1990). Ganciclovir. A review of its antiviral activity, pharmacokinetic properties and therapeutic efficacy in cytomegalovirus infections. Drugs 39, 597-638.

12. Gruijthuijsen, Y.K., Beuken, E.V.H., Smit, M.J., Leurs, R., Bruggeman, Vink, C. (2004). Mutational analysis of the R33-encoded G protein-coupled receptor of rat cytomegalovirus: identification of amino acid residues critical for cellular localization and ligand-independent signaling. J. Gen. Virol. 85, 897-909.

13. Gruijthuijsen, Y.K., Casarosa, P., Kaptein, S.J.F., Broers, J.L.V., Leurs, R., Bruggeman, C.A., Smit, M.J., and Vink, C. (2002). The rat cytomegalovirus R33-encoded $G$ protein-coupled receptor signals in a constitutive fashion. J. Virol. 76, 1328-1338.

14. Harada, K., Eizuru, Y., Isashiki, Y., Ihara, S., Minamishima, Y. (1997). Genetic analysis of a clinical isolate of human cytomegalovirus exhibiting resistance against both ganciclovir and cidofovir. Arch. Virol. 142, 215-225.

15. Heilbronn, R., Jahn, G., Burkle, A., Freese, U.K., Fleckenstein, B., zur Hausen, $H$. (1987). Genomic localization, sequence analysis, and transcription of the putative human cytomegalovirus DNA polymerase gene. J. Virol. 61, 119124.

16. Isegawa, Y., Ping, Z., Nakano, K., Sugimoto, N., Yamanishi, K. (1998). Human herpesvirus 6 open reading frame U12 encodes a functional $\beta$-chemokine receptor. J. Virol. 72, 6104-6112

17. Jacobson, M.A. (1992). Review of the toxicities of foscarnet. J. Acquir. Immune Defic. Syndr. 5, S11-S17. 
18. Kaptein, S.J.F., Beisser, P.S., Gruijthuijsen, Y.K., Savelkouls, K.G.M., van Cleef, K.W.R., Beuken, E., Grauls, G.E.L.M., Bruggeman, C.A., Vink, C. (2003). The rat cytomegalovirus $R 78 G$ protein-coupled receptor gene is required for production of infectious virus in the spleen. J. Gen. Virol. 84, 2517-2530.

19. Kaptein, S.J.F., Beuken, E., Grauls, G.E.L.M., Bruggeman, C.A., Vink, C. (2001). Rat cytomegalovirus open reading frame $\mathrm{R} 44$ is an early-late gene that encodes a nuclear protein. Arch. Virol. 146, 2211-2218.

20. Kaptein, S.J.F., van Cleef, K.W.R., Gruijthuijsen, Y.K., Beuken, E.V.H., Van Buggenhout, L., Beisser, P.S., Stassen, F.R.M., Bruggeman, C.A., Vink, C. (2004). The 131 gene of rat cytomegalovirus encodes a proinflammatory $C C$ chemokine homolog which is essential for the production of infectious virus in the salivary glands. Virus Genes 29, 43-61.

21. Kendle, J.B., Fan Havard, P. (1998). Cidofovir in the treatment of cytomegaloviral disease. Ann. Pharmacother. 32, 1181-1192.

22. Kouzarides, T., Bankier, A.T., Satchwell, S.C., Weston, K., Tomlinson, P., Barrell, B.G. (1987). Sequence and transcription analysis of the human cytomegalovirus DNA polymerase gene. J. Virol. 61, 125-133.

23. Lea, A.P., Bryson, H.M. (1996). Cidofovir. Drugs 52, 225-230.

24. Leport, C., Puget, S., Pepin, J.M., Levy, S., Perronne, C., Brun-Vezinet, F., Vilde, J.L. (1993). Cytomegalovirus resistant to foscarnet: clinicovirologic correlation in a patient with human immunodeficiency virus [letter]. J. Infect. Dis. 168, 1329-1330.

25. Littler, E., Stuart, A.D., Chee, M.S. (1992). Human cytomegalovirus UL97 open reading frame encodes a protein that phosphorylates the antiviral nucleoside analogue ganciclovir. Nature 358, 160-162.

26. Loregian, A., Rigatti, R., Murphy, M., Schievano, E., Palu, G., Marsden, H.S. (2003). Inhibition of human cytomegalovirus DNA polymerase by C-terminal peptides from the UL54 subunit. J. Virol. 77, 8336-8344.

27. MacDonald, M.R., Li, X.-Y., Virgin IV, H.W. (1997). Late expression of a $\beta$ chemokine homolog by murine cytomegalovirus. J. Virol. 71, 1671-1678.

28. Marschall, M., Freitag, M., Suchy, P., Romaker, D., Kupfer, R., Hanke, M., Stamminger, T. (2003). The protein kinase pUL97 of human cytomegalovirus interacts with and phosphorylates the DNA polymerase processivity factor pUL44. Virology 311, 60-71.

29. Martin, J.C., Dvorak, C.A., Smee, D.F., Matthews, T.R., Verheyden, J.P. (1983). 9-[(1,3-Dihydroxy-2-propoxy)methyl]guanine: a new potent and selective antiherpes agent. J. Med. Chem. 26, 759-761.

30. Menotti, L., Mirandola, P., Locati, M., Campadelli-Fiume, G. (1999). Trafficking to the plasma membrane of the seven-transmembrane protein encoded by human herpesvirus 6 U51 gene involves a cell-specific function present in T lymphocytes. J. Virol. 73, 325-333.

31. Milne, R.S.B., Mattick, C., Nicholson, L., Devaraj, P., Alcami, A., Gompels, U.A. (2000). RANTES binding and down-regulation by a novel human herpesvirus$6 \beta$ chemokine receptor. J. Immunol. 164, 2396-2404.

32. Nakano, K., Tadagaki, K., Isegawa, Y., Aye, M.M., Zou, P., Yamanishi, K. (2003). Human herpesvirus 7 open reading frame U12 encodes a functional betachemokine receptor. J. Virol. 77, 8108-8115. 
33. Noble, S., Faulds, D. (1998). Ganciclovir. An update of its use in the prevention of cytomegalovirus infection and disease in transplant recipients. Drugs 56 , 115-146.

34. Oliveira, S.A., Shenk, T.E. (2001). Murine cytomegalovirus M78 protein, a G protein-coupled receptor homologue, is a constituent of the virion and facilitates accumulation of immediate-early viral mRNA. Proc. Natl. Acad. Sci. USA 98, 3237-3242.

35. Pari, G.S., Kacica, M.A., Anders, D.G. (1993). Open reading frames UL44, IRS1/TRS1, and UL36-UL38 are required for transient complementation of human cytomegalovirus orhyt-dependent DNA synthesis. J. Virol. 67, 25752582.

36. Penfold, M.E.T., Dairaghi, D.J., Duke, G.M., Saederup, N., Mocarski, E.S., Kemble, G.W., Schall, T.J. (1999). Cytomegalovirus encodes a potent $\alpha$ chemokine. Proc. Natl. Acad. Sci. USA 96, 9839-9844.

37. Ripalti, A., Boccuni, M.C., Campanini, F., Landini, M.P. (1995). Cytomegalovirusmediated induction of antisense mRNA expression to UL44 inhibits virus replication in astrocytoma cell line: identification of an essential gene. J. Virol. 69, 2047-2057

38. Saederup, N., Aguirre, S.A., Sparer, T.E., Bouley, D.M., Mocarski, E.S. (2001). Murine cytomegalovirus CC chemokine homolog MCK-2 (m131-129) is a determinant of dissemination that increases inflammation at initial sites of infection. J. Virol. 75, 9966-9976.

39. Saederup, N., Lin, Y.C., Dairaghi, D.J., Schall, T.J., Mocarski, E.S. (1999). Cytomegalovirus-encoded $\beta$ chemokine promotes monocyte-associated viremia in the host. Proc. Natl. Acad. Sci. USA, 96, 10881-10886.

40. Sarasini, A., Baldanti, F., Furione, M., Percivalle, E., Brerra, R., Barbi, M., Gerna, G. (1995). Double resistance to ganciclovir and foscarnet of four human cytomegalovirus strains recovered from AIDS patients. J. Med. Virol. 47, $237-$ 244.

41. Smith, I.L., Cherrington, J.M., Jiles, R.E., Fuller, M.D., Freeman, W.R., Spector, S.A. (1997). High-level resistance of cytomegalovirus to ganciclovir is associated with alterations in both the UL97 and DNA polymerase genes. J. Infect. Dis. $176,69-77$.

42. Sullivan, V., Biron, K.K., Talarico, C., Stanat, S.C., Davis, M., Pozzi, L.M., Coen, D.M. (1993). A point mutation in the human cytomegalovirus DNA polymerase gene confers resistance to ganciclovir and phosphonylmethoxyalkyl derivates. Antimicrob. Agents Chemother. 37, 19-25.

43. Vink, C., Beuken, E., Bruggeman, C.A. (2000). Complete DNA sequence of the rat cytomegalovirus genome. J. Virol. 74, 7656-7665.

44. Waldhoer, M., Kledal, T.H., Farrell, H., Schwartz, T.W. (2002). Murine cytomegalovirus (CMV) M33 and human CMV US28 receptors exhibit similar constitutive signaling activities. J. Virol. 76, 8161-8168.

45. Weiland, K.L., Oien, N.L., Homa, F., Wathen, M.W. (1994). Functional analysis of human cytomegalovirus polymerase accessory protein. Virus Res. 34, 191 206.

46. Wolf, D.G., Lee, D.J., Spector, S.A. (1995). Detection of human cytomegalovirus mutations associated with ganciclovir resistance in cerebrospinal fluid of AIDS 
patients with central nervous system disease. Antimicrob. Agents Chemother. 39, 2552-2554. 


\section{DANKWOORD}


Lieve mensen, ik vrees dat ik ruimte en woorden te kort ga komen om iedereen persoonlijk te bedanken. Om ervoor te zorgen dat mijn dankwoord-sectie binnen de perken blijft, zal ik het kort moeten houden, wetende dat ik daarmee velen te kort ga doen, maar dat maakt mijn dank er zeker niet minder om.

Mijn eerste woord van dank gaat uit naar mijn promotor Cathrien Bruggeman. Al weer zes jaar geleden gaf zij mij de mogelijkheid om promotieonderzoek te verrichten aan de capaciteitsgroep Medische Microbiologie. Met je onuitputtelijke bron van energie en werklust, ben je verantwoordelijk voor het aansturen van de gehele onderzoeksgroep. Daarnaast ben je ook altijd geïnteresseerd in de activiteiten van de AiO's buiten de werkuren, ben je altijd in voor een geintje en heb ik onze gesprekken als buitengewoon prettig ervaren. Ik waardeer het bijzonder dat je in me bent blijven geloven en het resultaat van dat vertouwen ligt nu voor je in de vorm van dit 'ietwat verlate' proefschrift.

Niet in de laatste plaats is dit proefschrift er gekomen door de tomeloze inzet van mijn co-promotor Kees Vink. Kees, als hoofd van de RCMV-onderzoeksgroep, ben jij de direct verantwoordelijke geweest voor het tot stand komen van dit proefschrift. Je hebt op alsook buiten het lab een overweldigende (werk-)sfeer weten te creëeren, waardoor ik gemotiveerd bleef en die mij in staat heeft gesteld om over de nodige tegenvallers heen te stappen en in alle vrijheid door te gaan. Daarnaast was je nooit te beroerd om zelf de handen uit de mouwen te steken voor een klonering of het uitvoeren van je favoriete kunststukje (de eiwitgel) op momenten dat ik mijn handen vol had. Ook wist je het onderzoek bij te sturen als deze een doodlopende weg dreigde in te gaan en heb je een zeer verfijnd gevoel voor taal, waardoor aanvankelijk onsamenhangende stukken tekst werden omgetoverd in smakelijke artikels. Ik denk niet dat het te veel is gezegd dat je je als AiO geen betere begeleider kunt wensen.

Fonneke, de mutsketiers zijn dan uiteindelijk toch uit elkaar gegaan. Dat is misschien maar goed ook, aangezien onze collega's nogal wat moeite hadden om ons ("megatrut" en "superdoos") uit elkaar te houden (?!). Ondanks je 'geprikkeldheid, sarcasme, ironie en zwartgalligheid', heb ik jouw gezelschap vooral als bijzonder inspirerend ervaren. Ook buiten het lab heb je me aangespoord om grenzen te overschrijden (welk weldenkend mens gaat er nu immers in een gletcherspleet hangen?). Ik kets de bal dan ook gewoon terug: Wie is er hier nu eigenlijk de wortel (over de ezel zullen we maar zwijgen)? Ofschoon de gezellige (!) klets-, stampot-, film-, klim- (lees: klets-) avonden met intimi er tegenwoordig helaas niet vaak meer inzitten, ben ik ervan overtuigd dat er in de toekomst nog voldoende avontuur in het verschiet ligt. Eén voor allen en allen voor één!

Ook wil ik Patrick niet onvernoemd laten. Patrick, jij bent verantwoordelijk geweest voor mijn vuurdoop in dit fantastische vakgebied. Met je geweldig onderzoekende en creatieve geest heb je me wegwijs weten te maken in de wondere wereld van het CMV en ben je (nog steeds) een grote inspiratiebron voor mij (geweest). Ook zou menig figuur in en de omslag van dit proefschrift nooit het licht hebben gezien zonder jouw niet te evenaren tekenkunsten. De momenten dat ik je zo nu en dan het liefst achter het behang wilde plakken, zij je voor altijd vergeven. 
Koen, vanaf het moment dat jij je intrede deed in de AiO-kamer ben jij verworden van een stille jongen tot een heuse steukminol. Ons gevoel voor humor sluit naadloos op elkaar aan, waardoor we nu de schrik van de afdeling zijn en wat ons een ware bijnaam heeft opgeleverd ("de monsters"). Ofschoon we jou al een aantal jaren geleden een hint hebben gegeven door je met je verjaardag een uitzet cadeau te geven, drong die pas dit jaar tot je door. Maar goed, je beschikt dan ook over een voortreffelijk luistervermogen en geheugen ("sorry, jullie hebben het nu al twee keer gezegd, geloof $i k$, maar welke route lopen we morgen?"). Help je me er even aan herinneren dat ik je nog aan de andere paranimfe voorstel?

Erik, het feit alleen al dat je het zo lang met mij en mijn "gezang" hebt uitgehouden, is al een enorme pluim waard. Daarnaast heb je voor mij de nodige labwerkzaamheden uitgevoerd, zoals DNA-isolaties, maxiprep DNA-zuiveringen, sequencing, het genereren van expressie-constructen, etc. Ook beschik je over een enorme expertise, waardoor ik je bij tijd en wijlen de oren van het hoofd heb gevraagd. Ik ben je dan ook eeuwig dankbaar.

Gert, zonder jou zou het 'andere' lab verworden zijn tot één grote chaos. Ik heb dan ook dankbaar gebruik gemaakt van jouw zorgvuldig aangelegde systemen van virusstocks en cellen, alsook van jouw onuitputtelijke bron aan kennis betreffende kleuringen, cel- en viruskweek, en wat al niet meer.

Ook de mensen van de moleculaire diagnostiek en met name Lieve en Selma mogen hier niet ontbreken. Lieve, bedankt dat je, ondanks jouw drukke werkschema, toch tijd voor mij wist vrij te maken voor het inzetten van quantitatieve PCR's en de nodige gezellige babbels. Dit laatste geldt natuurlijk ook voor Selma. We hebben heel wat tijd weggekletst tijdens één van de prachtige wandelingen door het Limburgse landschap. een heerlijke Italiaans diner, over een kopje cappucino bij Coffee Lovers, of gewoon even op het werk.

Kim, pletskesgezich, natuurlijk ook jij bedankt voor het inzetten van de nodige hoeveelheid quantitatieve PCR's, de zoepavonden, de squashwedstrijden en het gekeet op het lab. Het is zeker significant stiller op het lab geworden sinds je weg bent.

Ook wil ik de mensen die op de 'allochtonenkamer' en de 'postdockamer' (Rajaa, Inge, Ellen, Xavier, Hilde, Martijn en Geoffrey) zitten, bedanken voor een plesante tijd en zou ik me misschien zelfs moeten verontschuldigen voor het feit dat ik (met de nodige hulp van anderen) enkelen van jullie herhaaldelijk op de kast heb gejaagd (èch nie!). Vooral 'ICT-man' Martijn (te bereiken op 76642) wil ik extra bedanken voor zijn onmisbare hulp omtrent hard- en software en zijn onuitputtelijke bron aan mp3-tjes (Hans Teeuwen, Harry Jekkers, André Hazes, Kinderen voor Kinderen, etc.).

Natuurlijk mogen ook andere (ex-)collega's/kamergenoten/stagiaires op de afdeling niet ontbreken in dit dankwoord: Frank, Rien, Aafke, Karen, John, Jeroen \& Susan, Joanne, Tryfon, Manuela, Rick, Sabine, Monique, Carola, Saskia, Mohammed, Evi, Alice, Astrid, Bart, Christine, kleine Erik, Claudia (dank voor de vertaling!), en al diegenen die ik vergeten ben te vernoemen. Als het onderzoek eventjes in een slop zat, dan wist de 
oergezellige sfeer op de kamer c.q. het lab me altijd wel op te beuren. Ik ben me er terdege van bewust dat zulk een collegialiteit een unicum is.

Ook de mensen van het secretariaat (José, Fia, Angèle, Patricia) en de mensen van de spoelkeuken (Ans, Verius, John) verdienen het om hier vernoemd te worden voor al het (vuile) werk waarmee ik ze opgezadeld heb.

Jag vill också tacka Cecilia Söderberg-Nauclér som gav mig möjligheten att jobba på institutionen för biovetenskap på Novum, Karolinska Institutet, Huddinge, Sverige. Självklart ska jag inte glömma Sara Gredmark, Sari Feld, Jenny Odeberg och Mohammed Homman som stod ut med mig och mitt sjungande på labbet i sex veckor, och för att de gav mig en härlig tid i Stockholm. Jag skriver bara lite svenska. Därför jag säger det kort: Tack så mycket för er gästfrihet. Hej då, kanske adjö och på återseende!

My gratitude also to Dr. Jay Nelson at the Department of Molecular Microbiology and Immunology at the Oregon Health Sciences University (OHSU), Portland, Oregon, USA. In particular, I would like to thank Dan Streblow and Patsy Smith for their excellent guidance in the lab and for inviting me at their homes at X-mas. Also, Susan Orloff, Dora Pancheva, Heather Meyers, Lisa Strelow. Craig Kreklywich, Ryan Melnychuk. Michael Munks, Franziska Ruchti and all the others in the lab for giving me an unforgettable time. Even after working hours you did not give me any time to get bored, taking me to basket ball and ice hockey games and learning me how to snowshoe and to do the 'faceplant'. Your hospitality has been overwhelming!

Ook wil ik mijn Wollukse middelbare schoolgroepje bedanken: Oliver, Astrid \& Edwin, Sabine, Mariëtte, Ageeth \& Frank, Frank IJ, Bianca \& Ruben en Pascal. Ondanks het feit dat ik de laatste jaren steeds minder tijd voor jullie heb kunnen vrijmaken, zijn jullie me niet vergeten. Zoals jullie nu wel kunnen lezen, ben ik ook jullie niet vergeten. Ik dank jullie voor jullie begrip en ik hoop dat onze vriendschap nog lang mag voortduren!

Degenen die ik zeker niet onvernoemd mag laten, zijn mijn broer en zus. Lieve Jeroen, als grote broer ben jij zeker iemand geweest tegen wie ik opkeek (en dat niet alleen vanwege mij lengte of eerder gezegd het tekort daaraan). Lieve Brigitte, ondanks het feit dat je samen met Martijn in het Haagie woont, weet je nog steeds wat Brabantse gezelligheid is! Het is heerlijk om te weten dat ik te allen tijde bij jullie welkom ben, waar ik dan ook het nodige misbruik van heb gemaakt om weer even op adem te kunnen komen. Je weet niet half hoe belangrijk je voor mij bent. Ik hoop dat ik in de toekomst wat meer tijd voor je kan vrijmaken. Ligt de haring met uitjes al klaar?

Lieve mams en paps. Natuurlijk kan en wil ik jullie niet vergeten te vernoemen. Sterker nog het laatste woord is voor jullie. Eigenlijk zeg ik het te weinig, maar nu staat het dan zwart op wit: Waar zou ik zijn zonder jullie onvoorwaardelijke steun en liefde? Daar kan eigenlijk geen dankwoord tegenop. Woorden schieten gewoonweg te kort... 


\section{CURRICULUM VITAE AND \\ LIST OF PUBLICATIONS}




\section{Curriculum vitae}

Suzanne Kaptein werd op 31 december 1971 geboren te Waalwijk. In 1984 begon ze haar middelbare schoolopleiding aan het Dr. Mollercollege in Waalwijk. Het eindexamen Atheneum B werd in 1992 behaald aan het Dag-/Avondcollege te 'sHertogenbosch. In datzelfde jaar begon zij aan de studie Gezondheidswetenschappen aan de Universiteit Maastricht, met als afstudeerrichting Biologische Gezondheidkunde. De afstudeerstage werd uitgevoerd bij de capaciteitsgroep Medische Microbiologie onder begeleiding van Dr. P. Beisser en omvatte de sequentie- en transcriptie-analyse van het major immediate early gen van het rat cytomegalovirus (Maastricht stam), in de periode 1996 tot 1997. Begin 1998 behaalde ze haar doctoraalexamen. Nadat zij nog enige tijd moleculair biologisch onderzoek heeft verricht naar Chlamydia pneumoniae aan de capaciteitsgroep Medische Microbiologie, is zij in augustus 1998 als Assistent in Opleiding begonnen aan dezelfde capaciteitsgroep onder supervisie van Prof. Dr. C. Bruggeman en Dr. C. Vink. Op dit moment verricht zij onder andere moleculair biologisch onderzoek naar het tweede CC chemokine-gen (r129) dat aanwezig is in het RCMV-genoom. 


\section{List of Publications}

Beisser PS, Kaptein SJF, Beuken E, Bruggeman CA, Vink C. (1998) The Maastricht Strain and England Strain of Rat Cytomegalovirus Represent Different Betaherpesvirus Species rather than Strains. Virology 245:341-351.

Kaptein SJF, Beuken E, Grauls GELM, Bruggeman CA, Vink C. (2001) Rat Cytomegalovirus Open Reading Frame R44 is an Early-Late Gene that Encodes a Nuclear Protein. Arch. Virol. 146:2211-2218.

Gruijthuijsen YK, Casarosa P, Kaptein SJF, Broers JL, Leurs R, Bruggeman CA, Smit MJ, Vink C. (2002) The Rat Cytomegalovirus R33-Encoded G Protein-Coupled Receptor Signals in a Constitutive Fashion. J. Virol. 76:1328-38.

Kaptein SJF, Beisser PS, Gruijthuijsen YK, Savelkouls KGM, Van Cleef KWR, Beuken E, Grauls GELM, Bruggeman CA, Vink C. (2003) The Rat Cytomegalovirus R78 G ProteinCoupled Receptor Gene is Required for the Production of Infectious Virus in the Spleen. J. Gen. Virol. 84:2517-30.

Kaptein SJF, Van Cleef KWR, Gruijthuijsen YK, Beuken EVH, Van Buggenhout L, Beisser PS, Stassen FRM, Bruggeman CA, Vink C. (2004) The 131 Gene of Rat Cytomegalovirus Encodes a Proinflammatory CC Chemokine Homolog which is Essential for the Production of Infectious Virus in the Salivary Glands. Virus Genes 29: 43-61.

Van Cleef KWR, Scaf WMA, Maes K, Kaptein SJF, Beuken E, Beisser PS, Stassen FRM, Grauls GELM, Bruggeman CA, Vink C. (2004) The Rat Cytomegalovirus Homolog of Parvoviral rep Genes, 1127, Encodes a Nuclear Protein with Single- and Double-Stranded DNA-Binding Activity that is Dispensable for Viral Replication in vivo. J. Gen. Virol. 85: 2001-2013.

Kaptein SJF, Gruijthuijsen YK, Beisser PS, Bruggeman CA, Vink C. (2004) Cytomegalovirus-Encoded Homologs of G Protein-Coupled Receptors: Stimulators of Viral Replication, Immune Evaders or Directors of Movement? Research Advances in Virology. R.M. Mohan (Ed.), Global Research Network, India, in press.

Kaptein SJF, Vink, C, Bruggeman CA, Stassen, FRM. (2005) The Rat Model for CMV Infection and Vascular Disease. Cytomegaloviruses: Pathogenesis, Molecular Biology, and Infection Control. M.J. Reddehase (Ed.), Horizon Scientific Press, Wymondham, UK in press. 